\title{
Towards Improved Removal of Uremic Toxins from Human Plasma
}

Denys Pavlenko 


\section{Towards Improved Removal of Uremic Toxins from Human Plasma}




\title{
TOWARDS IMPROVED REMOVAL OF UREMIC TOXINS FROM HUMAN PLASMA
}

\author{
DISSERTATION
}

to obtain

the degree of doctor at the University of Twente,

on the authority of the rector magnificus,

Prof. Dr. T.T.M. Palstra,

on account of the decision of the graduation committee,

to be publicly defended

on Wednesday the $24^{\text {th }}$ of January 2018 at 12.45

by

\section{Denys Pavlenko}

Born on the $24^{\text {th }}$ of January 1988

in Zhytomyr, Ukraine 
The dissertation has been approved by the supervisor:

Prof. Dr. D. Stamatialis

(C) Denys Pavlenko, the Netherlands, 2017

Cover: designed by Denys Pavlenko

ISBN: 978-90-365-4478-8

URL: https://doi.org/10.3990/1.9789036544788

Printed by Gildeprint 


\section{Graduation Committee}

Chairman:

Prof. Dr. ir. J.W.M. Hilgenkamp University of Twente

Supervisor:

Prof. Dr. D. Stamatialis

University of Twente

Committee Members:

Prof. Dr. D.W. Grijpma

University of Twente

Prof. Dr. N.E. Benes

University of Twente

Dr. K.G.F. Gerritsen

UMC Utrecht/Nephrologist

Prof. Dr. R. Masereeuw

University of Utrecht

Prof. Dr. Ing. J. Vienken

University of Strathclyde 


\section{Table of Contents}

Chapter 1

Chapter 2

Chapter 3

Chapter 4

Chapter 5

Chapter 6

Summary

Samenvatting

Acknowledgements

List of publications
Introduction 1

New low-flux mixed matrix membranes

that offer superior removal of proteinbound toxins from human plasma

Insights into blood compatibility of 45 mixed matrix membranes

Carbon adsorbents with dual porosity 69 for efficient removal of uremic toxins and cytokines from human plasma Low fouling membranes for 93 hemodialysis based on polyethersulfone / SlipSkin ${ }^{\mathrm{TM}}$ polymer blend

Conclusions and outlook 



\section{Chapter 1}

\section{Introduction}

Parts of this chapter have been published in the book "Biomedical membranes and (bio)artificial organs" (2018) 


\section{The kidneys and kidney disease}

Most people have two healthy kidneys responsible for the variety of the functions in their body. They regulate body fluid volume, osmolality and acid-base balance, produce hormones and, importantly, remove metabolic products and uremic toxins from human blood. One functioning kidney is usually enough to provide human body with all needed kidney functions. First problems begin to arise when kidney function drops to $30 \%$ and lower. Statistically', over $10 \%$ of the Dutch population, which is around 17 million, have chronic kidney damage. This category of people has an increased risk of renal failure and even higher risk of cardiovascular decease. Moreover, around 16000 people in this category have low kidney function and, thus, strongly depend on some sort of kidney replacement therapy ${ }^{1}$. Though kidney transplantation remains the best solution for patients that undergo renal replacement therapy, the lack of donor organs results in only around 1000 kidney transplantations annually in the Netherlands ${ }^{1}$.

\section{Uremic toxins}

As the result of kidney dysfunction various types of uremic toxins, that are normally excreted by kidneys, begin to accumulate in patients' blood $^{2}$. The EUTox work group of the European Society for Artificial Organs (ESAO) divided all blood toxins into three main categories: small water soluble, middle molecules and protein-bound toxins ${ }^{3}$. 
Small water soluble uremic toxins are molecules with molecular weight of less than $500 \mathrm{Da}$, for example urea and creatinine ${ }^{4}$. Removal of these toxins from human blood by first dialytic membranes in early 60s wakened patients from coma and partially reversed some of the uremic syndroms ${ }^{5}$. That provided convincing evidence that some of the small water soluble molecules are toxic. Therefore, for decades development of dialysis membranes was based on the efficiency of the urea removal from patients' blood 6 .

Second important group of uremic toxins is middle molecules: uremic toxins with molecular weight of more than $500 \mathrm{Da}$. Identification of middle molecules by EUTox group highlighted change in clinical attention from toxic effects from only small toxins to the potential toxicity of blood solutes of larger size. Among the middle molecules, $\beta 2$ microglobulin (11.6 kDa) has been studied most intensely ${ }^{6}$, but toxicity of other middle molecules was reported as well ${ }^{4}$.

The last group of uremic toxins consists of small solutes that are reversely bound to plasma proteins, mostly albumin ${ }^{7}$. As most of the membrane-based blood purification techniques are designed to retain albumin, dialytic clearance of bound toxins remains low: only the free, unbound fraction of these toxins contributes to the gradient of concentration across the membrane. Attention to this particular group of toxins was raised relatively recently due to extensive reports of their uremic toxicity ${ }^{8-13}$. 


\section{Extracorporeal blood purification}

Extracorporeal removal techniques are critical in sustaining life of kidney patients while they wait for kidney transplantation. Most of the kidney patients in the last decades were prescribed to some form of dialysis, which have gone a long way from highly selective experimental treatment to industrialized and profitable clinical solution ${ }^{14}$. Hemodialysis is based on the diffusion principle: the transport of solutes across a semipermeable membrane (Fig. 1) takes place due to a concentration gradient. In other words, the osmolar gradient between blood and dialysate solution allows small water soluble molecules to diffuse through the membrane while larger molecules and blood cells are retained in blood. However, despite all advances, people living on dialysis today have low quality of life and high mortality rates ${ }^{6,14,15}$, which is mostly attributed to the fact that dialysis does not fully reproduce normal kidney functions. In fact, hemodialysis mostly aims at removing accumulated body urea content during each of the three weekly sessions that dialysis patient undergoes $^{6}$. Other uremic toxins, like middle molecules and proteinbound toxins, are poorly removed by conventional hemodialysis due to diffusive limitations: large molecular size in case of middle molecules and protein binding of protein-bound solutes.

Combination of diffusive and convective removal of solutes through the membrane is achieved in extracorporeal techniques, like hemofiltration and hemodiafiltration. Here, the transport of fluid and uremic toxins across the membrane occurs mainly due to pressure 
gradients that allow improved transport of larger solutes ${ }^{16}$. Better removal of middle molecules in these techniques, in comparison standard hemodialysis, results in improved morbidity and mortality rates among kidney patients ${ }^{17}$.

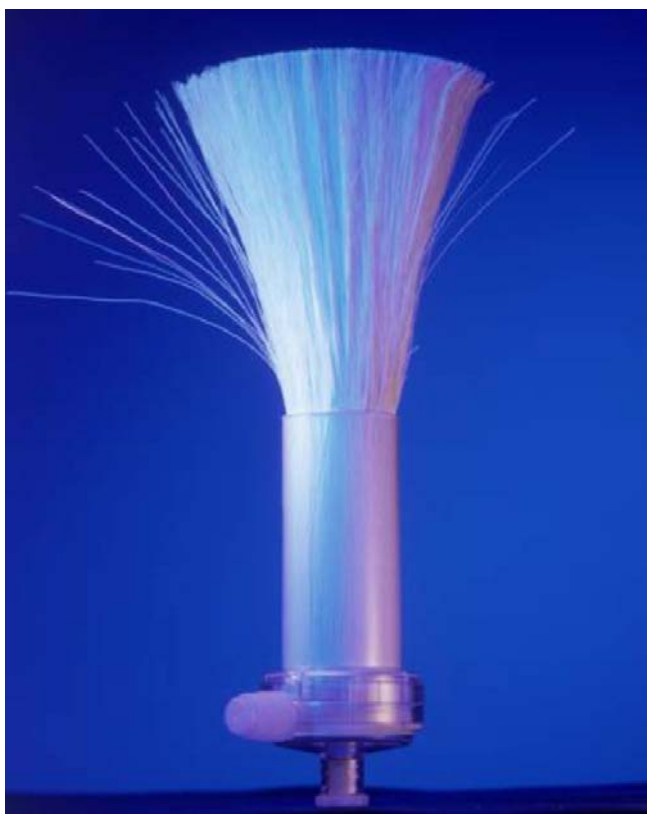

Fig. 1. Picture of the typical membrane module used in hemodialysis, hemofiltration and hemodiafiltration. Adapted from ${ }^{18}$.

Adsorption techniques, like hemoperfusion, were always considered as alternative to diffusion/convection based therapies ${ }^{19}$. In these techniques extracorporealy circulating blood from patient is purified by adsorption that happens on the surface of sorbent particles. Compared to hemodialysis hemoperfusion is more solute-specific technique rather than size- or concentration-specific ${ }^{17}$, meaning it is relatively independent of the solute size and concentration. For this reason adsorption is superior to hemodialysis when it comes to removal 
of slowly moving molecules of larger size: middle molecules and cytokines ${ }^{20,21}$. Though hemoperfusion is able to rapidly remove high quantities of various toxins from human blood, it also has a number of limitations. First, in order to avoid direct particle-blood contact, most of the sorbents are coated by hemocompatible coating that result in lower particle performance. Secondly, use of small particles in hemoperfusion columns may result in pressure drops that lead to blood cell rupture and possibly adverse hemocompatibility effect. Use of larger particles minimizes such risk, but also reduces effective surface area per hemoperfusion column and, as the result, reduces the sorbent capacity. And finally, hemoperfusion cannot correct acid-base, electrolyte and fluid balance ${ }^{19}$.

Summary of benefits of current extracorporeal techniques is presented in table 1 below. As it can be seen most widely used extracorporeal techniques do not provide complete blood purification which motivates the pursuit of better and more complete blood purification strategy. 
Table 1. Ability of various extracorporeal systems to replace kidney functions. Table is adapted from the book "Biomedical membranes and (bio)artificial) organs"

\begin{tabular}{ccccc}
\hline Function & $\begin{array}{c}\text { Hemo- } \\
\text { dialysis }\end{array}$ & $\begin{array}{c}\text { Hemo- } \\
\text { perfusion }\end{array}$ & $\begin{array}{c}\text { Hemo- } \\
\text { filtration }\end{array}$ & $\begin{array}{c}\text { Hemo- } \\
\text { diafiltration }\end{array}$ \\
\hline $\begin{array}{c}\text { Corrects } \\
\text { electrolyte } \\
\text { balance }\end{array}$ & YES & NO & YES & YES \\
\hline $\begin{array}{c}\text { Corrects } \\
\text { volume status }\end{array}$ & YES & NO & YES & YES \\
\hline $\begin{array}{c}\text { Removes small } \\
\text { molecules }\end{array}$ & YES & Partly & YES & YES \\
\hline $\begin{array}{c}\text { Removes } \\
\text { middle } \\
\text { molecules }\end{array}$ & Partly & Partly & Partly & Partly \\
\hline $\begin{array}{c}\text { Removes } \\
\text { protein-bound } \\
\text { toxins }\end{array}$ & Partly & YES & Partly & Partly \\
\hline & & & & \\
\hline
\end{tabular}

\section{Mixed matrix membranes}

Recently, a potential alternative to traditional extracorporeal removal of uremic toxins was proposed: the so-called Mixed Matrix Membrane $(\mathrm{MMM})^{22,23}$. These membranes consist of two layers: a polymeric, porous layer with embedded activated carbon particles (the mixed matrix membrane layer) and a layer consisting of a porous, polymeric particle-free layer (Fig. 2). Incorporation of activated carbon 
particles into the macroporous MMM makes it possible to combine the benefits of filtration and adsorption in one membrane. The particle-free polymeric layer prevents direct contact between patient's blood and the activated carbon particles. Additionally, this layer is responsible for the selectivity of the whole membrane.

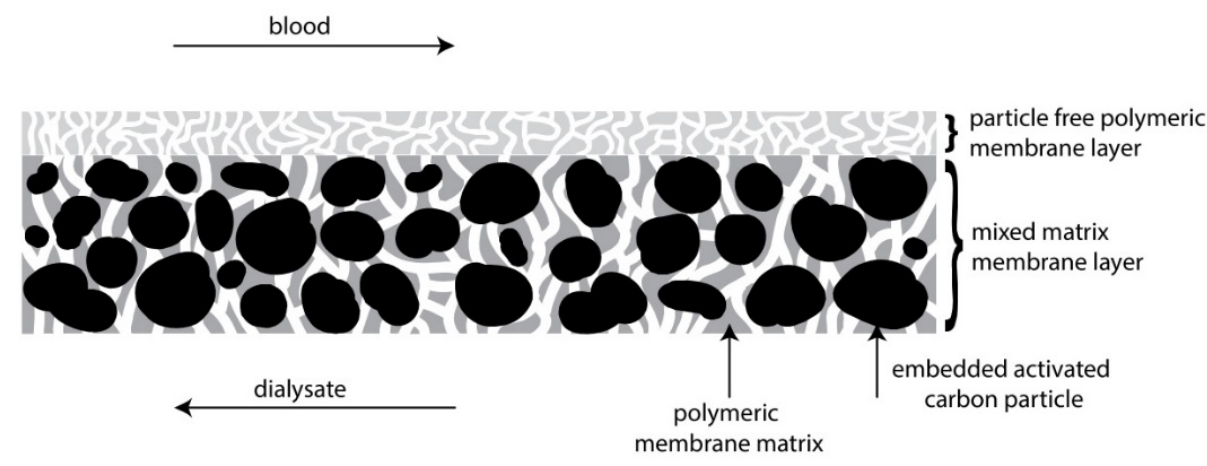

Fig.2. Concept of MMM, which combines filtration and adsorption in one membrane. Adapted from ${ }^{24}$.

In later studies 22 MMM hollow fibers were fabricated too. Both flat and hollow fiber MMMs pose a number of advantages compared to conventional therapies. Firstly, it is possible to use there relatively small adsorptive particles. Use of small particles increases the available surface area for the adsorption of the uremic toxins without the high pressure drops that can be observed in the adsorption columns. Secondly, the use of adsorptive particles inside the outer layer of the membrane increases the removal of the toxins by keeping the concentration gradient of the toxin at the maximum level, as most of the toxins that reach the outer layer are adsorbed. Finally, the presence of the outer layer can protect the 
blood from possible impurities that sometimes are present in the dialysate water.

\section{Aim and outline of the thesis}

The aim of current thesis is to develop new strategies to efficiently remove uremic toxins from human blood. More specifically, chapters 2 and 3 discuss development and characterization of hemocompatible mixed matrix membranes, whereas chapters 4 and 5 are focused on the development of new sorbent and membrane materials.

Chapter 2 describes the preparation and development of mixed matrix hollow fiber membranes for the improved removal of proteinbound uremic toxins from human plasma. First, MMM fabrication was optimized by tuning various spinning parameters. Second, MMM performance in uremic toxin removal from human plasma is evaluated and compared to industrial membranes.

Chapter 3 provides insights into the hemocompatibility of newly fabricated MMM and compares them to industrial dialysis membranes. We report extensive blood compatibility testing following ISO protocol 10993-4. Furthermore, link between hemocompatibility profile of the MMMs and their membrane characteristics is discussed in details.

Chapter 4 presents evaluation of new sorbent with dual porosity, namely CMK-3. Ability of the new sorbent material to remove small water soluble toxins (creatinine (113 Da)), protein-bound molecules (indoxyl sulfate (213 Da) and hippuric acid(179 Da)), middle molecules ( $\beta 2$ - 
microglobulin(11.6 kDa)) and cytokines of different sizes (IL-6 (24 kDa) and IL-8 (8 kDa)) from human plasma is presented and compared to scientific literature. Moreover, the performance of CMK-3 is compared with two commercially available carbon-based sorbents with predominant mesoporosity (Norit A Supra) and microporosity (Takeda 5A).

Chapter $\mathbf{5}$ investigates strategies to achieve new dialysis membranes with high fouling resistance to protein solutions. Firstly, we combine polyethersulfone with SlipSkin material, which is a copolymer of $\mathrm{N}$-vinylpyrrolidone and $\mathrm{n}$-butylmethacrylate, to produce reproducible and mechanically stable flat membranes with suitable dialytic properties. Second, we investigate anti-fouling performance of obtained membranes as well as compare them to literature and to industrial membranes.

Finally, chapter 6 presents general conclusions and suggests possible future direction in pursuit of better uremic toxin removal strategies. 


\section{Bibliography}

1. Kramer, A. et al. Renal replacement therapy in Europe: A summary of the 2013 ERA-EDTA Registry Annual Report with a focus on diabetes mellitus. Clin. Kidney J. 9, 457-469 (2016).

2. Sirich, T. L., Funk, B. a., Plummer, N. S., Hostetter, T. H. \& Meyer, T. W. Prominent Accumulation in Hemodialysis Patients of Solutes Normally Cleared by Tubular Secretion. J. Am. Soc. Nephrol. 25, 615-622 (2013).

3. Eloot, S. et al. Protein-bound solute removal during extended multipass versus standard hemodialysis. BMC Nephrol. 16, 57 (2015).

4. Liabeuf, S., Neirynck, N., Drüeke, T. B., Vanholder, R. \& Massy, Z. A. Clinical Studies and Chronic Kidney Disease: What Did we Learn Recently? Semin. Nephrol. 34, 164-179 (2014).

5. Meyer, T. W., Sirich, T. L. \& , and Thomas H. Hostettert, A. Dialysis Cannot be Dosed. Semin. Dial. 29, 997-1003 (2012).

6. Vanholder, R., Glorieux, G. \& Eloot, S. Once upon a time in dialysis: the last days of Kt/V? Kidney Int. 1-6 (2015).

7. Fagugli, R. M., De Smet, R., Buoncristiani, U., Lameire, N. \& Vanholder, R. Behavior of non-protein-bound and protein-bound uremic solutes during daily hemodialysis. Am. J. Kidney Dis. 40, 339-47 (2002).

8. Barreto, F. C. et al. Serum indoxyl sulfate is associated with vascular disease and mortality in chronic kidney disease patients. Clin. J. Am. Soc. Nephrol. 4, 1551-1558 (2009).

9. Meijers, B. K. I. et al. p-Cresol and cardiovascular risk in mild-to-moderate kidney disease. Clin. J. Am. Soc. Nephrol. 5, 1182-1189 (2010).

10. Koppe, L. et al. p-Cresyl Sulfate Promotes Insulin Resistance Associated with CKD. J. Am. Soc. Nephrol. 24, 88-99 (2012).

11. Vanholder, R., Schepers, E., Pletinck, A., Nagler, E. V \& Glorieux, G. The uremic toxicity of indoxyl sulfate and p-cresyl sulfate: a systematic review. J. Am. Soc. Nephrol. 25, 1897-907 (2014).

12. Raff, A. C., Meyer, T. W. \& Hostetter, T. H. New insights into uremic toxicity. Curr. Opin. Nephrol. Hypertens. 17, 560-5 (2008).

13. Zare-Zardini, H. et al. In vitro and in vivo study of hazardous effects of $\mathrm{Ag}$ 
nanoparticles and Arginine-treated multi walled carbon nanotubes on blood cells: Application in hemodialysis membranes. J. Biomed. Mater. Res. - Part A 103, 2959-2965 (2015).

14. Dobre, M., Meyer, T. W. \& Hostetter, T. H. Searching for uremic toxins. Clin. J. Am. Soc. Nephrol. 8, 322-327 (2013).

15. Eloot, S., Dhondt, A., Van Landschoot, M., Waterloos, M. A. \& Vanholder, R. Removal of water-soluble and protein-bound solutes with reversed mid-dilution versus post-dilution haemodiafiltration. Nephrol. Dial. Transplant. 27, 3278-3283 (2012).

16. Bello, G., Di Muzio, F., Maviglia, R. \& Antonelli, M. New membranes for extracorporeal blood purification in septic conditions. Minerva Anestesiol. 78, 1265-1281 (2012).

17. Eloot, S., Ledebo, I. \& Ward, R. A. Extracorporeal Removal of Uremic Toxins: Can We Still Do Better? Semin. Nephrol. 34, 209-227 (2014).

18. Stamatialis, D. F. et al. Medical applications of membranes: Drug delivery, artificial organs and tissue engineering. J. Memb. Sci. 308, 1-34 (2008).

19. Tyagi, P. K., Winchester, J. F. \& Feinfeld, D. a. Extracorporeal removal of toxins. Kidney Int. 74, 1231-3 (2008).

20. Song, M. et al. Cytokine removal with a novel adsorbent polymer. Blood Purif. 22, 428-434 (2004).

21. Schuijt, T. J., Poll, T. Van Der \& Wiersinga, W. J. Annual Update in Intensive Care and Emergency Medicine. Updat. Intensive Care Emerg. Med. 29-37 (2012). doi:10.1007/978-3-642-25716-2

22. Tijink, M. S. L. et al. Mixed matrix hollow fiber membranes for removal of protein-bound toxins from human plasma. Biomaterials 34, 7819-7828 (2013).

23. Tijink, M. S. L. et al. A novel approach for blood purification: Mixed-matrix membranes combining diffusion and adsorption in one step. Acta Biomater. 8, 2279-2287 (2012).

24. Tijink, M. Membrane concepts for blood purification : towards improved artificial kidney devices. (2013). doi:10.3990/1.9789036535472 


\section{Chapter 2}

\section{New low-flux mixed matrix membranes that offer superior removal of protein- bound toxins from human plasma}

Denys Pavlenko ${ }^{a}$, Esmée van Geffen ${ }^{\mathrm{a}, \mathrm{b}}$, Mies J. van Steenbergen ${ }^{c}$, Griet Glorieux ${ }^{\mathrm{d}}$, Raymond Vanholder $^{d}$, Karin G.F. Gerritsen ${ }^{b}$, Dimitrios Stamatialis ${ }^{a}$

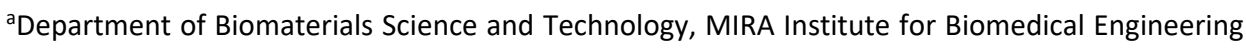
and Technical Medicine, University of Twente, P.O. Box 217, 7500 AE Enschede, The Netherlands

${ }^{b}$ Department of Nephrology and Hypertension, University Medical Centre Utrecht, P.O. Box 85500, 3508 GA Utrecht, The Netherlands

'Department of Pharmaceutics, Utrecht Institute for Pharmaceutical Sciences, Utrecht University, P.O. Box 80082, 3508 TB Utrecht, The Netherlands

${ }^{\mathrm{d}}$ Ghent University Hospital, Department of Internal Medicine, Nephrology Division, 9000 Ghent, Belgium 


\section{Abstract}

Hemodialysis is a widely available and well-established treatment for patients with End Stage Renal Disease (ESRD). However, although lifesustaining, patient mortality rates are very high. Several recent studies corroborated the link between dialysis patients' outcomes and elevated levels of protein-bound uremic toxins (PBUT) that are poorly removed by conventional hemodialysis. Therefore, new treatments are needed to improve their removal. Recently, our group showed that the combination of dialysis and adsorption on one membrane, the mixed matrix membrane (MMM), can effectively remove those toxins from human plasma. However, these first MMMs were rather large in diameter and their mass transport characteristics needed improvement before application in the clinical setting. Therefore, in this study we developed a new generation of MMMs that have a smaller diameter and optimized characteristics offering superior ability in removing the PBUT indoxyl sulfate (IS) and pcresyl sulfate (pCS) in comparison to first generation MMMs $(30 \%$ and $125 \%$ respectively), as well as, a commercial dialysis membrane (more than $100 \%$ better removal).

Keywords: Protein-bound uremic toxins, Dialysis, Membranes, Adsorption.0 


\section{Introduction}

Indoxyl sulfate (IS) and p-cresyl sulfate (pCS) are protein-bound uremic toxins (PBUT) that are known to accumulate in end stage kidney disease patients due to their poor removal by conventional hemodialysis ${ }^{1}$. Elevated serum concentrations of PBUTs have been directly associated with vascular disease, progression of kidney disease and high mortality rates in kidney patients ${ }^{2-12}$. The main reason for their poor removal is the fact that in dialysis patients $97 \%$ of IS and $95 \%$ of pCS is bound to albumin $^{13}$, which is retained by the dialysis membrane. Consequently, only the small unbound fraction can pass the membrane. It is clear that to achieve a higher level of removal of these toxins, a modification to existing treatment is urgently needed.

The use of adsorbent technology has always been considered to bea promising alternative to hemodialysis treatment. Although high removal rates have been achieved by adsorption techniques, such as hemoperfusion, for various blood toxins, including PBUTs, these techniques are rarely used in clinical practice ${ }^{14}$, primarily due to limited urea sorption and no control over the fluid balance. However, several recent studies have proposed to improve PBUT removal by combining the hemodialysis and adsorption techniques. For example, Brettschneider et $\mathrm{al}^{15}$ showed that fractionated plasma separation and adsorption (FPSA) therapy improves the removal of the IS and pCS by $187 \%$ and $127 \%$ respectively in comparison to conventional dialyzers. Comparable results for FPSA were also obtained by Meijers and co-workers ${ }^{16}$. In their work, 
FPSA was found to be superior to high flux hemodialysis in terms of pCS reduction. Alternatively, Sandeman et $\mathrm{al}^{17}$ developed a monolith adsorbent device able to reduce the blood concentration of IS and pCS when used complementary to standard hemodialysis. Meyer et $\mathrm{al}^{18}$ were also able to markedly improve the in vitro removal of $p$-cresol, $p$-cresol sulfate and indican from a plasma solution by adding charcoal to the dialysate side of a single-pass dialysis system. A mathematical model suggested that the improvement in PBUT clearance could be attributed to the maintenance of a virtually close to zero concentration of the uremic toxins at the dialysate side of the hemodialysis membranes, thereby maintaining a maximal concentration gradient, the driving force for toxin removal, across the dialyzer during the experiment.

Recently ${ }^{19}$, our group developed and proved the concept of double layer mixed matrix membranes (MMM) that combine dialysis and adsorption in a single step. The MMMs combine the benefits of diffusion and convection, provided by the membrane structure, and adsorption, achieved by activated carbon particles dispersed through the membrane. To avoid blood-sorbent contact, the blood side of the MMM consists of a particle-free polymeric layer. Our first results for removal of small watersoluble toxins and PBUTs by hollow MMM were encouraging ${ }^{20}$. However, these membranes were rather large (internal diameter of around $700 \mu \mathrm{m}$ ) in comparison to the hollow fibers of $200 \mu \mathrm{m}$ currently used in clinical practice, hampering clinical implementation. Additionally, these 
membranes had rather large pores, resulting in albumin leakage during convective treatments, which might be considered undesirable.

In this work, we develop a new generation of mixed matrix hollow fiber membranes that are suitable for dialysis treatment. The new membranes are smaller in diameter and do not suffer from albumin leakage, thereby meeting the characteristics of low-flux dialyzers used in the clinic. The performance of the new membranes for removal of creatinine, a small water soluble solute, and of the IS and p-CS is evaluated and compared to first generation of $\mathrm{MMM}^{20}$ and to Fresenius F8HPS low flux dialyser membranes, currently used in clinical practice. 


\section{Materials and methods}

For the preparation of the hollow fiber membranes, Ultrason E6020 polyethersulfone (PES, BASF, Ludwigshafen, Germany) and polyvinylpyrrolidone K90 (PVP, Sigma-Aldrich Chemie GmbH, Munchen, Germany) were dissolved in extra pure N-methylpyrrolidone (NMP, Acros Organics, Geel, Belgium). Activated carbon (Norit A Supra, Norit Netherlands BV, Amersfoort, the Netherlands) was sieved through $45 \mu \mathrm{m}$ sieve (VWR, Amsterdam, the Netherlands) and used as an adsorbent in outer polymer layer. All polymer solutions were allowed to degas for at least 24 hours prior to membrane fabrication. Creatinine, indoxyl sulfate, human serum albumin (HAS), inulin, vitamin B12, $\alpha$-lactalbumin and $\alpha$ chymotrypsin were purchased from Sigma Aldrich. p-Cresyl sulfate was synthesized by the Laboratory for Organic and Bio-organic Synthesis at the Ghent University (Belgium) following the method described by Feigenbaum et $\left.a\right|^{33}$.

Human plasma from healthy vol unteer donors was obtained from Sanquin (Amsterdam, the Netherlands) in compliance with local ethical guidelines. To prepare the dialysate solution $2 \mathrm{mM} \mathrm{KCl}, 140 \mathrm{mM} \mathrm{NaCl}, 1.5$ $\mathrm{mM} \mathrm{CaCl}_{2}, 0.25 \mathrm{mM} \mathrm{MgCl}_{2}, 35 \mathrm{mM} \mathrm{NaHCO}_{3}$ and $5.5 \mathrm{mM}$ glucose (all Sigma-Aldrich) were dissolved in ultra-pure water. Fresenius F8HPS lowflux dialysis membranes (kindly provided by FMC, Vlijmen, the Netherlands) were used as reference. 


\section{Hollow fiber membrane preparation}

The dual layer hollow fiber membranes were produced by dry-wet spinning (Fig. 1). Two polymer solutions (one particle-free and one with activated carbon) were transferred into stainless steel syringes and left to degas overnight. The following day the syringes were mounted in the high-pressure syringe pumps and connected to a specially designed spinneret together with the bore solution. Subsequently, the spinneret was placed above the coagulation bath at a fixed height (air gap). The collection of the resulting hollow fibers was by the collecting wheel.

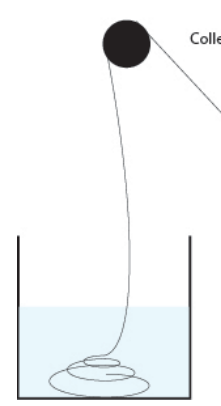

Collecting wheel

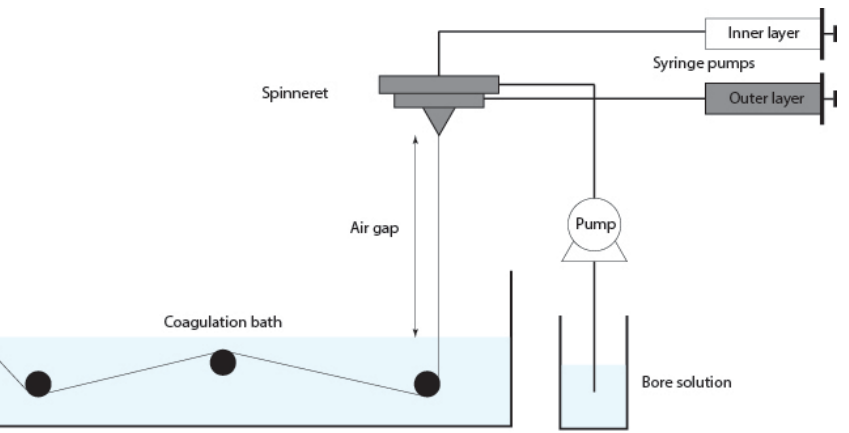

Fig. 1. Schematic of the hollow fiber spinning set-up.

To improve surface-to-volume ratio of the membrane modules, the new generation of the MMM hollow fibers was produced via a newly developed spinneret, which ensured smaller dimension of the produced hollow fibers. Table 1 compares the characteristics of the new spinneret to that used in an earlier study ${ }^{20}$. 
Table 1. Comparison of the spinneret specifications.

Spinneret $1^{20}$

Inner needle diameter $(\mathrm{mm})$

Outer needle diameter

(mm)

Inner diameter first orifice

(mm)

Outer diameter first orifice

(mm)

Inner diameter second

orifice $(\mathrm{mm})$
Spinneret 2

(this study)

0.16

0.26

$0.46 \quad 0.26$

$0.66 \quad 0.46$

$0.96 \quad 0.66$

1.66

0.86

\section{Membrane module preparation}

All fabricated membranes were washed in water to remove the remaining solvent and kept in ultra-pure water. Before module preparation, the membranes were dried in air at room temperature. Membrane modules were made by potting hollow fiber membranes inside the $14 \mathrm{~cm}$ long tubes with 2 Kartell T-connectors (VWR, Amsterdam, the Netherlands) located $2 \mathrm{~cm}$ from each end. As a result, the membrane modules had an effective length of $10 \mathrm{~cm}$. Modules of MMM contained three hollow fibers $\left(4.24 \mathrm{~cm}^{2}\right)$ and modules of F8HPS ten hollow fibers $\left(6.28 \mathrm{~cm}^{2}\right)$. Each end was glued by water-clear polyurethane casting resin (Easy Composites Ltd, London, UK) and cut open after the glue had hardened. 


\section{Membrane characterization}

\section{Ultrafiltration coefficient}

Modules containing three MMM hollow fibers were precompacted with ultra-pure water at a trans-membrane pressure (TMP) of $1500 \mathrm{mmHg}$ for at least one hour before measurements. After this, the amount of permeated water was measured over time under 375,750 , 1125 and $1500 \mathrm{mmHg}$ of transmembrane pressure (TMP). The ultrafiltration coefficient for the resulting membranes was calculated as the slope of the linear fit of the flux $\left(\mathrm{ml} / \mathrm{m}^{2} / \mathrm{h}\right)$ versus TMP graph.

\section{Scanning Electron Microscopy}

The morphological characteristics of the hollow fiber membranes were visualized by use of a scanning electron microscopy (SEM). The membranes were dried in air followed by fracturing in liquid nitrogen to reveal the cross-section. Subsequently, the samples were sputtered with gold using the Cressington 108 auto sputter (Cressington Scientific Instruments, Watford, UK) and examined using a Philips XL-30 ESEM-FEG Scanning Electron Microscope (Philips, Amsterdam, the Netherlands).

\section{Cross-flow transport experiments}

Fig. 2 presents the set-up used for the cross-flow transport experiments. Experimental set-up consists of two peristaltic pumps, four pressure detectors and two back-pressure valves. All the parts of the setup are connected via PTFE tubings. Feed and dialysate solutions are 
pumped to membrane module in counter-current mode of operation and their speeds are controlled by peristaltic pumps. Constant values of TMP are generated by the back pressure valves. TMP of the system is calculated following the formula below:

$$
\mathrm{TMP}=\frac{\mathrm{P}_{2}-\mathrm{P}_{1}}{2}-\frac{\mathrm{P}_{3}-\mathrm{P}_{4}}{2}
$$

where $P_{1}$ and $P_{2}$ are the pressure values before and after membrane module for feed solution and $\mathrm{P}_{4}$ and $\mathrm{P}_{3}$ are corresponding values for dialysate.

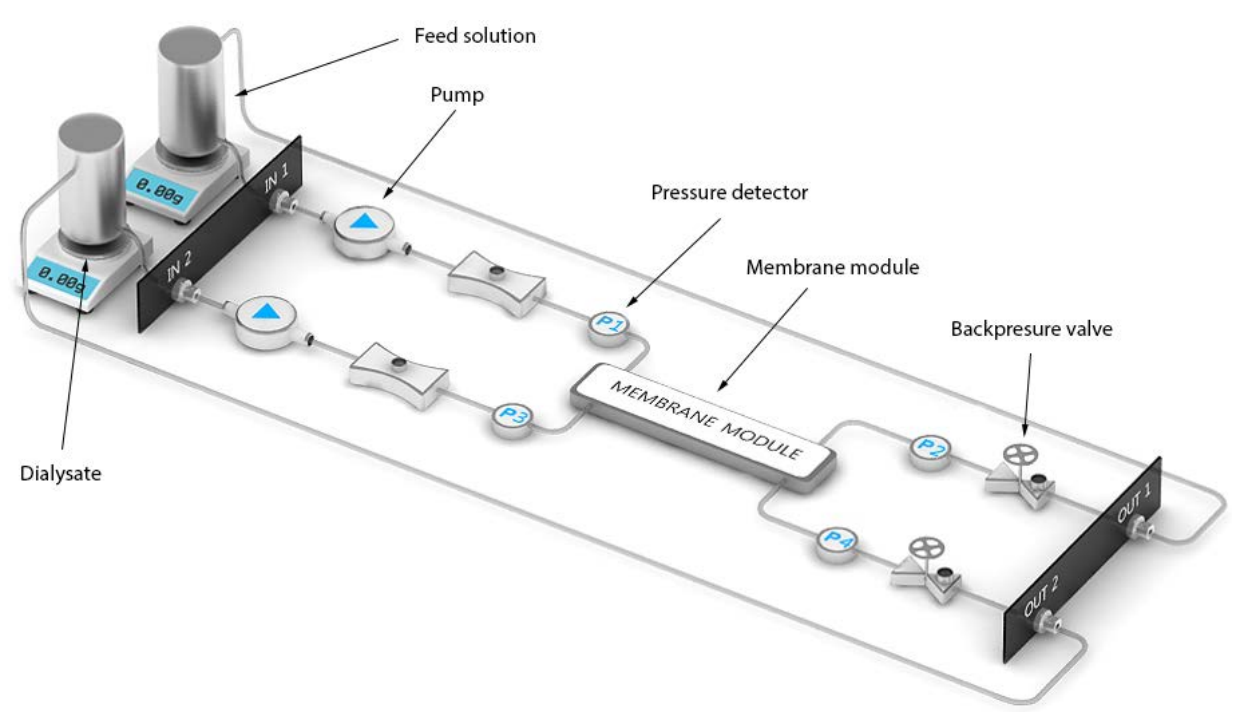

Fig. 2. Schematic of the experimental set-up.

Before the start of each experiment, the transport of clean water through the modules was measured for at least one hour under 750 $\mathrm{mmHg}$ of TMP to check whether all membrane bores were open. For the large diameter MMM it was really easy to see even with a light 
microscope whether all the bores are open. However, for the smaller Fresenius F8HPS fibers the light microscopy was not able to provide reliable results. For this reason, we performed clean water transport studies of modules with multiple fibers and we compared it to that with a single fiber. Increase in the number of fibers is expected to result in proportional increase of the flow values. Only modules with flow values proportional to number of fibers were considered open and were used in the experiments.

For the creatinine cross-flow measurements, the feed compartment contained $50 \mathrm{ml}$ of $0.1 \mathrm{~g} / \mathrm{l}$ creatinine solution in PBS while the dialysate compartment contained $50 \mathrm{ml}$ PBS. Flow rates were set at 5 $\mathrm{ml} / \mathrm{min}$ and $10 \mathrm{ml} / \mathrm{min}$ for feed and dialysate compartments, respectively. The TMP was kept at $0 \mathrm{mmHg}$ by adjusting the backpressure valve.

Subsequently, $50 \mathrm{ml}$ of human plasma, spiked with uremic concentrations $(40 \mathrm{mg} / \mathrm{l})$ of IS and $\mathrm{pCS}^{34}$, was applied at the feed side and protein-bound toxin removal was determined. Pre-prepared dialysate solution was used at the dialysate side of the set-up. Due to the viscosity of human plasma as compared to water, the flow rate of the feed solution was decreased to $1 \mathrm{ml} / \mathrm{min}$ to prevent pressure drops across the module.

Total creatinine and PBUT removal was calculated as the sum of diffusive and adsorptive removal. Diffusive removal was calculated by the concentrations of the solutes found in the dialysate, whereas the adsorptive removal was calculated as the difference between the total removal of the solutes from the "blood" side and the diffusive removal. It 
should be noted that for PBUTs total removal was equal to adsorptive removal since PBUTs were not detected in the dialysate side of the module. As the final step, all values of the PBUT and creatinine removal were normalized by the surface area as it has a direct influence on the creatinine and PBUT clearances ${ }^{23}$.

\section{Quantification of creatinine and protein-bound uremic toxins}

Creatinine (MW 113) concentrations were analysed by standard laboratory methods using the UV detection at $254 \mathrm{~nm}$.

The concentrations of IS (MW $212 \mathrm{Da}$, protein bound $\sim 97 \%{ }^{13}$ ) and pCS (MW $187 \mathrm{Da}$, protein bound $\sim 95 \%{ }^{13}$ ) were determined as described by Meert et $\mathrm{a}^{27}$. In short, plasma samples were deproteinized by heat treatment, filtered through $30 \mathrm{kDa}$ filters (Amicon Ultracel-30K, Merck Millipore Ltd) and subsequently analysed by reverse-phase highperformance liquid chromatography (RP-HPLC). Concentrations were measured by fluorescence analysis (IS: $\lambda_{\mathrm{ex}}=280 \mathrm{~nm}, \lambda_{\mathrm{em}}=340 \mathrm{~nm}$; pCS: $\left.\lambda_{\mathrm{ex}}=265 \mathrm{~nm}, \lambda_{\mathrm{em}}=290 \mathrm{~nm}\right)$.

\section{Molecular weight cut-off (MWCO) of the membranes}

The molecular weight cut-off of the membranes was estimated by filtration of marker molecules of various sizes: HSA , $\alpha$-chymotrypsin, $\alpha$ lactalbumin, inulin and vitamin B12. A series of the solutions was prepared by slow dissolution of the powdered molecule in the PBS solution. Concentrations of the solutions were determined both before and after 
the ultrafiltration experiments by the use of the UV-vis. More information can be found in the Table 2 .

Table 2. Experimental conditions for the hollow fiber MWCO determination

$\begin{array}{cccc}\text { Marker molecule } & \begin{array}{c}\text { MW } \\ \text { (kDa) }\end{array} & \begin{array}{c}\text { Concentration } \\ \text { (mg/ml) }\end{array} & \begin{array}{c}\text { UV wavelength } \\ (\mathbf{n m})\end{array} \\ \text { HSA } & 66.5 & 1 & 280 \\ \boldsymbol{\alpha} \text {-chymotrypsin } & 25 & 0.1 & 280 \\ \boldsymbol{\alpha} \text {-lactalbumin } & 14.2 & 1 & 280 \\ \text { Inulin } & 5 & 0.1 & 285 \\ \text { B12 } & 1.3 & 0.1 & 550\end{array}$

Ultrafiltration experiments were performed as follows. MMMs were pressurized by demi-water under $1500 \mathrm{mmHg}$ for two hours prior to the experiment. As a next step, a solution of each of the marker molecules was filtered through the MMM in a dead-end setting at $375 \mathrm{mmHg}$. After $1 \mathrm{ml}$ of the solution had permeated through the membrane, sieving coefficients were calculated as:

$$
S c=\frac{C_{p}}{C_{f}}
$$

where $C_{p}$ and $C_{f}$ are the protein concentrations in the permeate and feed solutions respectively. 


\section{Statistics}

Results are presented as average values of single experiment using multiple modules $(n=4)$ and their corresponding standard deviations. Comparative statistical analysis was performed using the IBM SPSS Statistics 22 software package. Statistical difference was determined by independent samples t-test, with the significance level set to $\mathrm{P}<0.05$. 


\section{Results and discussion}

\section{Development of the new hollow fiber membranes}

Six batches of the dual layer hollow fiber membranes were produced by a dry-wet spinning method. The spinning conditions were tuned to obtain membranes featuring optimal particle loading and morphological characteristics. As the adsorbent material Norit A Supra was used as it has high adsorption capacity and selectivity to creatinine and PBUT ${ }^{19,20}$. Table 3 summarizes the conditions under which membranes were fabricated and Fig. 3 presents typical SEM images of the resulting hollow fibers.

The first membranes (M1) produced using the new spinneret (see Figure 3a) had low activated carbon (AC) loading of the outer membrane layer. Additionally, the ratio between the outer and inner membrane layers was not optimal. Double layer hollow fibers should have a thin inner layer to minimize mass transfer resistance and a thick outer mixed matrix to improve adsorption capacity. Consequently, the adaptation of the inner and outer layer pumping speeds resulted in a thinner inner layer and increased the thickness of MMM layer. Moreover, the loading of the AC was gradually increased from $37.5 \%$ to $60 \%$ in the outer membrane layer (see membrane M2, Fig. 3b). A higher AC content of the outer layer should improve the overall adsorption capacity of the hollow fibers. It was noticed that an activated carbon loading of higher than $60 \%$ sharply increases the brittleness of the membranes. The PVP content of the 
polymer dopes was also increased from $5 \%$ to $7 \%$ to avoid formation of undesirable macro-voids in the inner membrane layer.

Table 3. Spinning conditions of the various double layer membranes.

\begin{tabular}{|c|c|c|c|c|c|c|}
\hline & M 1 & M 2 & M 3 & M 4 & M 5 & M 6 \\
\hline $\begin{array}{l}\text { Inner layer } \\
\text { (PES/PVP) }\end{array}$ & $15 / 5$ & $15 / 7$ & $15 / 10$ & $15 / 10$ & $15 / 7$ & $15 / 7$ \\
\hline $\begin{array}{l}\text { Outer layer } \\
\text { (PES/PVP/AC) }\end{array}$ & $14 / 1.4 / 37.5$ & $14 / 1.4 / 60$ & $14 / 1.4 / 60$ & $14 / 1.4 / 60$ & $14 / 1.4 / 60$ & $14 / 1.4 / 60$ \\
\hline $\begin{array}{l}\text { Inner layer } \\
\text { pumping } \\
\text { speed } \\
\text { (ml/min) }\end{array}$ & 0.5 & 0.4 & 0.4 & 0.4 & 0.4 & 0.4 \\
\hline $\begin{array}{l}\text { Outer layer } \\
\text { pumping } \\
\text { speed } \\
\text { (ml/min) }\end{array}$ & 1 & 1.6 & 2 & 1.6 & 1.6 & 1.6 \\
\hline $\begin{array}{l}\text { Bore liquid } \\
\text { pumping } \\
\text { speed } \\
\text { (ml/min) }\end{array}$ & 1.2 & 1.2 & 2 & 2 & 1.2 & 1.2 \\
\hline $\begin{array}{c}\text { Bore } \\
\text { composition }\end{array}$ & B1 & B1 & B2 & B2 & B2 & B1 \\
\hline Air gap (cm) & 15 & 15 & 10 & 10 & 10 & 10 \\
\hline $\begin{array}{l}\text { Spinneret } \\
\text { type }\end{array}$ & $\begin{array}{c}\text { Spinneret } \\
2.0\end{array}$ & $\begin{array}{c}\text { Spinneret } \\
2.0\end{array}$ & $\begin{array}{c}\text { Spinneret } \\
2.0\end{array}$ & $\begin{array}{c}\text { Spinneret } \\
2.0\end{array}$ & $\begin{array}{c}\text { Spinneret } \\
2.0\end{array}$ & $\begin{array}{c}\text { Spinneret } \\
2.0\end{array}$ \\
\hline $\begin{array}{c}\text { Collecting } \\
\text { speed } \\
\text { (m/min) }\end{array}$ & Free fall & Free fall & Free fall & Free fall & 3.5 & 3.5 \\
\hline
\end{tabular}

*Bore liquid B1 consists of pure water and the bore liquid B2 contains $60 \%$ NMP and $5 \%$ PVP in pure water.

** Amount of activated carbon was calculated in relation to the amount of PES.

M3 membranes, which were the next step in MMM optimization, were prepared using increased pumping speed for the outer layer. That resulted in noticeable separation of the inner and outer layers, so the polymer pumping speed was decreased back to $1.6 \mathrm{ml} / \mathrm{min}$ for the subsequent membrane batches (M4, M5, M6), while keeping the ratio 1:4 
of the inner to outer layer pumping speeds (Fig.3d). The adhesion of the inner and outer layers of the M4 membranes was better than for M3. However, delamination could still occur due to significant difference in viscosities of polymer dopes. Therefore, it was decided to decrease the PVP content of the inner layer back to $7 \%$. 

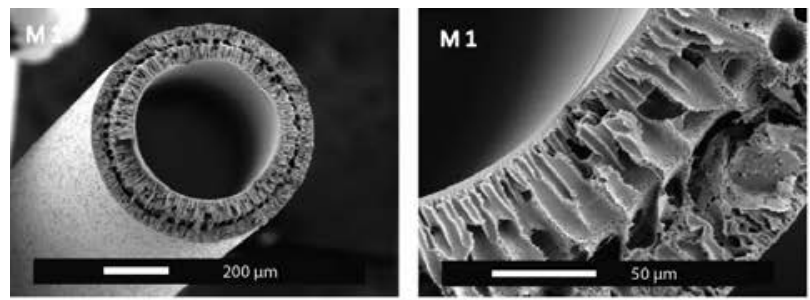

A
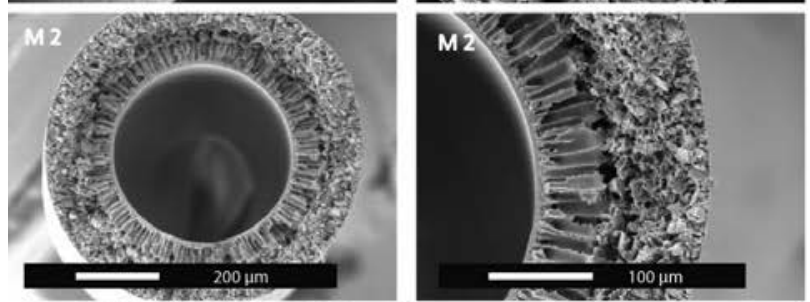

B
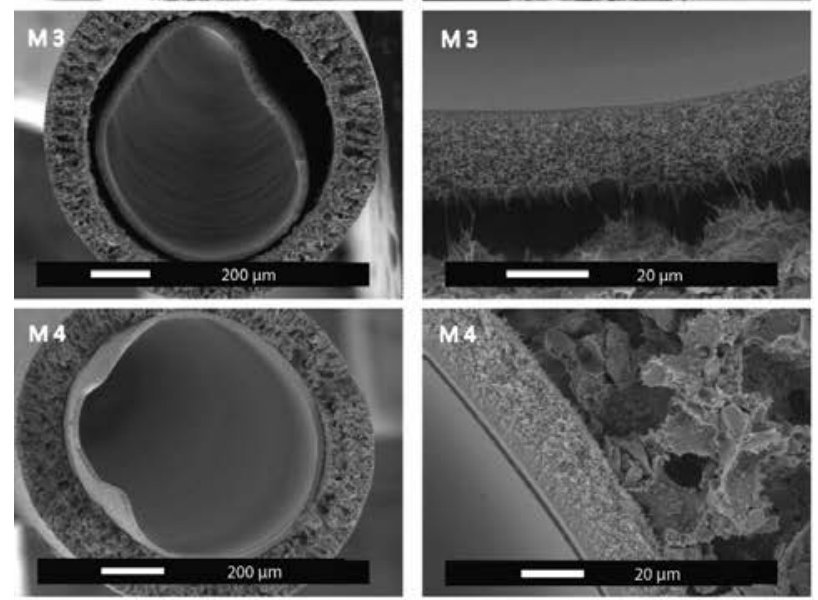

C
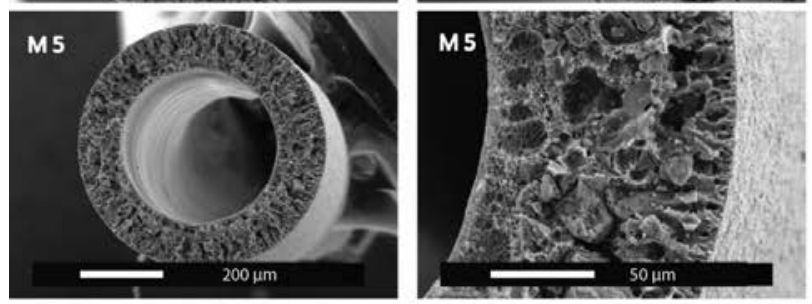

$\mathrm{D}$
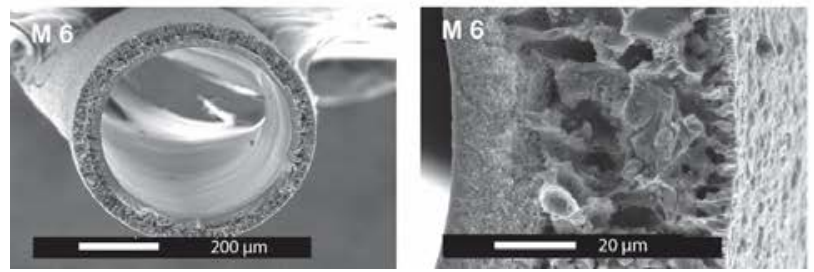

E

F

Fig. 3. Scanning electron microscopy images of double layer mixed matrix membranes (see Table 3. for details of fabrication) 
For the M5 membrane, there was no noticeable interface between the inner and outer layers (Fig. 3e). In other words, by decreasing the viscosity difference between the two extruded polymer solutions, we were able to avoid skin formation between the two membranes. In fact, the M5 membranes have a more interconnected structure than all previous membrane batches. Moreover, the introduction of the collecting wheel during the spinning and the reduction in the bore liquid pumping speed resulted in noticeably smaller diameter in comparison to M4 (376 $\mu \mathrm{m}$ vs $759 \mu \mathrm{m}$, respectively). The M5 membranes, similar to M3 and M4, were prepared with bore liquid composition that consists of $60 \%$ NMP and 5\% PVP in pure water. Due to the presence of the solvent NMP in the bore liquid, demixing of the polymer is delayed resulting in an inner layer with a sponge-like structure and higher transport. Unfortunately, the ultrafiltration coefficient of the membranes was too high, reaching values up to $183 \mathrm{ml} / \mathrm{h} / \mathrm{m}^{2} / \mathrm{mmHg}$ (M5) with noticeable loss of plasma proteins during filtration of human plasma through the membrane. The flux of the membrane could become lower when using water as the bore liquid and the parameters that are described in Table 3. The M6 membrane has the optimal characteristics required for our application: low ultrafiltration coefficient, no albumin leakage and small diameter and therefore will be used in further studies of solute transport (see Table 4 for a comparison of the $\mathrm{M} 6$ to the earlier $\mathrm{MMM}^{20}$ and to the low flux dialysis membranes F8HPS used currently in clinical practice). In fact, M6 has a low ultrafiltration coefficient in comparison to Fresenius F8HPS and 
previously reported membranes, and can be classified as low-flux membrane with MWCO around 12 kDa (see Fig. 1 of the appendix).

Table 4. Properties of the mixed matrix and industrial membranes

\begin{tabular}{|c|c|c|c|}
\hline & $\begin{array}{l}\text { Mixed matrix } \\
\text { membranes } \\
\text { (M 6) }\end{array}$ & F8HPS & Tijink et $\boldsymbol{a} \mathbf{l}^{1}$ \\
\hline $\begin{array}{l}\text { Lumen diameter } \\
(\mu \mathrm{m})\end{array}$ & 450 & 200 & 669 \\
\hline Inner layer ( $\mu \mathrm{m})$ & 21 & 40 & 49 \\
\hline Outer layer $(\mu \mathrm{m})$ & 47 & N/A & 111 \\
\hline $\begin{array}{l}\text { Ultr. coeff. } \\
\left(\mathrm{ml} / \mathrm{h} / \mathrm{m}^{2} / \mathrm{mmHg}\right)\end{array}$ & 3.35 & 10 & 78 \\
\hline Albumin leakage & NO & NO & YES \\
\hline $\begin{array}{l}\text { Creatinine removal } \\
\text { after } 4 \text { hours } \\
\left(\mathrm{mg} / \mathrm{m}^{2}\right)\end{array}$ & 2579 & 3420 & 2825 \\
\hline
\end{tabular}

\section{Creatinine removal by the membranes}

For the M6 membrane, creatinine is removed by the combination of diffusion and adsorption (see Fig. 4) consistent to the results of earlier study $^{20}$. After four hours, the M6 membranes remove $2549 \mathrm{mg} / \mathrm{m}^{2}$ of creatinine in comparison to the $3420 \mathrm{mg} / \mathrm{m}^{2}$ removed by the F8HPS membrane. This difference is due to the difference between the ultrafiltration coefficients of the two membranes: $3.4 \mathrm{ml} / \mathrm{h} / \mathrm{m}^{2} / \mathrm{mmHg}$ for the M6 membranes vs $10.0 \mathrm{ml} / \mathrm{h} / \mathrm{m}^{2} / \mathrm{mmHg}$ for the F8HPS. Clearly, the more open the membrane structure the higher the transport rate of the small solute, like creatinine, through the membrane. However, it is important to note here that although the F8HPS membrane has three times the ultrafiltration coefficient of MMM, it only removes $30 \%$ more 
creatinine in four hours of treatment, while in the first hour of the experiment, during which M6 membranes have maximum adsorption, there is small difference in creatinine removal between two membranes. In other words, if the adsorption capacity of the AC will be bigger, for example by the use of smaller particles with higher surface area, difference in creatinine removal between the two types of membranes is expected to be smaller than $30 \%$ percent. We believe that this result indicates the strong additive effect of the adsorption to the removal, which becomes even more remarkable for the removal of the proteinbound toxins (see next section).

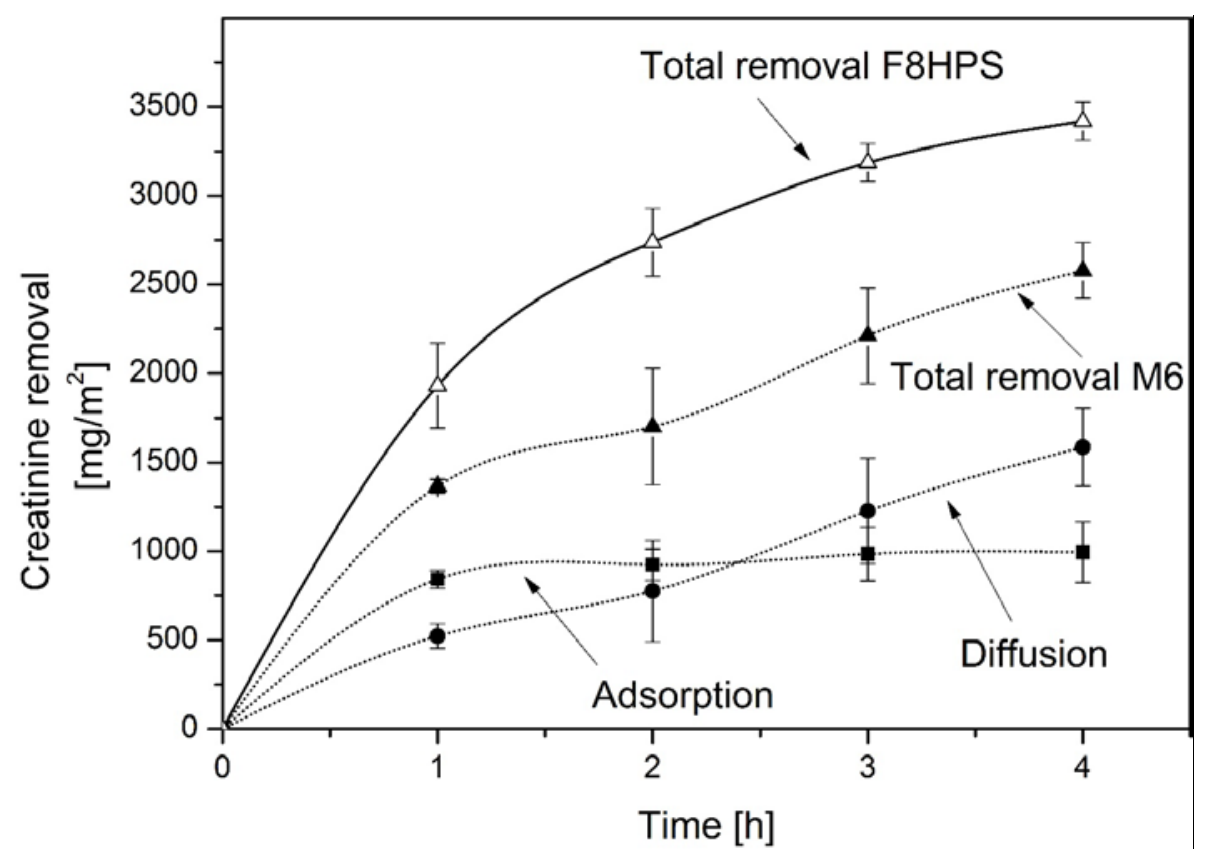

Fig. 4. Comparison of the creatinine removal of mixed matrix membrane (dotted line) vs industrial membrane (solid line). The error bars indicate standard deviation of single experiment using multiple modules $(n=4)$ 
Using the first generation of $M M M^{20}$, creatinine removal was $2825 \mathrm{mg} / \mathrm{m}^{2}$, only $9 \%$ higher than the M6 membrane, even though these membranes had 23 times the ultrafiltration coefficient. We think that the excellent performance of the M6 membranes is attributed to small inner wall thickness. The selective inner layer is much thinner in comparison to previous generation of the fibers (table 4) and so is the diffusion length of the solutes to the activated carbon, which is responsible for the adsorptive removal.

\section{Protein-bound toxin removal by the membranes}

In the case of the water-soluble creatinine, the low ultrafiltration coefficient of the MMM results in a lower rates of removal. However, in the case of the PBUT the pore size of the membranes and their ultrafiltration coefficient should have little influence on the removal of substances bound to albumin ${ }^{21-23}$. Fig. 5 compares the removal of a mixture of IS and pCS from human plasma by the M6 and the F8HPS membrane. The M6 membranes have a very high rate of removal of 367 $\mathrm{mg} / \mathrm{m}^{2}$ for IS and $380 \mathrm{mg} / \mathrm{m}^{2}$ for $\mathrm{pCS}$ in comparison to the Fresenius dialysis fiber (removal of $187 \mathrm{mg} / \mathrm{m}^{2}$ and $225 \mathrm{mg} / \mathrm{m}^{2}$ of IS and pCS respectively) and the previous generation of the mixed matrix membranes ${ }^{20}\left(252 \mathrm{mg} / \mathrm{m}^{2}\right.$ and $160 \mathrm{mg} / \mathrm{m}^{2}$ of IS and pCS respectively). For our M6 membranes, the removal is entirely due to adsorption since in four hours of the experiment we did not detect any IS and pCS in the dialysate compartment. For the F8HPS membranes, the removal is due to diffusion of the toxins to the dialysate compartment. For the M6 membrane, the 
PBUT removal is the highest during the first hour of the experiment, but similarly to the creatinine removal, the activated charcoal saturation seems to occur in time. In case of the F8HPS membranes, the removal has constant rate throughout the four hours of the dialysis experiment.

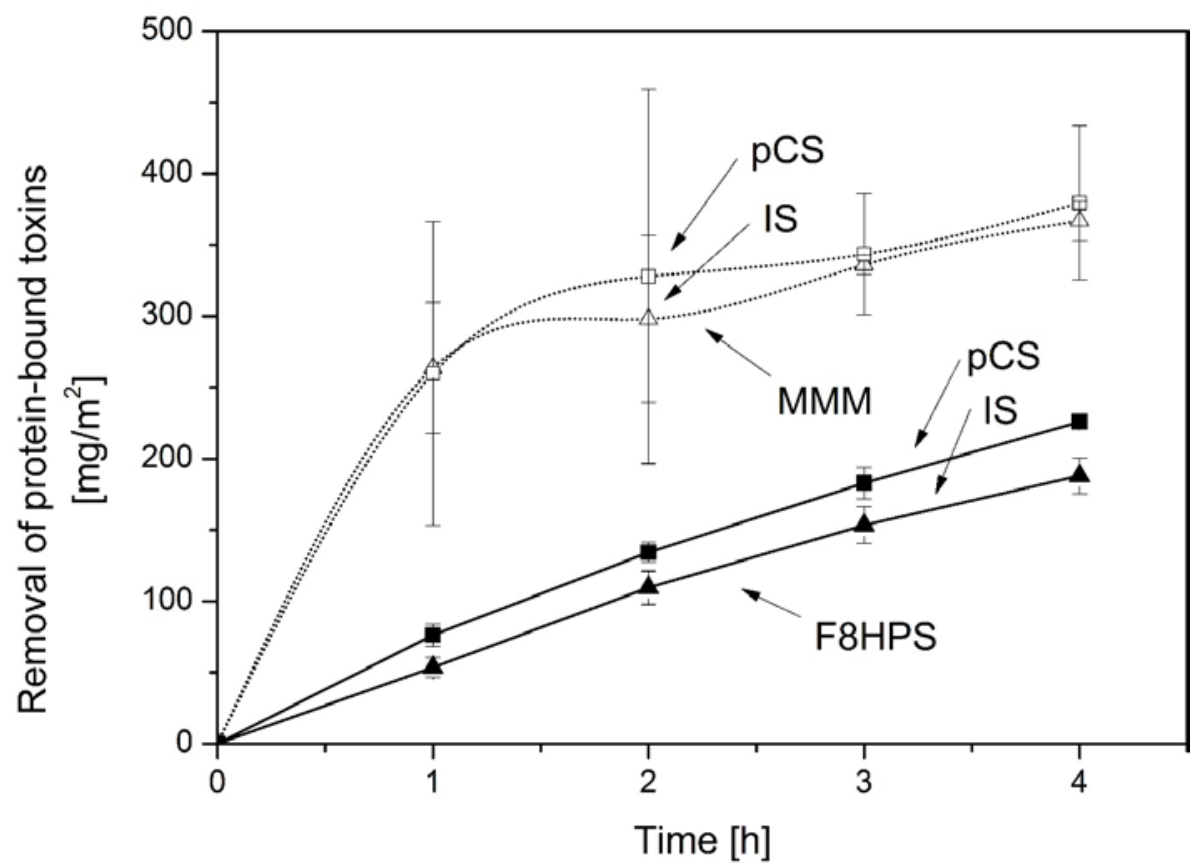

Fig. 5. Removal of protein-bound toxins by F8HPS and mixed matrix membrane over time. Error bars indicate standard deviation of one experiments using multiple modules $(n=4)$.

The remarkably higher removal rates achieved by our membranes are due to the adsorption layer. In fact, during the experiment, the free fraction of the IS and pCS passes the inner selective membrane layer and is quickly adsorbed by the particles inside the outer layer. This keeps the concentration gradient for the removal very high and stimulates the release of the free fraction of toxins from the protein to the plasma, 
resulting in even higher removal. For F8HPS membranes, the removal of the free fraction of toxins is driven by diffusion, which also stimulates the release of the free fraction, but the concentration gradient is much lower. Meyer et $\mathrm{al}^{18}$ showed that adding sorbent in the dialysate can also improve significantly the removal of PBUTs by the dialysis membrane. In fact, they predicted from modelling studies that adsorption could increase the driving force for the removal, leading to higher removal rates consistent with our findings reported here. However, as also highlighted by Meyer et $\mathrm{al}^{18}$ the adsorbent particles needed to be well mixed to be able to adsorb the toxins that permeate through the membranes, especially at low concentrations. In the case of our MMM, the adsorption particles are evenly dispersed inside the membrane, thereby minimizing the diffusion length for the toxins to be removed and making the sorbent evenly available over the entire membrane surface. All our results strongly indicate the significant improvement of our membrane in comparison to first generation, and its great potential for the removal of PBUT.

Figure 6 compares the removal of IS and pCS by the M6 membranes with that cited in various published papers, where researchers tried to improve the removal of PBUTs by using more open membranes, that had higher reduction ratios of the urea and creatinine $^{21,22}$. The optimised M6 membranes of this study, as well as the first generation of $M M M$, have the highest removal for both toxins ${ }^{20}$. Fig. 6 also shows clearly that the ultrafiltration coefficient of the standard 
dialysis membrane has no major effect on the removal of the PBUTs. It seems that only a small fraction of un-bound toxins is eliminated by diffusion through the membrane, so, contrary to small water-soluble molecules, the larger pore size seems to have little or no influence on the diffusive removal of PBUTs, due to the low concentration of the free fraction in the plasma. It is possible to augment their removal by prolonged dialysis treatment ${ }^{24,25}$, larger membrane surface area 23,26 or/and by facilitating the diffusion of the toxins through the membrane $18,27-29$. Our mixed matrix membrane actually achieves the latter. It combines the enhanced mass transfer characteristics of the inner thin membrane layer (see Table 4) with the increased driving force for removal due to the adsorption in the outer layer, leading to superior performance in comparison to current state-of-the-art dialysis membranes. 


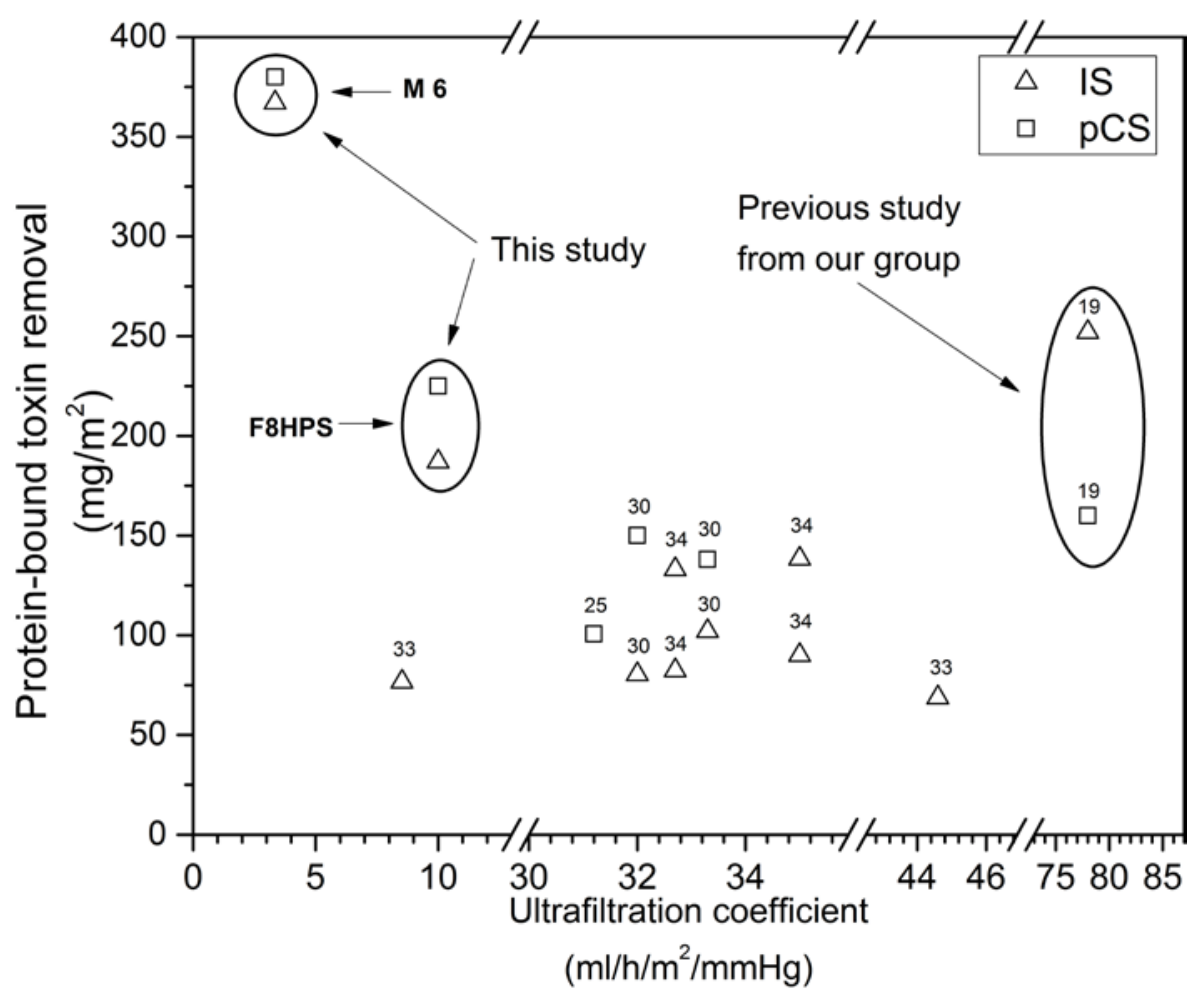

Fig. 6. Removal of protein-bound toxins as a function of membrane permeability taken from multiple studies ${ }^{20,26,30-32}$. Ultrafiltration coefficients represent the type of membrane used in the studies. Some studies ${ }^{30}$ used different membranes to evaluate the influence of ultrafiltration coefficient on the PBUT removal. Others ${ }^{32}$ used same membranes under the varying conditions, such as 4 and 8 hours of dialysis treatment. 


\section{Conclusions and Outlook}

This study presents the development of a new generation of mixed matrix hollow fiber membranes that can provide significant benefits to hemodialysis therapies in terms of the protein-bound toxin removal. These membranes offer superior performance in comparison to existing commercial dialysers during in vitro studies of four hours. In future, the new MMM will be assembled into the modules with high surface area and their performance will be investigated in vitro with full blood and in vivo using uremic goats. 


\section{Appendix}

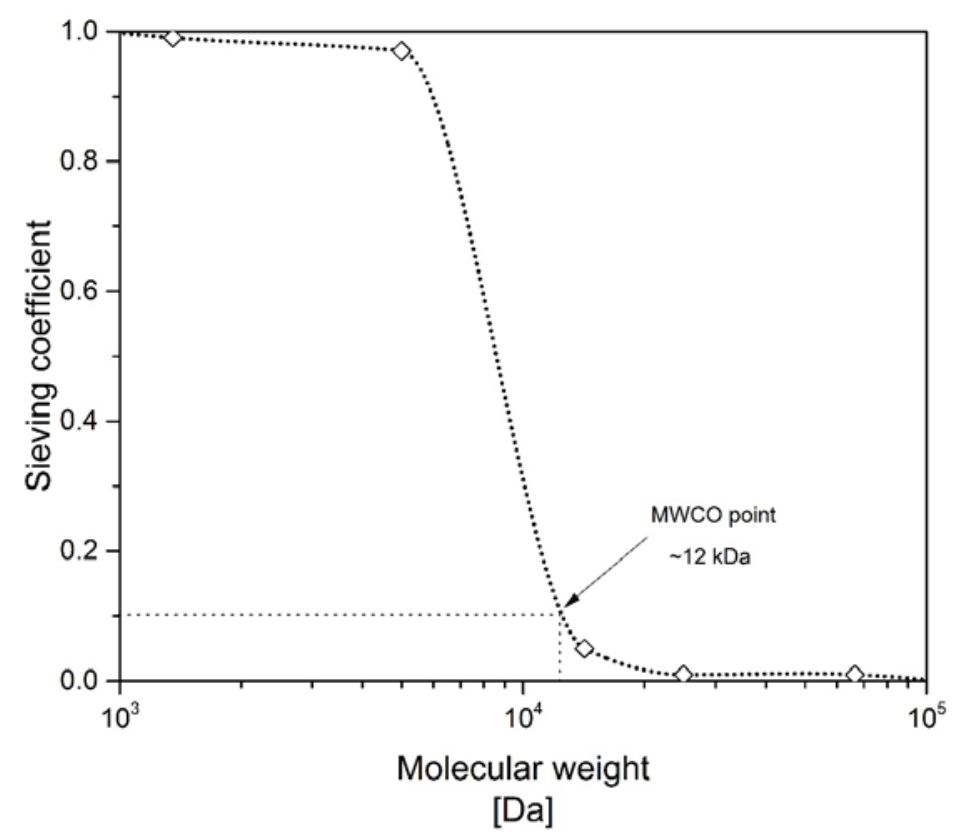

Appendix Fig. 1. Sieving curve for the M6 MMM membranes. 


\section{Bibliography}

1. Eloot, S., Van Biesen, W. \& Vanholder, R. A sad but forgotten truth: The story of slow-moving solutes in fast hemodialysis. Semin. Dial. 25, 505509 (2012).

2. Barreto, F. C. et al. Serum indoxyl sulfate is associated with vascular disease and mortality in chronic kidney disease patients. Clin. J. Am. Soc. Nephrol. 4, 1551-1558 (2009).

3. Liabeuf, S., Drüeke, T. B. \& Massy, Z. a. Protein-bound uremic toxins: New insight from clinical studies. Toxins (Basel). 3, 911-919 (2011).

4. Shafi, T. et al. Free Levels of Selected Organic Solutes and Cardiovascular Morbidity and Mortality in Hemodialysis Patients: Results from the Retained Organic Solutes and Clinical Outcomes (ROSCO) Investigators. PLoS One 10, e0126048 (2015).

5. Dou, L. et al. The uremic solutes p-cresol and indoxyl sulfate inhibit endothelial proliferation and wound repair. Kidney Int. 65, 442-451 (2004).

6. Meijers, B. K. I. et al. Free p-cresol is associated with cardiovascular disease in hemodialysis patients. Kidney Int. 73, 1174-1180 (2008).

7. Nii-Kono, T. et al. Indoxyl sulfate induces skeletal resistance to parathyroid hormone in cultured osteoblastic cells. Kidney Int. 71, 738743 (2007).

8. Dobre, M., Meyer, T. W. \& Hostetter, T. H. Searching for uremic toxins. Clin. J. Am. Soc. Nephrol. 8, 322-327 (2013).

9. Meijers, B. K. I. et al. P-Cresyl Sulfate and Indoxyl Sulfate in Hemodialysis Patients. Clin. J. Am. Soc. Nephrol. 4, 1932-1938 (2009).

10. Vanholder, R., Schepers, E., Pletinck, A., Nagler, E. V \& Glorieux, G. The uremic toxicity of indoxyl sulfate and p-cresyl sulfate: a systematic review. J. Am. Soc. Nephrol. 25, 1897-907 (2014).

11. Wu, I. W. et al. P-cresyl sulphate and indoxyl sulphate predict progression of chronic kidney disease. Nephrol. Dial. Transplant. 26, 938-947 (2011).

12. Raff, A. C., Meyer, T. W. \& Hostetter, T. H. New insights into uremic toxicity. Curr. Opin. Nephrol. Hypertens. 17, 560-5 (2008). 
13. Itoh, Y., Ezawa, A., Kikuchi, K., Tsuruta, Y. \& Niwa, T. Protein-bound uremic toxins in hemodialysis patients measured by liquid chromatography/tandem mass spectrometry and their effects on endothelial ROS production. Anal. Bioanal. Chem. 403, 1841-1850 (2012).

14. Tyagi, P. K., Winchester, J. F. \& Feinfeld, D. a. Extracorporeal removal of toxins. Kidney Int. 74, 1231-3 (2008).

15. Brettschneider, F. et al. Removal of Protein-Bound, Hydrophobic Uremic Toxins by a Combined Fractionated Plasma Separation and Adsorption Technique. Artif. Organs 37, 409-416 (2013).

16. Meijers, B. K. et al. Removal of the uremic retention solute p-cresol using fractionated plasma separation and adsorption. Artif. Organs 32, 214219 (2008).

17. Sandeman, S. R. et al. An adsorbent monolith device to augment the removal of uraemic toxins during haemodialysis. J. Mater. Sci. Mater. Med. 25, 1589-1597 (2014).

18. Meyer, T. W. et al. Increasing the clearance of protein-bound solutes by addition of a sorbent to the dialysate. J. Am. Soc. Nephrol. 18, 868-874 (2007).

19. Tijink, M. S. L. et al. A novel approach for blood purification: Mixed-matrix membranes combining diffusion and adsorption in one step. Acta Biomater. 8, 2279-2287 (2012).

20. Tijink, M. S. L. et al. Mixed matrix hollow fiber membranes for removal of protein-bound toxins from human plasma. Biomaterials 34, 7819-7828 (2013).

21. Lesaffer, G. et al. Intradialytic removal of protein-bound uraemic toxins: role of solute characteristics and of dialyser membrane. Nephrol. Dial. Transplant 15, 50-57 (2000).

22. Meert, N. et al. Comparison of removal capacity of two consecutive generations of high-flux dialysers during different treatment modalities. Nephrol. Dial. Transplant 26, 2624-30 (2011).

23. Vanholder, R., Glorieux, G. \& Eloot, S. Once upon a time in dialysis: the last days of Kt/V? Kidney Int. 1-6 (2015). doi:10.1038/ki.2015.155 
24. Basile, C. et al. Removal of uraemic retention solutes in standard bicarbonate haemodialysis and long-hour slow-flow bicarbonate haemodialysis. Nephrol. Dial. Transplant. 26, 1296-1303 (2011).

25. Fagugli, R. M., De Smet, R., Buoncristiani, U., Lameire, N. \& Vanholder, R. Behavior of non-protein-bound and protein-bound uremic solutes during daily hemodialysis. Am. J. Kidney Dis. 40, 339-47 (2002).

26. Sirich, T. L., Luo, F. J. G., Plummer, N. S., Hostetter, T. H. \& Meyer, T. W. Selectively increasing the clearance of protein-bound uremic solutes. Nephrol. Dial. Transplant. 27, 1574-1579 (2012).

27. Meert, N. et al. Effective removal of protein-bound uraemic solutes by different convective strategies: A prospective trial. Nephrol. Dial. Transplant. 24, 562-570 (2009).

28. Meyer, T. W., Sirich, T. L. \&, and Thomas H. Hostettert, A. Dialysis Cannot be Dosed. Semin. Dial. 29, 997-1003 (2012).

29. Luo, F. J.-G. et al. Effect of increasing dialyzer mass transfer area coefficient and dialysate flow on clearance of protein-bound solutes: a pilot crossover trial. Am. J. Kidney Dis. 53, 1042-9 (2009).

30. De Smet, R. et al. Effect of the super-flux cellulose triacetate dialyser membrane on the removal of non-protein-bound and protein-bound uraemic solutes. Nephrol. Dial. Transplant. 22, 2006-2012 (2007).

31. Martinez, A. W., Recht, N. S., Hostetter, T. H. \& Meyer, T. W. Removal of P-cresol sulfate by hemodialysis. J. Am. Soc. Nephrol. 16, 3430-3436 (2005).

32. Cornelis, T. et al. Protein-bound uraemic toxins, dicarbonyl stress and advanced glycation end products in conventional and extended haemodialysis and haemodiafiltration. Nephrol. Dial. Transplant. 1-8 (2015). doi:10.1093/ndt/gfv038

33. Feigenbaum, J. \& Neuberg, C. A. Simplified Method for the Preparation of Aromatic Sulfuric Acid Esters. J. Am. Chem. Soc. 63, 3529-3530 (1941).

34. Duranton, F. et al. Normal and Pathologic Concentrations of Uremic Toxins. J. Am. Soc. Nephrol. 23, 1258-1270 (2012). 



\title{
Chapter 3
}

\section{Insights into blood compatibility of mixed matrix membranes}

\author{
$\underline{\text { D. Pavlenko }}$, K. Maksymow ${ }^{\text {b }}$, H.-D. Lemke ${ }^{\text {b }}$, D. Stamatialis ${ }^{a}$
}

aDepartment of Biomaterials Science and Technology, MIRA Institute for Biomedical Engineering and Technical Medicine, University of Twente, Enschede, The Netherlands

${ }^{b}$ eXcorLab GmbH, Industrie Center Obernburg, Obernburg, Germany 


\begin{abstract}
Hemodialysis is vital in sustaining life of patients that suffer from kidney malfunction. Despite important developments in hemodialysis therapy in the last five decades' the mortality rate among dialysis patients remains high, mostly due to inadequate removal of several uraemic toxins. Alternative sorption-based techniques perform better in reducing blood levels of all uremic toxins, but, unfortunately, cannot correct bodyfluid balance. Moreover, the use of adsorptive particles often results in hemocompatibility complications when adsorptive particles are brought into direct contact with blood. Therefore, adsorbents are often coated with hemocompatible coating, which notably reduces their performance. In earlier studies, we have developed mixed matrix membrane (MMM) which combine of advantages of filtration and adsorption and have superior removal of protein-bound toxins form human plasma. In this work, we perform extensive blood compatibility tests of the newly developed MMM following ISO protocol 10993-4. Our results show that the membranes have high blood compatibility comparable to membranes currently used in the clinic.
\end{abstract}

Key words: membranes; hemodialysis; hemocompatibility. 


\section{Introduction}

Hemodialysis is a vital technique to sustain life of the renal patients who wait for the kidney transplantation. Membrane in hemodialysis is playing the central role making it possible to separate toxic uremic solutes from patience blood. As membrane always operates in direct contact with blood, high blood compatibility of membrane surface is of utmost importance ${ }^{2}$.

Cellulose-based membranes (CBM) were one of the first to be used at a commercial scale for the hemodialysis purpose mostly due to low cost and limited number of alternative membrane materials available at that time $\mathrm{e}^{3-5}$. These membranes had, in general, low hydraulic permeability and, as later found, had suboptimal hemocompatibility, inducing high complement activation ${ }^{4,6}$. Because of this, they were actually substituted by synthetic memrbanes with better hemocompatibility profiles. In fact, the current membranes for hemodialysis are produced using synthetic polymers including polyamide (PA), polymethyl methacrylate (PMMA), polyacrylonitrile (PAN), polysulfone (PS) and polyethersulfone (PES) ${ }^{2}$. The last two occupy the majority of the membrane market due to good balance between permeability, selectivity and sterilization resistance. Still, the relative high hydrophobicity of most of synthetic materials may cause adverse effect when material is brought to direct contact with blood. For this reason several studies had been focused on further tuning ${ }^{7}$ of the membranes' 
hydrophilicity/hydrophobicity by means of grafting ${ }^{8-12}$, coating ${ }^{13,14}$ and blending of membrane with hydrophilic additives ${ }^{9,11,15-17}$.

Alternative to hemodialysis for removing uraemic toxins from patients' blood is the use of hemoperfusion. There, adsorptive particles are packed inside the hemoperfusion column and blood is passed through it. Hemoperfusion, in practice, is able to efficiently remove high quantities of various uraemic toxins, but it is not designed to correct the fluid balance. Moreover, due to hemocompatibility issues of direct sorbentblood contact coating of the column particles with hemocompatible coatings is often required which, however, decreases their performance. Additionally, the use of small or uninform size adsorbent particles inside the column may result in high pressure drops and consequent to protein denaturation, or blood cells damages. For these reasons hemodialysis remains the preferred option to sustain life of patients that wait for kidney transplantation.

Recently our laboratory developed the concept of double layer mixed matrix membranes (MMM), where inner blood contacting layer is responsible for the selectivity of the membrane, while the outer mixed matrix layer improves overall toxin removal via adsorption. In fact, the adsorption maximizes the concentration gradient of the toxins across the membrane leading to higher removal ${ }^{1,19,20}$. First results ${ }^{1}$ showed that the MMM remove comparable amounts of creatinine from human plasma and $200-300 \%$ more protein-bound toxins in comparison to industrial benchmark membranes. However, prior to application of the MMM in 
vivo, it would be important to investigate in detail the membrane's hemocompatibility ${ }^{7,18}$. Therefore in this work, we performed a set of hemocompatibility tests of the MMM following ISO 10993-4. The results are compared to two industrial membranes: Fresenius F60 and Cuprophan ${ }^{\circledR}$ F1. F60 membranes were used as positive control due to excellent track record of their performance in clinic, while Cuprophan ${ }^{\circledR} \mathrm{F} 1$ membranes were used as negative control for $\mathrm{C} 5 \mathrm{a}$ generation. 


\section{Materials and methods \\ Scanning electron microscopy (SEM)}

The morphological characteristics of the hollow fiber membranes were visualized by use of a scanning electron microscopy (SEM). The membranes were dried in air followed by fracturing in liquid nitrogen to reveal the cross-section. Subsequently, the samples were sputtered with gold using the Cressington 108 auto sputter (Cressington Scientific Instruments, Watford, UK) and examined using a Philips XL-30 ESEM-FEG Scanning Electron Microscope (Philips, Amsterdam, the Netherlands).

\section{X-ray photoelectron spectroscopy (XPS)}

XPS membrane surface analysis was performed using Quantera SXM from Physical electronics. Data analysis was done with Compass for XPS control, Multipak v 9.4.0.7.

\section{Attenuated Total Reflectance-Fourier Transform Infrared Spectroscopy (ATR-FTIR)}

Analysis of the membrane surface chemistry was performed by ATR-FTIR spectroscopy (Spectrum Two, PerkinElmer) and Spectrum Quant software. All scans were performed in triplicate on various parts of the membrane surface, at a resolution of $4 \mathrm{~cm}^{-1}$ and at room temperature.

\section{Materials and chemicals}

Polyethersulfone (Ultrason E6020, BASF, Germany) was mixed with polyvinylpyrrolidone K90 (Sigma-Aldrich Chemie $\mathrm{GmbH}$, Germany) and dissolved in extra pure $\mathrm{N}$-methylpyrrolidone (Acros Organics, 
Belgium). In case of MMM, activated carbon (Norit A Supra, Norit Netherlands B.V., the Netherlands) was sieved through $45 \mu \mathrm{m}$ sieve (VWR, the Netherlands) and added to the outer layer of mixed matrix membranes. All polymer solutions were mixed on the roller bench for 3 days and were allowed to degas for at least 24 hours prior to membrane spinning.

All membranes were produced by dry-wet spinning following the protocol developed earlier ${ }^{1}$. Briefly, degassed polymer solutions (particlefree and with activated carbon) were transferred into two separate stainless steel syringes. As the next step syringed were connected to double layer spinneret that allows simultaneous co-extrusion of two polymer layers. The spinneret together with two connected syringes was placed above the coagulation bath at a specific height (air gap). Collection of the produced fibers was done by the collecting wheel just after the coagulation bath.

Two separate spinning session were performed (Table 1): firstly, only the inner membrane layer without particles was extruded through the spinneret needle to produce single layer membranes (used as the reference) and then outer the dual MMM layer was extruded. Subsequently, the fabricated membranes were washed with water and stored for further use. 


\section{Water permeation experiments}

Modules containing 3 fibers with total surface area of $\sim 5 \mathrm{~cm}^{2}$ were prepared. Nextly, they were pre-compacted with ultrapure water at transmembrane pressure (TMP) of 2 bar for at least 1 hour before further measurements. Subsequently, the amount of permeated water was measured as the function of time at TMP of 2, 1.5, 1 and 0.5 bar TMP pressure points. The water permeance in $\mathrm{L} / \mathrm{m}^{2} / \mathrm{h} /$ bar was measured as the slope of the linear fit of the flux vs TMP graph.

Table 1. Spinning parameters for the produced fibers. All membranes were produced using the same spinneret described elsewhere ${ }^{1}$.

Spinning conditions

$\begin{array}{lc}\text { Inner layer (PES/PVP) } & 15 / 7 \\ \text { Outer layer (PES/PVP/AC) } & 14 / 1.4 / 60 \\ \text { Inner layer pumping speed (ml/min) } & 0.4 \\ \text { Outer layer pumping speed (ml/min) } & 1.6 \\ \text { Bore liquid pumping speed (ml/min) } & 1.2 \\ \text { Bore composition } & \text { Pure water } \\ \text { Air gap (cm) } & 10 \\ \text { Collecting speed (m/min) } & 3.5\end{array}$

\section{Large Module preparation}

For the hemocompatibility studies we prepared large scale modules with only PES/ PVP and dual layer MMM fiber. Predefined surface areas of corresponding membranes were inserted into the 
housing and potted with polyurethane glue by MAT Adsorption Technologies GmbH (Obernburg, Germany) as it is shown on the Fig.1.
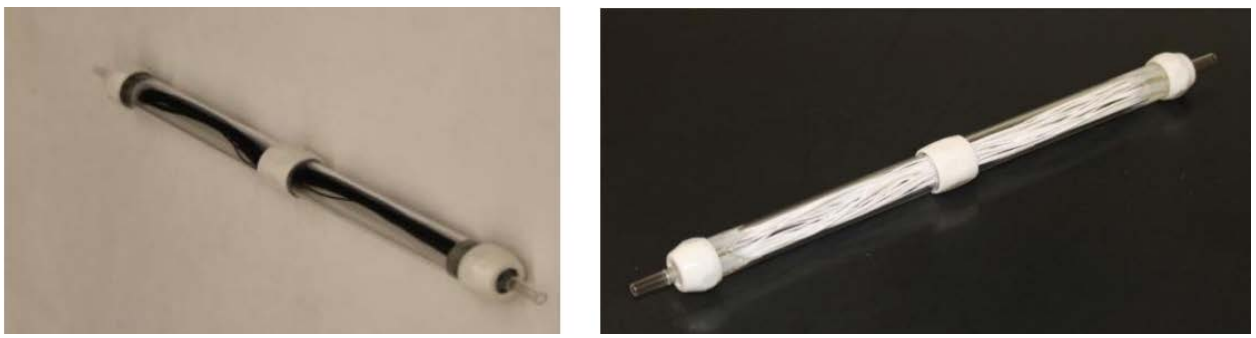

Fig. 1. Double layer mixed matrix membrane (left) and single layer membrane (right) modules used in the study.

In total 4 modules were prepared: 1 . Mixed matrix membranes; 2. Single layer PES/PVP membranes; 3. Cuprophan ${ }^{\circledR}$ F1 (Membrana GmbH, used as the "negative' reference due to high C5a activation) and 4. Fresenius Polysulfone ${ }^{\circledR}$ F60 (Fresenius Medical Care AG, used as the "positive" reference as this membrane is widely used in clinic and has good hemocompatibility profile). Module characteristics can be found in the table 2 . 
Table 2. Parameters of the membrane modules used in the study

\begin{tabular}{|c|c|c|c|c|c|c|}
\hline & Minimodule materials & $\begin{array}{c}\text { Reference } \\
\text { name }\end{array}$ & $\begin{array}{l}\text { Effective } \\
\text { surface } \\
\text { area } \\
\left(\mathrm{cm}^{2}\right)\end{array}$ & $\begin{array}{l}\text { Diameter/ } \\
\text { Wall } \\
\text { thickness } \\
\text { ( } \mu \mathrm{m})\end{array}$ & $\begin{array}{l}\text { Effective } \\
\text { length } \\
\text { (cm) }\end{array}$ & $\begin{array}{l}\text { Number } \\
\text { of fibers }\end{array}$ \\
\hline 1 & $\begin{array}{l}\text { Mixed Matrix Membranes } \\
\text { Polyethersulfone/Activated } \\
\text { carbon }\end{array}$ & MMM & 58 & $312 / 105$ & 16.4 & 36 \\
\hline 2 & $\begin{array}{c}\text { Single Layer Membranes } \\
\text { Polyethersulfone }\end{array}$ & SL & 56 & $301 / 92$ & 16.4 & 36 \\
\hline 3 & $\begin{array}{c}\text { Cuprophan }^{\circledR} \text { F1 } \\
\text { Cellulose }\end{array}$ & F1 & 250 & $200 / 8$ & 23 & 174 \\
\hline 4 & $\begin{array}{c}\text { Polysulfone }{ }^{\circledR} \text { F60 } \\
\text { Polysulfone }\end{array}$ & F60 & 250 & $200 / 30$ & 14 & 284 \\
\hline
\end{tabular}

\section{Hemocompatibility tests}

The hemocompatibility of the tested modules was assessed according to ISO 10993-4 and following standard operation protocols, developed by eXcorLab (Industrie Center Obernburg, Obernburg, Germany). All experiments were performed on the miniaturized set-up with human blood and blood flow rates linearly downsized from a Cuprophan ${ }^{\circledR}$ hemodialysis membrane surface area used clinically $\left(1.5 \mathrm{~m}^{2}\right.$ and $Q_{b}=300 \mathrm{ml} / \mathrm{min}$ to $250 \mathrm{~cm}^{2}$ of the respective Cuprophan ${ }^{\circledR}$ minimodule) resulting in an experimental blood flow rate of $5 \mathrm{ml} / \mathrm{min}$. Experimental set-up is depicted in Figure 2. 


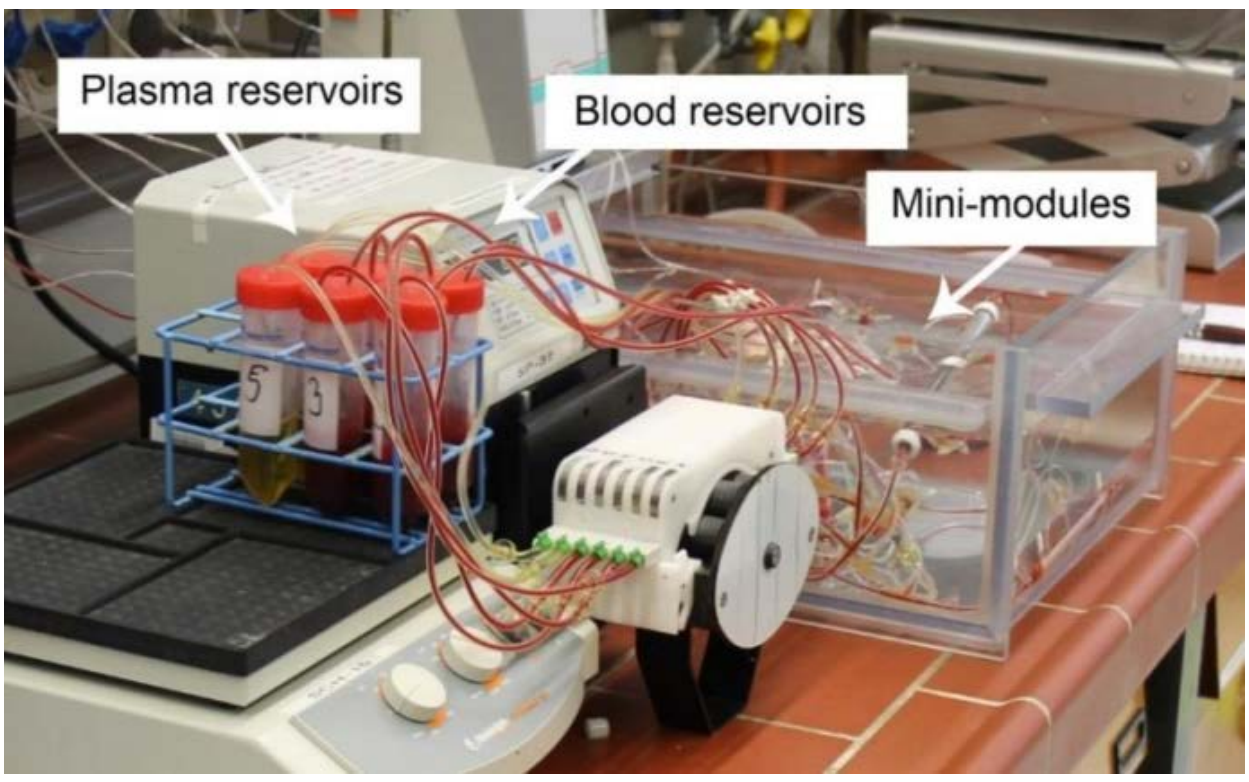

Fig.2. Set-up used to access blood compatibility.

As a preparation step, all modules were rinsed with saline solution in single pass ( $30 \mathrm{~min}$ with flow rates of $5 \mathrm{ml} / \mathrm{min}$ ). The saline was replaced by heparinized $(5 \mathrm{U} / \mathrm{ml}$ ) human blood for 180 min with intraluminal flow and $20 \mathrm{ml}$ of blood was recirculated in each circuit. The modules were kept at $37^{\circ} \mathrm{C}$ whereas medium reservoirs where kept at room temperature on a shaker to avoid sedimentation of blood cells. Blood samples were taken at time points of 0 and $180 \mathrm{~min}$ to count total leukocytes (WBC), red blood cells (RBC) and platelets (PLT). Samples for the measurement of the activation of coagulation (thrombinantithrombine III complex, TAT), complement activation (C5a) and hemolysis were taken at the end of the experiment (180 $\mathrm{min})$. 
C5a and TAT were determined by ELISA (DRG, Marburg, Roche, Mannheim). WBC, RBC and PLT were counted in an ABX Pentra 60 cell counter (Agon Lab AG, Reichenbach, Stuttgart). Hemolysis was measured by photometry using three wavelengths to correct for background: $\mathrm{OD}_{560}$ $\mathrm{nm}, \mathrm{OD}_{576 \mathrm{~nm}}$ and $\mathrm{OD}_{592 \mathrm{~nm}}$ (UV1650PC, Shimadzu Deutschland $\mathrm{GmbH}$ ). Equation 1 was used to calculate hemolysis (plasma free, $\mathrm{fHb}$ ):

$$
\mathbf{f H b}=\frac{\left[\left(2 \mathrm{OD} \mathrm{D}_{576}-\left(\mathrm{OD}_{560 \mathrm{~nm}}+\mathrm{OD}_{592 \mathrm{~nm}}\right)\right) 99.82+0.36\right.}{1000}
$$

Total $f \mathrm{Hb}$ at $\mathrm{t}=0$ after complete red cell lysis was taken to express hemolysis in \%.

The module pressures at the inlet and outlet were recorded with the multichannel pressure transducer (DPT-6300, Codan pvb Medical $\mathrm{GmbH}$, Forstinning, Germany) and a laboratory data acquisition system (MSR-manager, HITEC Zang, Herzogenrath, Germany). Each experiment was repeated three times per module using blood of 3 different donors.

\section{Statistics}

Data analysis was performed by two-way ANOVA (Minitab 17, Minitab Inc.). If ANOVA revealed a significant influence of the materials, the material related means were compared by the Tuckey method. Probability value of $p<0.05$ was considered statistically significant. 


\section{Results and discussion \\ Membrane characterization}

The morphology of the produced membranes was verified using SEM. Fig. 3 shows the images of the produced dual layer MMM and SL fibers. The membranes have similar dimensions in terms of internal diameter (312 $\mu \mathrm{m}$ for MMM vs $301 \mu \mathrm{m}$ for $\mathrm{SL}$ ) and the thickness of fiber walls (105 $\mu \mathrm{m}$ for MMM vs $92 \mu \mathrm{m}$ for SL). Additionally, both membranes have typical anisotropic morphology, where the selective layer is present in the inner (blood-contacting) lumen of the fiber with finger-like macrovoids close to the outer side of the membrane walls.
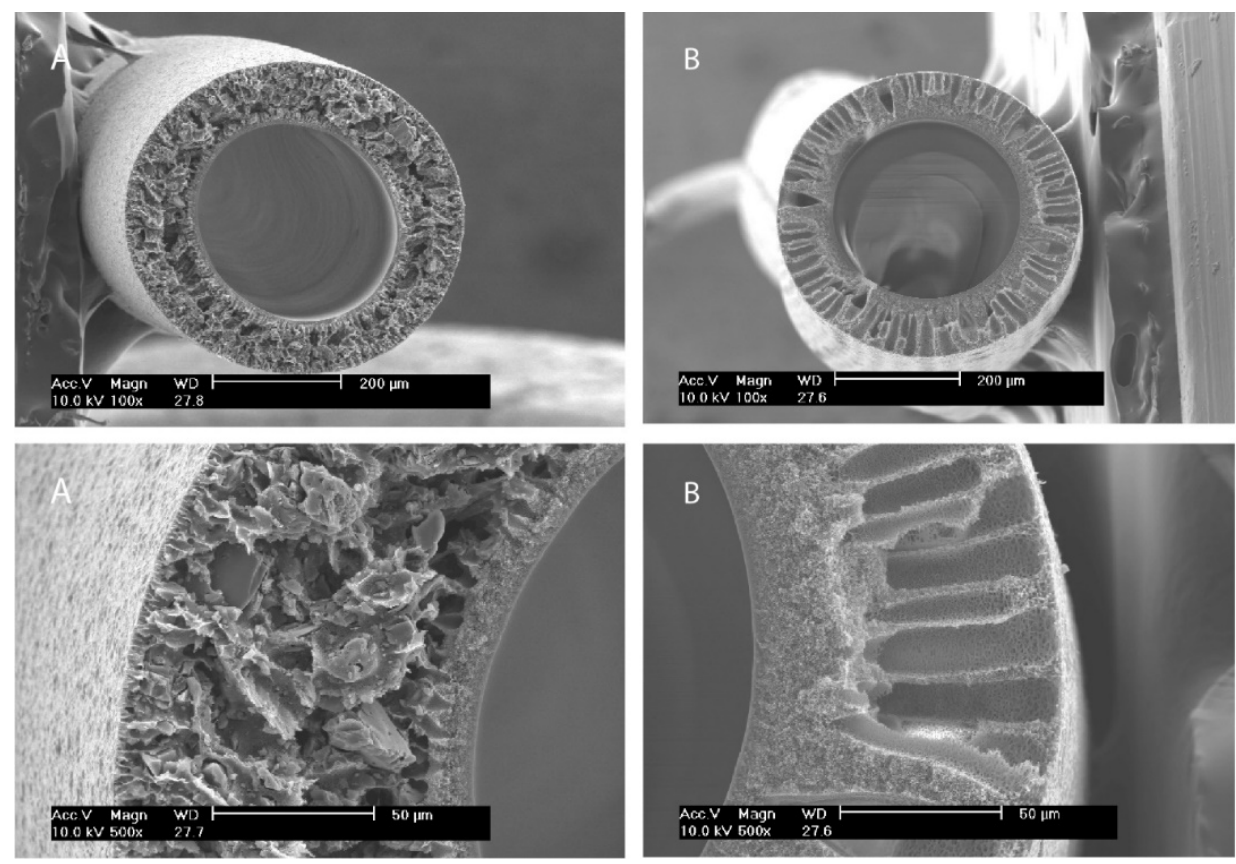

Fig. 3. Morphology of the produced Mixed Matrix Membranes (A, left) and Single Layer (B, right) membranes used in this study. 
The clean water flux of the produced membranes was measured as well as the stability of operation under varied pressure conditions. Here, the MMM has permeance values of $3.2 \pm 0.6 \mathrm{~L} / \mathrm{m}^{2} / \mathrm{h} / \mathrm{bar}$ and the $\mathrm{SL}$ membrane of $7.6 \pm 0.5 \mathrm{~L} / \mathrm{m}^{2} / \mathrm{h} /$ bar, which characterizes both as low-flux dialysis membranes. The difference in water permeance of the membranes can be attributed to the presence of the outer particle layer, which influences the membrane formation. In fact, single layer membranes are thicker than the selective layer of the MMM which in theory could lead to lower flux values, but possibly due to higher surface porosity, the SL membrane has higher flux.

The membrane surface characterization was performed by means of ATR-FTIR and XPS measurements. Figure 4 compares the ATR - FTIR spectra of MMM, the SL membrane and of the Fresenius F60 membrane. It can be seen that that peak at $1677 \mathrm{~cm}^{-1}$ corresponding to carbonyl groups of PVP has noticeably higher intensity for the MMM in comparison to the F60 and pure PES material, indicating higher concentration of the PVP at the MMM surface in comparison to the other two membranes. Similar conclusion can be also made from the Fig. 5 which presents the XPS data. There, the MMM has higher total nitrogen concentration at the surface in comparison to Fresenius F60 (5.29\% vs $4.08 \%$ in F60 fibers) which indirectly indicates higher concentration of PVP for the MMM. 


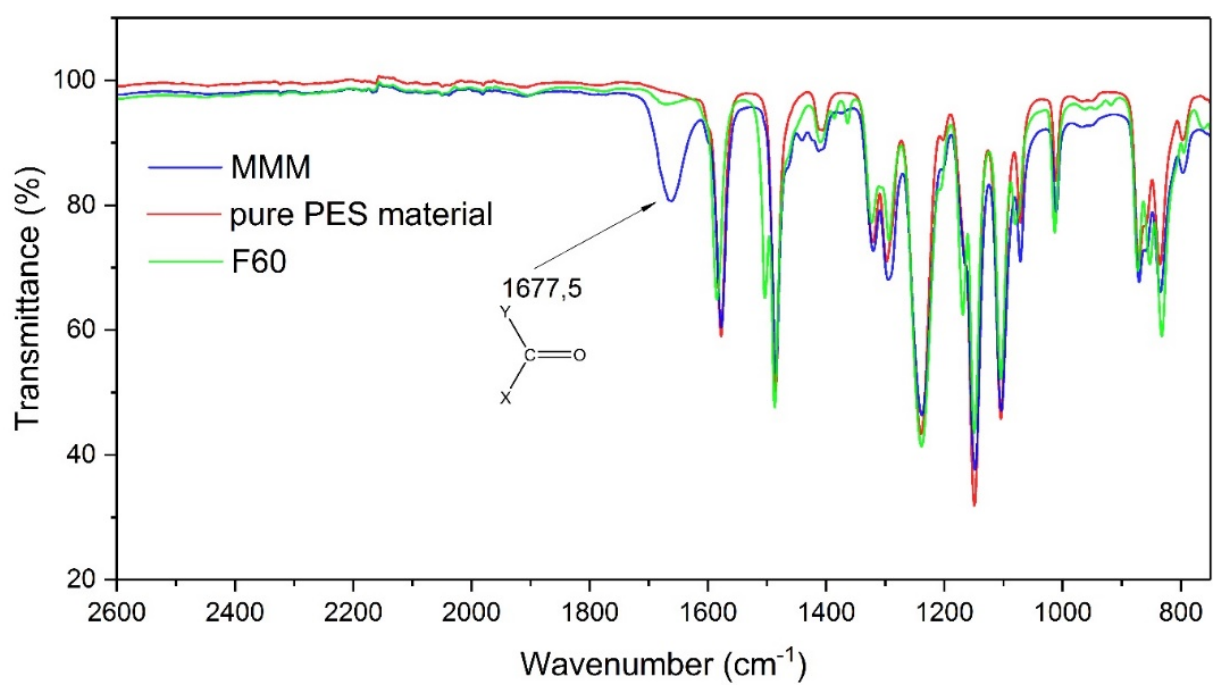

Fig. 4. FTIR data of the membrane selective layer. Pure PES film without PVP (in red) was used as the reference. 

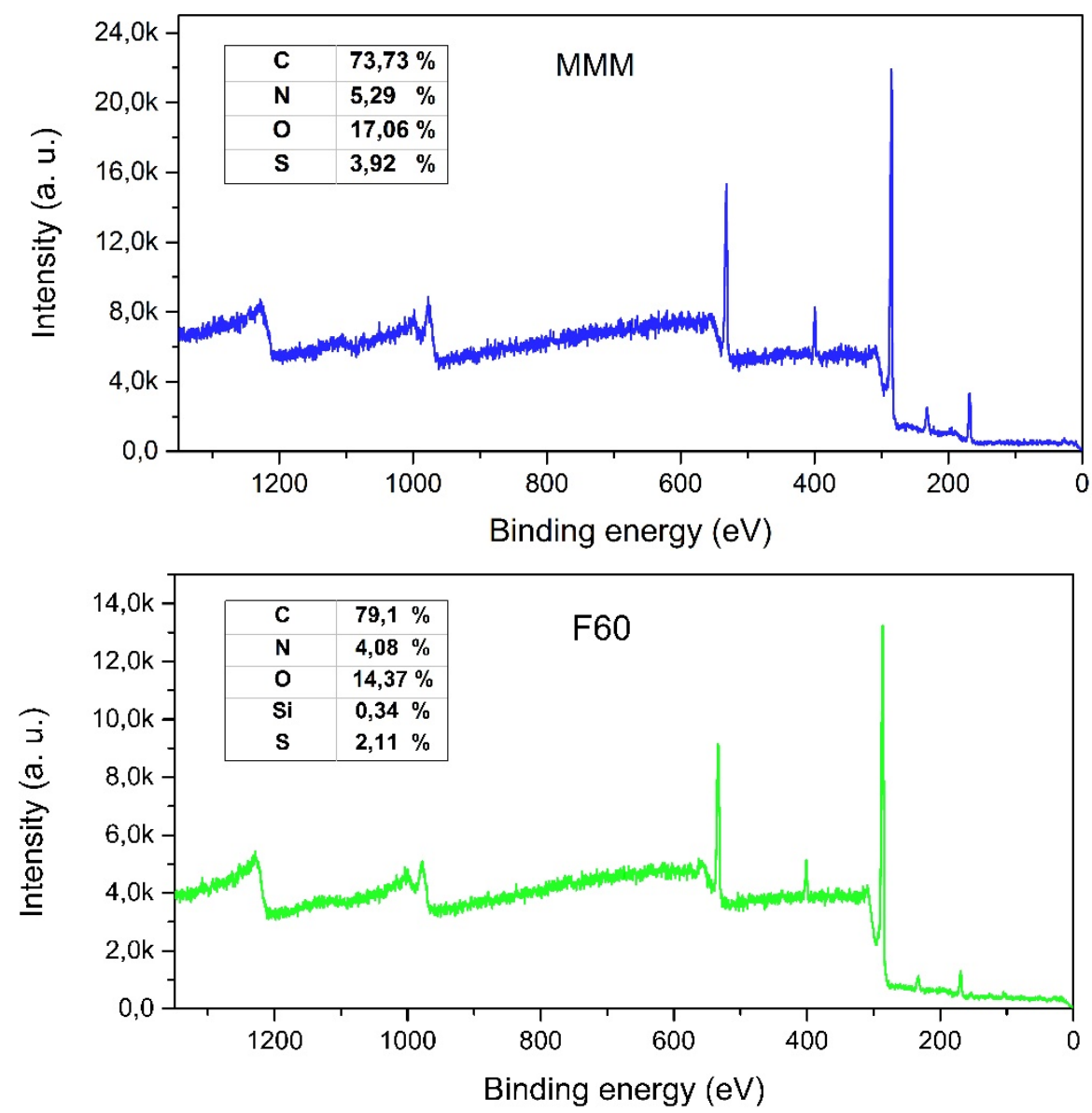

Fig. 5. XPS spectra of the selective layers of MMM and F60 fibers.

\section{Hemocompatiblity tests}

Table 3 shows the results of cell count as the percent of initial values for TAT, C5a and of hemolysis at the end of the experiment (180 min) for all tested membrane modules.

Platelet count (PLT) values show the percentage of initial platelets after $180 \mathrm{~min}$. High loss of platelets indicates adhesion of platelets on the membrane surface, mostly hydrophobic in nature and might result in 
generation of reactive oxygen species ${ }^{19}$. The $\mathrm{MMM}$, as well as, the $\mathrm{SL}$ and Cuprophan ${ }^{\circledR} \mathrm{F} 1$ membranes, show minor platelet loss. On the other hand, higher platelet loss was measured for F60 fibers. We speculate that this could be attributed to slightly higher hydrophobicity of inner surface of the F60, consistent with the XPS and ATR-FTIR results (see Figure 4 and 5). In fact, the MMM have higher concentration of PVP at the surface than the F60 fibers and, thus, have better hydrophilicity, which results in lower platelet loss for both SL and MMM fibers. The Cuprophan membrane is prepared from cellulose which is a highly hydrophilic membrane material.

The blood flow in hemodialyzer is relatively high, around 200 $\mathrm{ml} / \mathrm{min}$, which results in sheer force generation and may lead to rupturing of red blood cells (RBC). Due to RBC rupture, hemoglobin is released to the hemodialyzer which should be avoided. Therefore, values of hemolysis and RBC count were measured for all membranes. 
Table 3. Data from hemocompatibility experiments after 180 min with human blood.

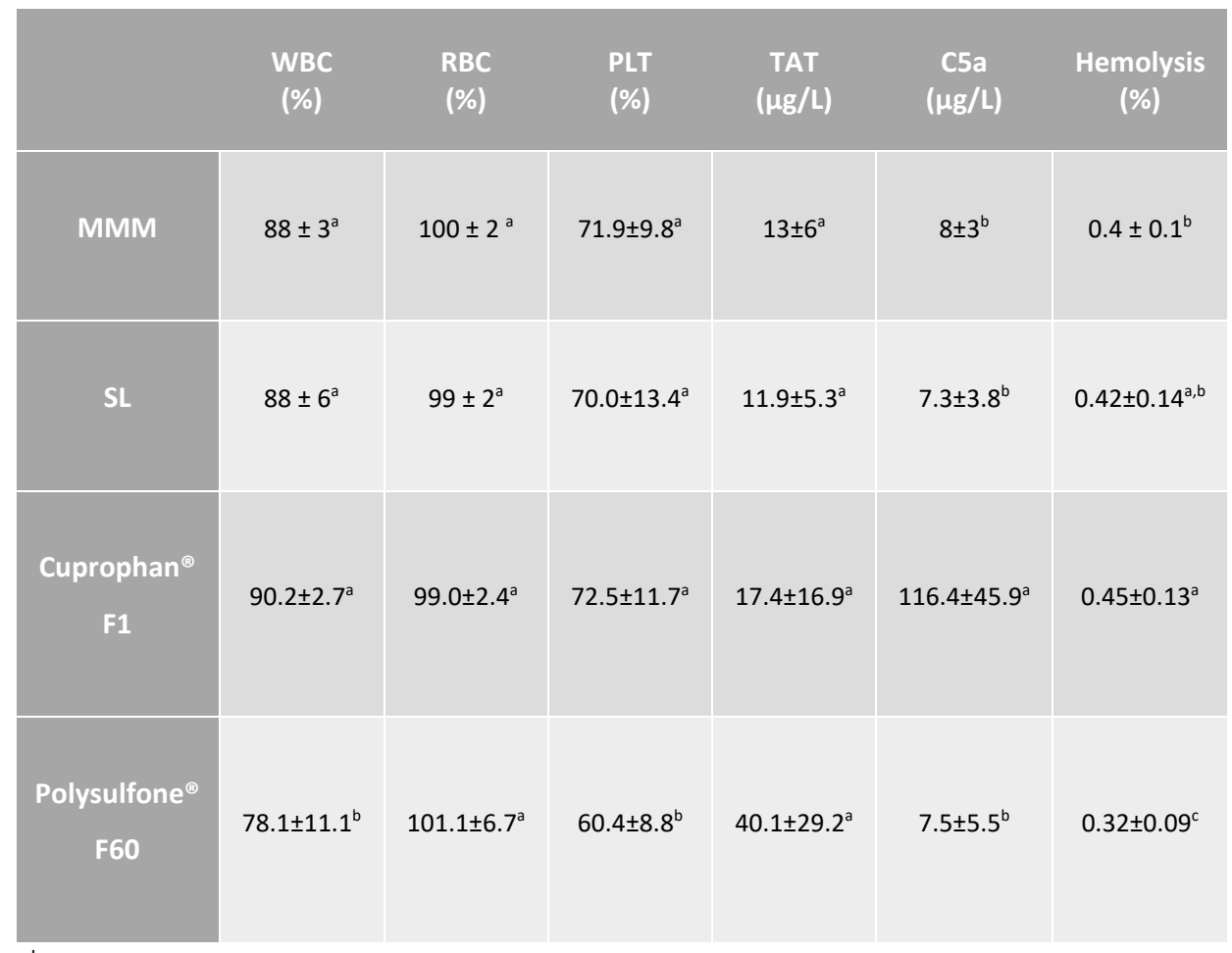

$a, b, c$ Samples are statistically different from each other when they do not carry the same character ( $p<0.05$, mean of 3 experiments, read columns only).

Hemolysis was found to be in range of $0.3-0.5 \%$ for all membranes. Slight and statistically significant differences between samples (Table 3) have no biological significance. To the best of our knowledge there are no accepted limits or guidelines for acceptance/rejection of hemolysis data for medical device. All membranes have values below $0.8 \%$ which compares well with $0.8 \%$ in Europe and $1 \%$ in USA, that are accepted limits for red cell concentrates stored for 42 days in blood banks. A drop in red blood cell count reflects substantial damage of red cells due to e.g. mechanical sheer stress mentioned before, but also trapping or adhesion 
of the cells in the experimental set-up. As it is seen from table 3 none of the membranes causes red blood cell damage during 3 hours of each test. Both MMM and SL membranes have noticeable macrovoids (Fig 2) at the outer side of the membrane and one could have expected that there cells adhesion would take place in the entrance of the membrane module. However, the results of the Table 3 as well as visual inspection of the tested modules did not show any cell adhesion.

Thrombin-Antithrombin III-Complex (TAT). The physiological reference range for TAT in healthy donors is from 2.0 to $4.2 \mu \mathrm{g} / \mathrm{L}$. Increased TAT values mean activation of the coagulation pathway. This occurs when blood comes into contact with an artificial surface, for example activated carbon, even in the presence of the anticoagulant (heparin). The TAT generation was the lowest for the MMM and SL membranes, while the TAT values for the F60 module were the highest (but did not reach statistical significance). Even though, the surface area of MMM and SL membranes was lower than the reference fibers (58 and $56 \mathrm{~cm}^{2}$ respectively, only $20 \%$ of area of the reference modules) even 5 times higher TAT values for MMM would still give TAT values in an acceptable range. These results leads us to a conclusion that particle free layer of the MMM does not allow contact of blood with the activated carbon particles incorporated inside polymeric matrix.

Crucial part of body's innate immune system is complement system, which provides defense against foreign bodies. C5a anaphylatoxins are liberated as products of immune activation and they 
result in leukocyte activation after binding to specific cell receptors. Detectable amounts of $\mathrm{C} 5 \mathrm{a}$ in the outlet of hemodialyzer depend mainly on grade of their generation and also on ability of the membrane surface to adsorb them. Physiological reference range for $\mathrm{C} 5 \mathrm{a}$ is from 0.15 to 0.5 $\mu \mathrm{g} / \mathrm{L}$. A higher C5a value indicates activation of the complement system. MMM, SL and F60 membranes cause similar, low activation of the complement system which indicates hemocompatibility of their surface. Additionally, the generation of $\mathrm{C} 5 \mathrm{a}$ for Cuprophan F1 membranes in our experiments is expectedly higher as compared to the other membranes (Table 3). Due to high complement activation, cellulose-based Cuprophan $^{\circledR}$ membranes are no longer used clinically for hemodialysis, thus, Cuprophan ${ }^{\circledR}$ membranes is an ideal positive control for a complement activation. Another important factor to take into account when analyzing $\mathrm{C} 5 \mathrm{a}$ data is the adsorption of the $\mathrm{C} 5 \mathrm{a}$ by the membrane material itself, especially in case of MMM. For example, polyacrorylonitrile-based AN69 hemodialysis membrane is known to adsorb C5a almost completely from blood stream.

Here we can conclude that the inner layer of MMM membranes is not causing complement activation and, importantly, that the activated carbon outer layer of MMM fibers does not influence complement activation indirectly. Besides, one could speculate that the due to enhanced toxin removal the removal of $\mathrm{C} 5 \mathrm{a}$ from the bloodstream due to improved diffusion (see Chapter 2 for more details) in comparison to other studied membranes, C5a will be extensively removed from blood 
after their generation. However, due to size exclusion (MW of $\mathrm{C} 5 \mathrm{a}$ a is around $11 \mathrm{kDa}$, while MWCO of MMM is around $12 \mathrm{kDa}$ ) this option remains less probable.

White blood cell (WBC). A drop in WBC count is normally observed in extracorporeal circuits during clinical application of hemodialysis membranes (called leukopenia) and indicates adhesion of leukocyte cells to the extracorporeal materials, most probably membranes in use. MMM show low drop in total leukocyte count $(88.2 \pm 3.2 \%)$ together with SL $(88.2 \pm 6.2 \%)$ and $F 1(90.2 \pm 2.7 \%)$ fibers. A drop in WBC was a bit higher (78.1 $\pm 11.1 \%)$ for the F60 reference membranes possibly due to more hydrophobic polysulfone material in use. It should be also mentioned that the difference in WBC between MMM /SL membranes and F60 fibers can also be attributed to the difference in surface area of the membranes used in the study: smaller surface area of the MMM and SL modules might result in smaller degree of white blood cells adhesion.

\section{Conclusions}

This work presents a detailed hemocompatibility characterization of MMM following the ISO 10993-4 Our results show that the MMM have excellent hemocompatibility profile. Indeed, in our tests MMM have low drop in white blood cell and platelet count combined with low TAT and C5a generation. Additionally, absence of hemolysis and no significant drop in red blood cell count makes them perfect candidates for next step 
in medical device development. In the future, we plan to investigate performance of MMM in vivo using uremic animal models. 


\section{Bibliography}

1. Pavlenko, D. et al. New low-flux mixed matrix membranes that offer superior removal of protein-bound toxins from human plasma. Sci. Rep. 6, 34429 (2016).

2. Kokubo, K., Kurihara, Y., Kobayashi, K., Tsukao, H. \& Kobayashi, H. Evaluation of the Biocompatibility of Dialysis Membranes. Blood Purif. 40, 293-297 (2015).

3. Amri, C., Mudasir, M., Siswanta, D. \& Roto, R. In vitro hemocompatibility of PVA-alginate ester as a candidate for hemodialysis membrane. Int. J. Biol. Macromol. 82, 48-53 (2016).

4. Mulvihill, J. et al. Minimodule dialyser for quantitative ex vivo evaluation of membrane haemocompatibility in humans: comparison of acrylonitrile copolymer, cuprophan and polysulphone hollow fibres. Biomaterials 13, 527-536 (1992).

5. Gao, A., Liu, F. \& Xue, L. Preparation and evaluation of heparinimmobilized poly (lactic acid) (PLA) membrane for hemodialysis. J. Memb. Sci. 452, 390-399 (2014).

6. Bouré, T. \& Vanholder, R. Which dialyser membrane to choose? Nephrol. Dial. Transplant. 19, 293-296 (2004).

7. Roy, A., Dadhich, P., Dhara, S. \& De, S. Understanding and tuning of polymer surfaces for dialysis applications. Polym. Adv. Technol. (2016). doi:10.1002/pat.3872

8. Zhu, L. J., Liu, F., Yu, X. M., Gao, A. L. \& Xue, L. X. Surface zwitterionization of hemocompatible poly(lactic acid) membranes for hemodiafiltration. $J$. Memb. Sci. 475, 469-479 (2015).

9. Roy, A., Dadhich, P., Dhara, S. \& De, S. In vitro cytocompatibility and blood compatibility of polysulfone blend, surface-modified polysulfone and polyacrylonitrile membranes for hemodialysis. RSC Adv. 5, 7023-7034 (2015).

10. Xie, B. et al. Decoration of heparin and bovine serum albumin on polysulfone membrane assisted via polydopamine strategy for hemodialysis. J. Biomater. Sci. Polym. Ed. 27, 880-897 (2016). 
11. Ye, S. H., Watanabe, J., Takai, M., Iwasaki, Y. \& Ishihara, K. High functional hollow fiber membrane modified with phospholipid polymers for a liver assist bioreactor. Biomaterials 27, 1955-1962 (2006).

12. Li, J. et al. A novel natural hirudin facilitated anti-clotting polylactide membrane via hydrogen bonding interaction. J. Memb. Sci. 523, 505-514 (2017).

13. Omichi, M., Matsusaki, M., Maruyama, I. \& Akashi, M. Improvement of blood compatibility on polysulfone-polyvinylpyrrolidone blend films as a model membrane of dialyzer by physical adsorption of recombinant soluble human thrombomodulin (ART-123). J. Biomater. Sci. Polym. Ed. 23, 593-608 (2012).

14. Heintz, K. et al. Preparation and evaluation of PEO-coated materials for a microchannel hemodialyzer. J. Biomed. Mater. Res. - Part B Appl. Biomater. 102, 1014-1020 (2014).

15. Ran, F. et al. Toward a highly hemocompatible membrane for blood purification via a physical blend of miscible comb-like amphiphilic copolymers. Biomater. Sci. 2, 538 (2014).

16. Yin, Z. et al. Hemocompatible polyethersulfone/polyurethane composite membrane for high-performance antifouling and antithrombotic dialyzer. J. Biomed. Mater. Res. - Part B Appl. Biomater. 103, 97-105 (2015).

17. Zhu, L., Liu, F., Yu, X. \& Xue, L. Poly(Lactic Acid) Hemodialysis Membranes with Poly(Lactic Acid)-block-Poly(2-Hydroxyethyl Methacrylate) Copolymer As Additive: Preparation, Characterization, and Performance. ACS Appl. Mater. Interfaces 7, 17748-17755 (2015).

18. Erlenkötter, A., Endres, P., Nederlof, B., Hornig, C. \& Vienken, J. Score model for the evaluation of dialysis membrane hemocompatibility. Artif. Organs 32, 962-969 (2008).

19. Tijink, M. et al. Development of novel membranes for blood purification therapies based on copolymers of $\mathrm{N}$-vinylpyrrolidone and $\mathrm{n}$ butylmethacrylate. J. Mater. Chem. B 1, 6066 (2013).

20. Tijink, M. S. L. et al. A novel approach for blood purification: Mixed-matrix membranes combining diffusion and adsorption in one step. Acta Biomater. 8, 2279-2287 (2012). 


\section{Chapter 4}

\section{Carbon Adsorbents With Dual Porosity For Efficient Removal Of Uremic Toxins And Cytokines From Human Plasma}

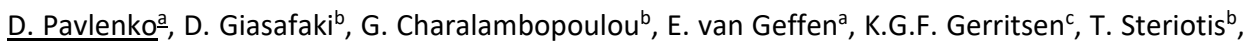
D. Stamatialis ${ }^{\text {a }}$.

${ }^{a}$ Department of Biomaterials Science and Technology, MIRA Institute for Biomedical Engineering and Technical Medicine, University of Twente, P.O. Box 217, 7500 AE Enschede, The Netherlands

bNational Center for Scientific Research "Demokritos", Agia Paraskevi Attikis, 15341 Athens, Greece

'Department of Nephrology and Hypertension, University Medical Centre Utrecht, P.O. Box 85500, 3508 GA Utrecht, The Netherlands 


\section{Abstract}

The number of patients with chronic kidney disease increases while the number of available donor organs stays at approximately the same level. Unavoidable accumulation of the uremic toxins and cytokines for these patients comes as the result of malfunctioning kidneys and their high levels in the blood result in high morbidity and mortality. Unfortunately, the existing methods, like hemodialysis and hemofiltration, provide only partial removal of uremic toxins and/or cytokines from patients' blood. Consequently, there is an increasing need for the development of the extracorporeal treatments which will enable removal of broad spectrum of uremic toxins that are usually removed by healthy kidneys. Therefore, in this work we developed and tested ordered mesoporous carbons as new sorbents with dual porosity (micro/meso) that provide selective and efficient removal of a broad range of uremic toxins from human plasma. The new sorbents, CMK3 are developed by nanocasting methods and have two distinct pore domains, i.e. micropores and mesopores, therefore show high adsorption capacity towards small water soluble toxins (creatinine), protein-bound molecules (indoxyl sulfate and hippuric acid), middle molecules ( $\beta$-2-microglobulin) and cytokines of different size (IL-6 and IL-8). Our results show that small amounts of CMK-3 could provide selective and complete blood purification.

Key words: adsorption; cytokines; protein-bound; kidney; mesoporous carbons. 


\section{Introduction}

Patients with kidney malfunction suffer from consequences of unavoidable accumulation of uremic toxins in their blood. All these uremic toxins are generally divided into three main groups based on their size and/or properties. The first group consists of small water soluble molecules with molecular weights (MW) lower than 500 Da. Molecules from this group, like creatinine and urea, are traditionally removed well by diffusion-based membrane treatment, for example hemodialysis, using "low-flux" dialysis membranes. The second group of toxins consists of “middle molecules', which have MW larger than $500 \mathrm{Da}$, for example $\beta$-2microglobulin ( $\beta 2 \mathrm{~m}$ ) and cytokines like IL-6 and IL-8, and as such they have low diffusion rates. Removal of these molecules can be improved by using "high-flux" membranes with more open structure (in comparison to "low flux" membranes) and by adding convection (hemofiltration) to diffusion (a treatment called hemodiafiltration) ${ }^{1}$. The third group of uremic toxins comprises of solutes that are bound to human serum albumin (HSA) in human blood (protein-bound toxins, PBT). As both high-flux and low-flux dialysis membranes are designed to retain albumin, only the free fraction of these toxins (unbound to albumin) is removed by hemodialysis, hemofiltration and hemodiafiltration ${ }^{1,2}$.

Adsorption techniques can in principle offer better removal of PBT, middle molecules and cytokines from patients' blood. For example, during hemoperfusion the patients' blood is pumped through a column packed with adsorbent particles. These particles provide rather fast and 
efficient adsorptive removal of all the toxins they are designed to remove. As the result this treatment found its application in intensive medical care units for removal of inflammatory cytokine mediators in septic patients. However, hemoperfusion does not offer control over the fluid balance and ability to remove urea. Nevertheless, combination of both modes of blood purification, membrane- and adsorption-based, can in principle provide better blood purification to kidney patients. For example, clinically relevant blood purification methods like Adsorbents Recirculation System (MARS, Gambro), Prometheus System (Fresenius Medical Care) and Coupled Plasma Plasma Filtration and Adsorption (Bellco) successfully use both adsorption and membrane-based techniques to remove the toxins from patients ${ }^{3}$. Besides, recently our laboratory successfully combined the benefits of adsorption and diffusion in one membrane, the mixed matrix membrane (MMM), which consists of two layers: a selective inner layer which is responsible for blood contact and selectivity and an outer layer where adsorptive particles are incorporated in a highly porous membrane matrix ${ }^{4,5}$. The addition of the outer layer with adsorptive particles improves the concentration gradients of the toxins across the membrane resulting in high removal of PBT in vitro in comparison to current dialysis membranes ${ }^{4,6}$.

In all the above cases the properties of adsorptive particles are very important for successful therapy. Therefore, significant efforts have been focused on the development of appropriate adsorbent materials which can remove a broad range of blood toxins from patients' blood. For 
example, Harm et $\mathrm{al}^{3}$ showed that the pore size of the sorbent material determines the selectivity towards the blood toxins. So, the efficiency of the adsorbent can be adjusted to the needs of the treatment by tailoring its pore size distribution. In fact, microporous adsorbent particles (with pores $<2 \mathrm{~nm}$ according to IUPAC) cannot remove substances with high and middle Mw. Larger molecules, such as $\beta 2 \mathrm{~m}$, and cytokines, such as IL$6, I L-8$, and most of PBTs could be better removed by mesoporous sorbents (pores of 2-50 nm) due to improved pore accessibility. Based on this, various researchers focused on development of adsorbent materials with hierarchical porosity: sorbents with pores of two or more length scales $^{7}$ (micro-, meso- and macro pores). The first results of, for example, Presser et al were quite encouraging ${ }^{8}$, however authors indicated that material performance, e.g. selectivity, can be further improved by narrowing the pore size distribution of the sorbents. Besides, one limitation of these sorbents was the high adsorption of large protein molecules (like HSA and often indicated by protein loss), which limited the accessibility of small pores and, thus, reduce the adsorptive capacity of the material ${ }^{8}$.

In this work, we hypothesize that carbon-based sorbent materials with two well-defined pores sizes could provide better removal of a broad range of the uremic toxins and cytokines. Therefore, we use an ordered nanoporous sorbent material (CMK-3 type) which has two distinct pore domains, i.e. micropores and mesopores. This sorbent consists of a set of parallel rods that are hexagonally packed and interconnected with thin 
carbon strands. Due to the carbon precursor pyrolysis process these rods are microporous (0.8-1 $\mathrm{nm})$, and are responsible for the efficient adsorption of small water soluble molecules and PBTs. The space between the rods creates the well-defined and easily tuneable mesoporous system ( $5 \mathrm{~nm}$ in our case) that should achieve the removal of middle molecules and cytokines without blocking the micropores. For the proof of concept here, we investigated the removal of a broad range of toxins from human plasma by CMK-3 type adsorbent, including small water soluble molecules, like creatinine (113 Da), middle molecules, like $\beta 2 \mathrm{~m}$ (11.6 kDa), and PBTs like hippuric acid (179 Da, 48\% bound to HSA) and indoxyl sulfate (213 Da, 98\% bound to HSA), as well as the removal of two cytokines, IL-6 and IL-8 (24kDa and $8 \mathrm{kDa}$ respectively). The performance of CMK-3 was compared with two commercially available carbon-based sorbents with predominant mesoporosity (Norit A Supra, $3 \mathrm{~nm}$ ) and microporosity (Takeda 5A, $0.6 \mathrm{~nm}$ ). Norit A Supra was previously used by our laboratory in MMM and showed good ability to remove creatinine and PBTs from human plasma, while Takeda was used practically as a negative control. 


\section{Materials and Methods}

\section{Synthesis of mesoporous carbon CMK-3}

The synthesis of the CMK-3 type ordered mesoporous carbon was carried out following the hard-templating procedure, described in details elsewhere ${ }^{9}$. In short, SBA-15 hexagonally ordered mesoporous silica template (Claytec Inc., USA) was infiltrated twice with an aqueous sucrose solution containing minute amounts of $\mathrm{H} 2 \mathrm{SO} 4$. The composite was heat treated in air $\left(6 \mathrm{~h}\right.$ at $100^{\circ} \mathrm{C}$ followed by $6 \mathrm{~h}$ at $160^{\circ} \mathrm{C}$ ) and consequently carbonized at $900^{\circ} \mathrm{C}$ for $2 \mathrm{~h}\left(10^{\circ} \mathrm{C} / \mathrm{min}\right)$ in a temperature-programmed horizontal tubular furnace (MTI GSL-1100X) under $\mathrm{N}_{2}$ flow $(80 \mathrm{ml} / \mathrm{min})$. Finally, the carbon/silica composite was treated with HF (48 wt\%) at room temperature to remove the silica part. In this respect, the final porous carbon is actually a negative replica of the silicious structure and thus its mesoporosity is determined by the pore size and wall thickness of the starting SBA-15 material. The carbon precursor (sucrose) pyrolysis process always creates a microporous network due to inefficient stacking of the developed graphitic platelets. Microporosity can be controlled through the pyrolysis conditions (e.g. temperature, time) and can be further increased by activation (i.e. partial oxidation). It should be noted that in our case a rather typical protocol was followed (as a proof of principle) and thus both microporosity and mesopore size and thus adsorptive capacity can certainly be optimized in the future. Details on the surface chemistry of CMK-3 can be found elsewhere ${ }^{10}$. In brief, the sample contains a significant amount of surface oxygen functionalities, the 
majority being C-O-C (ether/epoxy) groups, while smaller amounts of hydroxyl, carbonyl and carboxyl groups are also present.

\section{Carbon characterization}

The properties of the porous carbon materials, CMK-3, Norit A Supra and Takeda, in this study were estimated via $\mathrm{N}_{2}$ adsorptiondesorption isotherms (Autosorb-1 MP, Quantachrome). All the samples were degassed under vacuum $\left(10^{-6} \mathrm{mbar}\right)$ for around 12 hours at $250^{\circ} \mathrm{C}$ before each measurement. Moreover, small angle x-ray scattering (SAXS) measurements were performed for the CMK-3 sample in order to verify its pore ordering.

\section{Static batch adsorption experiments}

Healthy human plasma was obtained from Sanquin (Deventer, Netherlands) and stored frozen at $-20^{\circ} \mathrm{C}$. Prior to the experiments, the plasma was defrosted at $37^{\circ} \mathrm{C}$ and spiked with uraemic concentrations of small water soluble and protein bound toxins, middle molecules and cytokines as it is shown in table 1.

Table 1. Initial concentrations of the toxins and cytokines used in this study

\begin{tabular}{|c|c|c|c|c|}
\hline & MW, kDa & Concentration & Batch & Protein bounding \\
\hline Creatinine & 0.113 & $130 \mu \mathrm{g} / \mathrm{ml}$ & I & No \\
\hline Indoxyl Sulfate & 0.213 & $25 \mu \mathrm{g} / \mathrm{ml}$ & I & $97.70 \%{ }^{11}$ \\
\hline Hippuric acid & 0.179 & $80 \mu \mathrm{g} / \mathrm{ml}$ & I & $48.30 \%{ }^{11}$ \\
\hline $\boldsymbol{\beta 2 m}$ & 11.6 & $84.7 \mu \mathrm{g} / \mathrm{ml}$ & II & No \\
\hline IL-6 & 24 & $500 \mathrm{pg} / \mathrm{ml}$ & II & No \\
\hline IL-8 & 8 & $500 \mathrm{pg} / \mathrm{ml}$ & II & No \\
\hline
\end{tabular}


The blood plasma adsorption experiments were divided into two batches. First batch (batch I) was spiked with creatinine, IS and HA, while batch II was spiked with $\beta 2 \mathrm{~m}, \mathrm{IL}-6$ and IL-8. In all experiments $25 \mathrm{mg}$ of carbon material was added to $4 \mathrm{ml}$ of human plasma. The obtained solutions were shaken gently and left in an incubator at $37^{\circledR} \mathrm{C}$ for 4 hours. After adsorbtion, all samples (triplicates for each measurement) were centrifuged at $3500 \mathrm{rpm}$ for 10 minutes to separate the adsorbents from plasma. Afterwards, the concentrations of uremic toxins and cytokines were analysed as described below.

\section{Total protein and uremic toxin analysis}

The $\beta 2 m$ concentration analysis was performed with $\beta 2 m$ ELISA kit (Siemens, Germany). The concentrations of the cytokines were identified by specific ELISA kits (BioLegend, Inc, Germany). The creatinine concentrations in plasma were determined with Creatinine Assay Kit from Sigma-Aldrich (Netherlands). The total protein concentrations were analysed by the Protein Assay kit (BioRad Laboratories $\mathrm{GmbH}$ ).

For the analysis of plasma levels of PBTs, the plasma samples were deproteinized by heat treatment and filtered through $30 \mathrm{kDa}$ filters (Amicon Ultracel-30 K, Merck Millipore Ltd). Subsequently, the concentrations of IS and HA were analysed following the protocol described by Meert et $a l^{12}$. 


\section{Statistics}

All results are presented as average values with corresponding standard deviations $(n=3)$. Software package IBM SPSS Statistics was used for comparative statistical analysis (Independent student t-test, $p<0.05$ ). 


\section{Results and discussion}

\section{Characterization of synthesized carbons.}

In this study the performance of CMK-3 was compared with two commercially available carbon-based sorbents: Norit A Supra that consists of micropores $(<0.7 \mathrm{~nm}$, i.e. $0.5 \mathrm{~nm})$, micropores of about $0.9 \mathrm{~nm}$ and small mesopores of around $3 \mathrm{~nm}$ and Takeda $5 \mathrm{~A}$ which is clearly an ultramicroporous material with pores of $0.6 \mathrm{~nm}(<0.7 \mathrm{~nm})$. As for the CMK-3, it is a micro-mesoporous material with mesopores of $\sim 5 \mathrm{~nm}$ and micropores of $\sim 1 \mathrm{~nm}$ (Figure 1) in accordance with literature data ${ }^{13}$. Additionally, there is a difference in the Brunauer - Emmett - Teller (BET) surface area between the carbon materials studies. Here, the specific surface area of CMK-3 is around $1250 \mathrm{~m}^{2} / \mathrm{g}$, higher than the one of Takeda $5 \mathrm{~A}\left(560 \mathrm{~m}^{2} / \mathrm{g}\right)$, but lower than the one of Norit A Supra (approximately $1700 \mathrm{~m}^{2} / \mathrm{g}$.)
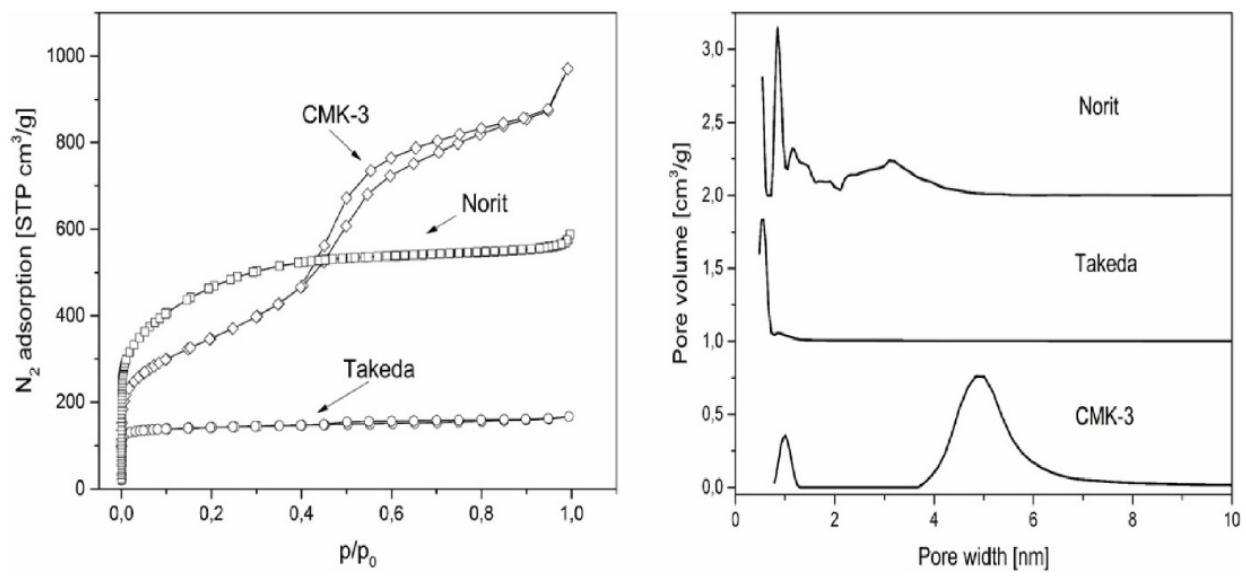

Fig. 1. $\mathrm{N}_{2}$ adsorption-desorption isotherm for studied carbon materials (left) and pore size distribution for studied carbons obtained from quenched solid state functional theory (right). 
Sorbent properties are described in table 2. Both CMK-3 and Norit A Supra have relatively small diameter, 1-15 $\mu \mathrm{m}$ and 2-40 $\mu \mathrm{m}$, respectively. The Takeda particles have noticeably higher particle size range $(3-150 \mu \mathrm{m})$ with predominantly big particles $(>100 \mu \mathrm{m})$ and rather low surface area $\left(500-600 \mathrm{~m}^{2} / \mathrm{g}\right)$. The Norit particles have the highest surface area of all materials.

Table 2. Material properties of studied nanoporous carbons

$\begin{array}{cccc} & \begin{array}{c}\text { Particle size } \\ (\mu m)\end{array} & \begin{array}{c}\text { Pore size } \\ (n m)\end{array} & \begin{array}{c}\text { BET surface area } \\ \left(\mathrm{m}^{2} / g\right)\end{array} \\ \text { CMK-3 } & 1-15 & 0.8-1 \text { and } 5 & 1250\end{array}$

Takeda

3-150

0.6

560

Norit A Supra

$2-40$

0.9 and 3

1700

\section{Adsorption of total plasma proteins}

Fig. 2 presents the relative total plasma protein concentration after the contact with nanoporous carbons for 4 hours. All data were normalized to a control (plasma without any particles). No significant difference $(p<0.05, n=3)$ between initial $(103.5 \mathrm{~g} / \mathrm{l})$ and final protein concentrations was observed for all used carbon materials. 


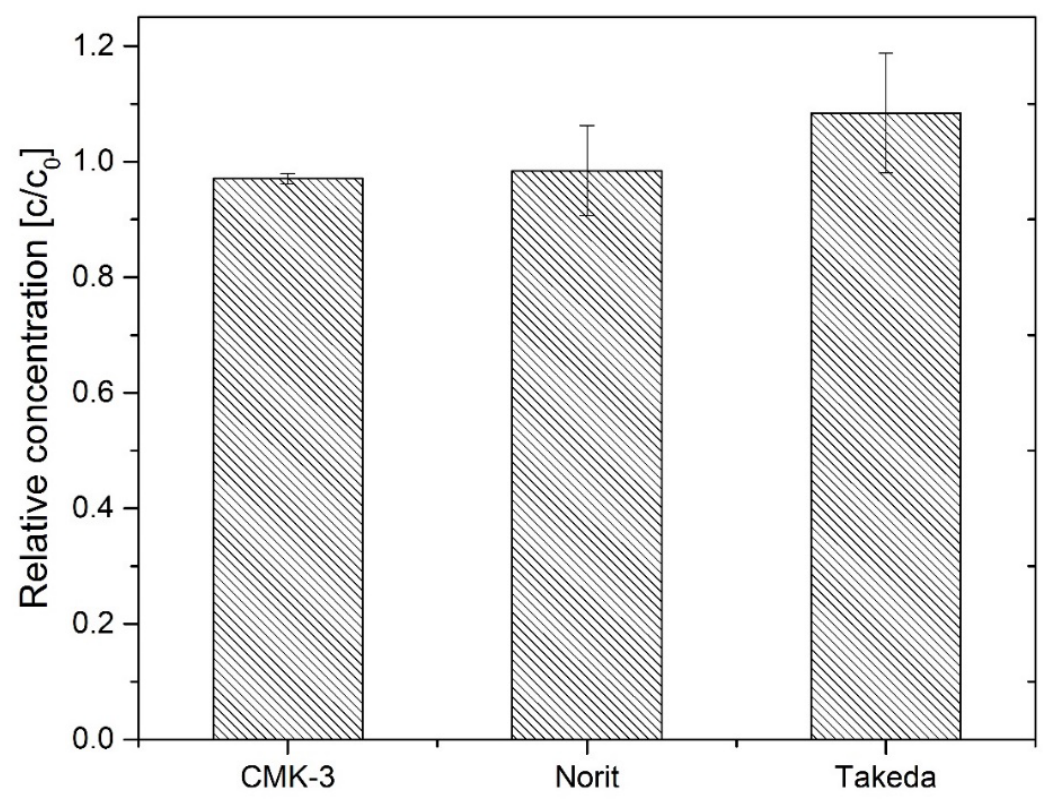

Fig. 2. Total plasma protein levels after the adsorption experiments.

In other studies ${ }^{3,14}$ where carbon materials were designed to remove cytokines from human plasma, researchers observed noticeable plasma protein adsorption to the particles. For example, Howel et al ${ }^{15}$ reported that dextran coating of the particle could reduce HSA adsorption, though not completely. Even though HSA plays important role in body hemostasis, negative effect of its adsorption have not yet being reported ${ }^{15}$. Nevertheless, albumin adsorption onto the porous materials can generally reduce the specific surface area (SSA) of the adsorbent ${ }^{15}$, which is expected to have negative effect on its adsorption capacity ${ }^{8}$. In other words, adsorption of the HSA on the carbon adsorbers would perhaps not cause any side effects, but it should be avoided to prevent that it decreases the adsorption capacity, and thus to performance, of the 
sorbent concerning the removal of uremic solutes. As shown in Figure 2 the CMK3 and the other sorbents tested here showed no significant protein adsorption.

\section{Adsorption of small and protein-bound toxins}

Figure 3 shows the average relative concentrations of creatinine, $\mathrm{HA}$ and IS in human plasma (normalized by the initial toxin concentration) after contact with the tested adsorbents. First, creatinine, marker molecule of kidney function, belongs to the group of small water soluble molecules; its adsorptive removal is mainly driven by its diffusion to the adsorptive sites of the nanoporous materials and sorbent affinity to creatinine itself. From Figure 3 it is clear that the CMK-3 and Norit adsorb the majority of the creatinine from the plasma, while Takeda particles only achieve minor adsorption. The small difference in the performance between CMK-3 and Norit can be attributed to difference in their SSA rather than their affinities to creatinine. In fact, when we normalized the amount of toxins adsorbed to SSA (table 3), we found that CMK-3 actually adsorbs slightly higher amount in comparison to Norit (14.0 and 10.7 $\mathrm{mg} / 1000 \mathrm{~m}^{2}$ respectively). Based on these data, to remove the daily creatinine production of kidney patients (around $1800 \mathrm{mg}$ ), one would need only $128 \mathrm{~g}$ of CMK-3. Of course, the amount of CMK-3 required could be further decreased by increasing its SSA and/or in number of pores per gram of material. This can be rather easily achieved, e.g. by using less carbon precursor per gram of SBA-15 silica or with mild activation (heating under $\mathrm{CO}_{2}$ flow). 


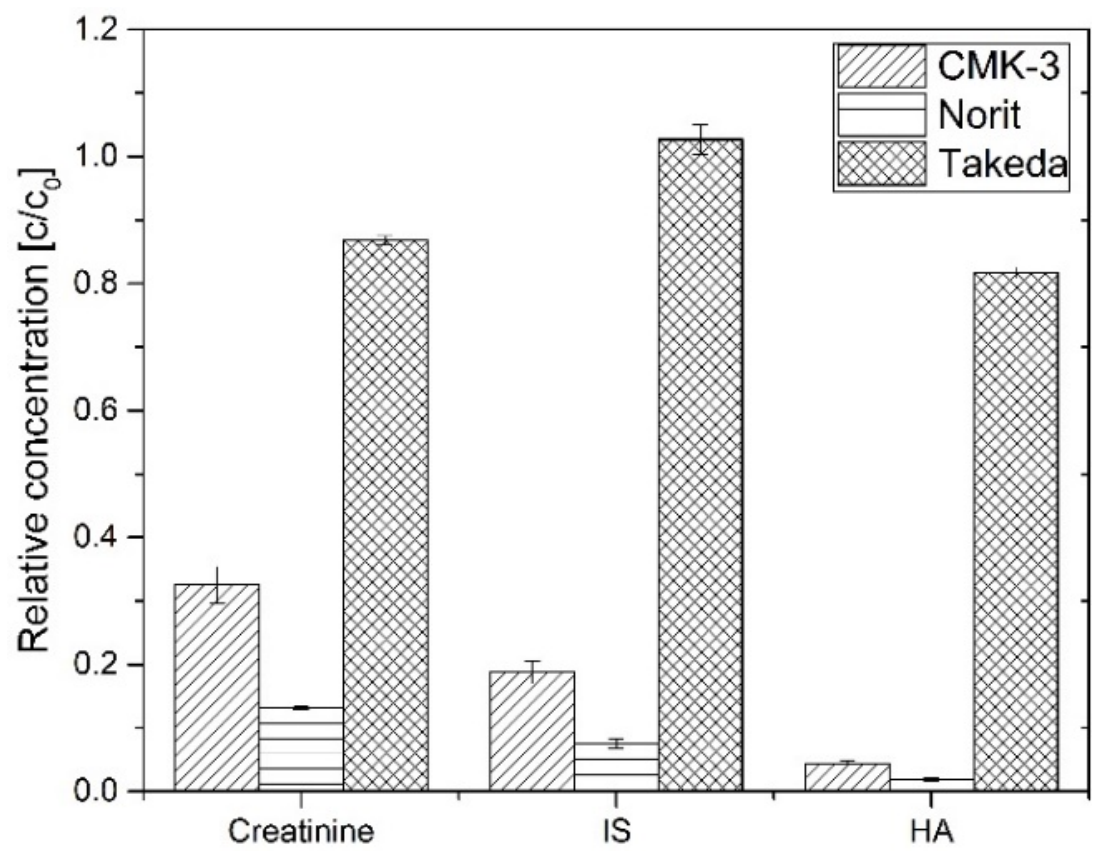

Fig. 3. Relative plasma concentrations of small water soluble and protein-bound toxins after contact with carbon materials for 4 hours.

Figure 3 also depicts the removal of HA and IS by the tested materials from human plasma samples. The IS removal is slightly lower than the corresponding one for HA. Even though the studied PBT had different initial concentration, which might also have influenced the final result, we could attribute the difference in the removal to different albumin binding properties of the two studied uremic toxins. Similar to creatinine removal, the amount of $\mathrm{PBT} / \mathrm{m}^{2}$ adsorbed by CMK-3 is slightly higher than Norit (see Table 3). Based on the adsorption results for IS and HA by CMK-3, one would only need $22 \mathrm{~g}$ of CMK-3 material to remove the mean daily excretion of the IS and HA by a patient (69 and $270 \mathrm{mg}^{16}$, respectively). 
Generally, we find that the degree of binding to albumin of respective toxins have direct correlation to their removal and is consistent to other literature ${ }^{11}$. The higher the concentration of the free fraction in plasma, the higher the removal. However, due to usually high protein binding properties most of the PBTs are poorly removed by dialysis ${ }^{1,12,17}$. Unlike hemodialysis, carbon materials are usually in close contact with blood or plasma, making the diffusion length for toxin free fraction much smaller and, thus, making adsorption a good alternative and/or complement to conventional hemodialysis ${ }^{3-5,18,19}$. 
Table 3. Removal of all studied molecules normalized for the gram and SSA of the tested materials.

* value below detection limits

** indicated that the saturation of the carbon material was not reached as all the IL- 8 was removed from the plasma solution.

\begin{tabular}{|c|c|c|c|c|c|c|c|c|c|c|}
\hline & \multirow{2}{*}{\multicolumn{2}{|c|}{$\begin{array}{l}\text { Small water soluble } \\
\text { (MW) }\end{array}$}} & \multicolumn{4}{|c|}{ Protein-bound solutes (MW) } & \multicolumn{4}{|c|}{ Cytokines (MW) } \\
\hline & & & \multicolumn{2}{|c|}{ IS (213 Da) } & \multicolumn{2}{|c|}{ HA (179 Da) } & \multicolumn{2}{|c|}{ IL-6 (24 kDa) } & \multicolumn{2}{|c|}{ IL-8 (8kDa) } \\
\hline & $\mathrm{mg} / \mathrm{g}$ & $\begin{array}{c}m g / 1000 \\
m^{2} \\
\end{array}$ & $\mathrm{mg} / \mathrm{g}$ & $\begin{array}{c}m g / 1000 \\
m^{2} \\
\end{array}$ & $\mathrm{mg} / \mathrm{g}$ & $\begin{array}{c}m g / 1000 \\
m^{2} \\
\end{array}$ & $n g / g$ & $\begin{array}{c}n g / 1000 \\
m^{2} \\
\end{array}$ & $n g / g$ & $\begin{array}{c}n g / 1000 \\
m^{2}\end{array}$ \\
\hline CMK-3 & $14.0 \pm 2.3$ & $11.2+1.9$ & $3.2 \pm 1.4$ & $2.6 \pm 1.2$ & $12.2 \pm 0.3$ & $9.8 \pm 0.3$ & $32.9 \pm 7.1$ & $26.4 \pm 5.7$ & $80 * *$ & $64 * *$ \\
\hline Norit & $18.1 \pm 0.2$ & $14.5 \pm 0.1$ & $3.7 \pm 0.6$ & $2.9 \pm 0.4$ & $12.6 \pm 0.2$ & $10.1 \pm 0.1$ & $0^{*}$ & $0^{*}$ & $72.6 \pm 1.8$ & $58.0 \pm 1.4$ \\
\hline Takeda & $2.8 \pm 0.6$ & $2.2 \pm 0.5$ & $0^{*}$ & $0^{*}$ & $2.3 \pm 0.7$ & $1.9 \pm 0.5$ & $0^{*}$ & $0^{*}$ & $13.1 \pm 5.4$ & $10.5 \pm 4.4$ \\
\hline
\end{tabular}




\section{Adsorption of middle molecules and cytokines}

Fig. 4 compares the removal of the $\beta 2 \mathrm{~m}$ and of IL- 6 and IL- 8 from human plasma after contact with the studied sorbents. IL-8, the smallest cytokine ( $\mathrm{MW}=8 \mathrm{kDa}$ ) is completely adsorbed by the CMK-3 in all samples after 4 hours. The concentration of the IL- 8 was also decreased by $90 \%$ by the Norit sorbent whereas Takeda sorbent performed very modestly by decreasing the IL- 8 concentrations only by $16 \%$.

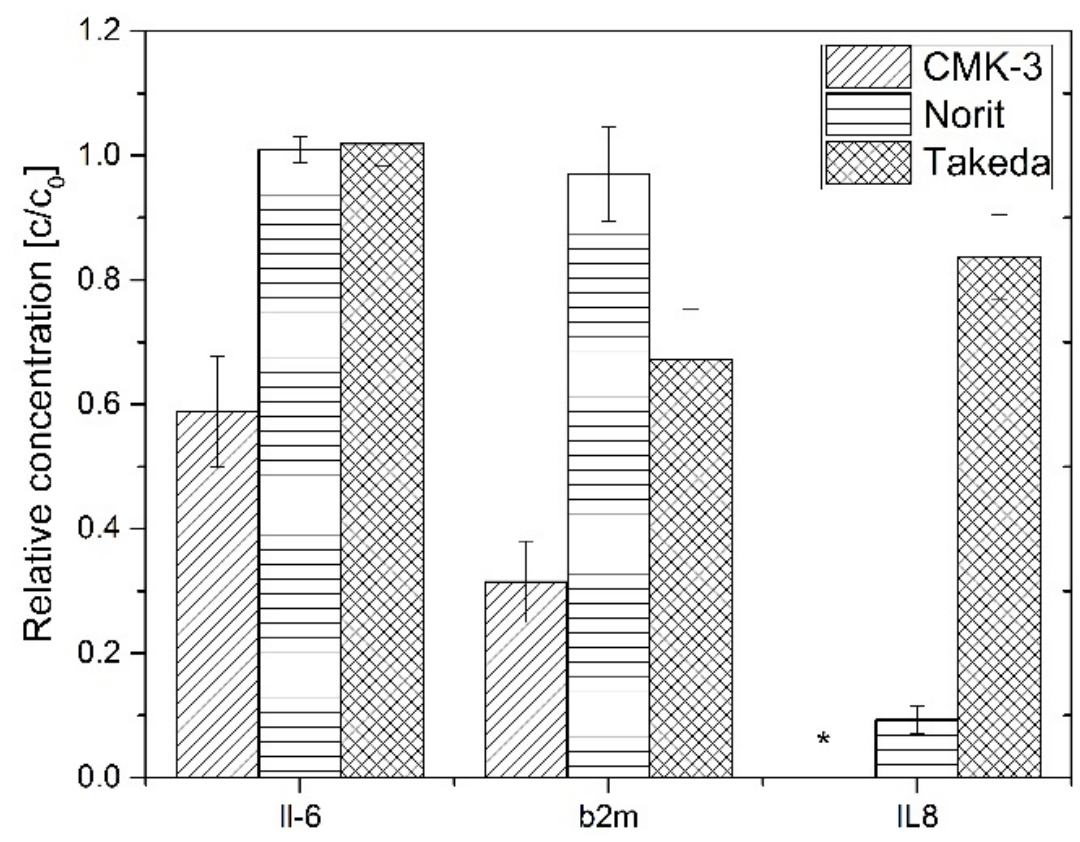

Fig. 4. Relative plasma concentrations of middle molecules and cytokines toxins after contact with carbon materials for 4 hours.

The CMK-3 carbon also removed $42 \%$ of IL-6 (24 kDa) and $68 \%$ of the $\beta 2 \mathrm{~m}$ (11.8 kDa) after 4 hours of adsorption while both Norit and Takeda performed rather poorly (even though Takeda removed 22\% of 
the $\beta 2 \mathrm{~m}$ from human plasma samples). The main reason for the high removal of the cytokines and middle molecules is the porous structure of CMK-3. It seems that the distance between the rods $(5 \mathrm{~nm})$ that creates the mesoporosity is suitable for the adsorption of the selected cytokines without the HSA adsorption.

Direct comparison of our results to other literature studies is not easy due to differences in testing protocols (different starting concentrations, experimental time, plasma-to-carbon ratios etc.) used. There are a few studies, however, where comparison is possible. For example, Song et $\mathrm{al}^{20}$ could remove $12.5 \mathrm{ng} / \mathrm{g}$ of IL-6 by using commercially available Cytosorb ${ }^{\mathrm{TM}}$ sorbent, which is much lower than the removal of the $33 \mathrm{ng} / \mathrm{g}$ by CMK-3. Their experiments were carried out in dynamic conditions and showed fast adsorption of IL-6. Besides, in contrast to our work where we measure no protein loss; in their study total protein levels decreased rapidly during the first hour of the experiment indicating the low selectivity of the Cytosorb ${ }^{T M}$ materials. Another study by Howel and co-workers ${ }^{21}$ used adsorptive beads that have slightly higher removal of IL-6 than Cytosorb ${ }^{\text {TM }}$, with $14.3 \mathrm{ng} / \mathrm{g}$ of IL6 removed, which is still much lower in comparison to CMK-3 carbon materials with removal of $33 \mathrm{ng} / \mathrm{g}$ of IL-6. Other studies showed that the adsorption of the cytokines is significantly influenced by the number and size of mesopores present in the adsorbent material ${ }^{22,23}$. There, the tested adsorbing material, carbide-derived carbon, was able to remove $1.25 \mathrm{ng} / \mathrm{g}$ of IL-8 and $5 \mathrm{ng} / \mathrm{g}$ of IL-6. In our work, CMK-3 removes much more, namely 
$80 \mathrm{ng} / \mathrm{g}$ of IL-8 and $33 \mathrm{ng} / \mathrm{g}$ of IL-6. Despite the differences in testing conditions between the two studies, especially experimental time ( 2 hours $^{22}$ vs 4 hours in our study) and in carbon-plasma ratios ( $0.2 \mathrm{~g}$ in 0.5 $\mathrm{ml}$ of plasma there, $25 \mathrm{mg}$ per $4 \mathrm{ml}$ of plasma in our study) these results clearly show the great potential of CMK-3 particles for removing a broad range of toxins.

The CMK-3 particles have relatively modest surface area per gram of the material $\left(1250 \mathrm{~m}^{2} / \mathrm{g}\right)$, which can be significantly increased, leading to even small amounts necessary. Their size is small and they are not suitable as fillers for the adsorption columns, since relatively small sizes of the adsorbents usually result in significant pressure drops ${ }^{24}$, and there is always increased chance of small particle leakage into the blood stream, unless particle filter is introduced ${ }^{8}$. We foresee the incorporation of CMK3 into the mixed matrix membranes (MMM) where, as we have shown earlier ${ }^{24}$, application of small particles does not result in noticeable pressure drops and makes it possible to combine benefits of membrane filtration and adsorption in one device. ${ }^{4-6}$.

\section{Conclusions and Outlook}

A sorbent particles, namely $\mathrm{CMK}-3$, were developed with the capacity to remove high spectrum of uraemic toxins from human plasma solutions: small water soluble molecules, middle molecules and proteinbound toxins. Additionally, this material did not show tendency to lower total plasma protein levels through 4 hours of direct plasma-sorbent 
contact and shows potential to be used in extracorporeal blood purification treatments.

Future work of our lab will focus on incorporation of CMK-3 inside mixed matrix membranes: earlier results with incorporation of Norit $A$ Supra (used as the reference in this study) particles inside the MMM were very promising. Results with Norit A highlighted that the MMM can boost the removal of indoxyl sulfate and p-cresyl sulfate up to $100-200 \%$ in comparison to particle-free industrial membranes ${ }^{4}$. As it was shown in the current study, Norit carbons perform rather well in removing the proteinbound and small water soluble molecules, but show noticeably lower performance when applied for the removal of cytokines and $32 \mathrm{~m}$. We believe that incorporation of the CMK-3 carbons inside MMM will not only broaden the application of the new membrane material, but will also help to avoid complications caused by relatively small adsorbent particles inside the adsorption columns, e.g. pressure drops and leakage of the particles. 


\section{Bibliography}

1. Eloot, S., Van Biesen, W. \& Vanholder, R. A sad but forgotten truth: The story of slow-moving solutes in fast hemodialysis. Semin. Dial. 25, 505509 (2012).

2. Vanholder, R., Glorieux, G. \& Eloot, S. Once upon a time in dialysis: the last days of Kt/V? Kidney Int. 1-6 (2015).

3. Harm, S., Falkenhagen, D. \& Hartmann, J. Pore size - A key property for selective toxin removal in blood purification. Int. J. Artif. Organs 37, 668678 (2014).

4. Pavlenko, D. et al. New low-flux mixed matrix membranes that offer superior removal of protein-bound toxins from human plasma. Sci. Rep. 6, 34429 (2016).

5. Tijink, M. S. L. et al. Mixed matrix hollow fiber membranes for removal of protein-bound toxins from human plasma. Biomaterials 34, 78197828 (2013).

6. Tijink, M. S. L. et al. A novel approach for blood purification: Mixedmatrix membranes combining diffusion and adsorption in one step. Acta Biomater. 8, 2279-2287 (2012).

7. Davis, M. E. Ordered porous materials for emerging applications. Nature 417, 813-821 (2002).

8. Presser, V. et al. Hierarchical Porous Carbide-Derived Carbons for the Removal of Cytokines from Blood Plasma. Adv. Healthc. Mater. 1, 796800 (2012).

9. Karavasili, C. et al. Development of new drug delivery system based on ordered mesoporous carbons: characterisation and cytocompatibility studies. J. Mater. Chem. B 1, 3167 (2013).

10. Giasafaki, D. et al. Comparing hydrogen sorption in different Pd-doped pristine and surface-modified nanoporous carbons. Carbon N. Y. 98, 114 (2016). 
11. Itoh, Y., Ezawa, A., Kikuchi, K., Tsuruta, Y. \& Niwa, T. Protein-bound uremic toxins in hemodialysis patients measured by liquid chromatography/tandem mass spectrometry and their effects on endothelial ROS production. Anal. Bioanal. Chem. 403, 1841-1850 (2012).

12. Meert, N. et al. Effective removal of protein-bound uraemic solutes by different convective strategies: A prospective trial. Nephrol. Dial. Transplant. 24, 562-570 (2009).

13. Ryoo, R., Joo, S. H., Kruk, M. \& Jaroniec, M. Ordered mesoporous carbons. Adv. Mater. 13, 677-681 (2001).

14. Tripisciano, C., Eichhorn, T., Harm, S. \& Weber, V. Adsorption of the inflammatory mediator high-mobility group box 1 by polymers with different charge and porosity. Biomed Res Int 2014, 238160 (2014).

15. Howell, C. A. et al. New dextran coated activated carbons for medical use. Carbon N. Y. 97, 134-146 (2016).

16. Martinez, A. W., Recht, N. S., Hostetter, T. H. \& Meyer, T. W. Removal of P-cresol sulfate by hemodialysis. J. Am. Soc. Nephrol. 16, 3430-3436 (2005).

17. Fagugli, R. M., De Smet, R., Buoncristiani, U., Lameire, N. \& Vanholder, R. Behavior of non-protein-bound and protein-bound uremic solutes during daily hemodialysis. Am. J. Kidney Dis. 40, 339-47 (2002).

18. Sandeman, S. R. et al. An adsorbent monolith device to augment the removal of uraemic toxins during haemodialysis. J. Mater. Sci. Mater. Med. 25, 1589-1597 (2014).

19. Meyer, T. W. et al. Increasing the clearance of protein-bound solutes by addition of a sorbent to the dialysate. J. Am. Soc. Nephrol. 18, 868-874 (2007).

20. Song, M. et al. Cytokine removal with a novel adsorbent polymer. Blood Purif. 22, 428-434 (2004).

21. Howell, C. A. et al. Nanoporous activated carbon beads and monolithic columns as effective hemoadsorbents for inflammatory cytokines. Int. J. Artif. Organs 36, 624-632 (2013). 
22. Yushin, G. et al. Mesoporous carbide-derived carbon with porosity tuned for efficient adsorption of cytokines. Biomaterials 27, 5755-5762 (2006).

23. Yachamaneni, S. et al. Mesoporous carbide-derived carbon for cytokine removal from blood plasma. Biomaterials 31, 4789-4794 (2010).

24. Tetala, K. K. R., Skrzypek, K., Levisson, M. \& Stamatialis, D. F. A metal ion charged mixed matrix membrane for selective adsorption of hemoglobin. Sep. Purif. Technol. 115, 20-26 (2013). 


\section{Chapter 5}

\section{Low fouling membranes for hemodialysis based on polyethersulfone/SlipSkin ${ }^{\mathrm{TM}}$ polymer blend}

O.E.M. ter Beek ${ }^{a}$, D. Pavlenko ${ }^{a}$, D. Snisarenko ${ }^{b}$, M.H. Suck ${ }^{a}$, S. Helfrich ${ }^{a}$, C. Causserand ${ }^{b}$, D. Stamatialis ${ }^{a}$

aBioartificial Organs, Department of Biomaterials Science and Technology, MIRA Institute, Faculty of Science and Technology, University of Twente, 7500 AE Enschede, the Netherlands

bLaboratorie de Genie Chimique, Universite de Toulouse, CNRS, INPT, UPS, Toulouse, France 


\begin{abstract}
Prolonged dialysis in the form of nocturnal dialysis or by using a portable/ wearable artificial kidney can significantly improve the removal of toxins, especially middle molecules and protein bound toxins, from the blood of patients with end-stage renal disease (ESRD). However, longer treatment time also requires longer contact time between ESRD patients' blood and the membrane material of the dialysis system. Therefore, membranes with long-term hemocompatibility, selectivity and fouling resistance are required. Current membranes for hemodialysis often contain hydrophilic additives to ensure hemocompatibility and fouling resistance. However, these additives could elute during sterilization processes and / or during long term filtration. In this study, we develop new membranes based on blending of polyethersulfone (PES), a material already used for fabrication of dialysis membranes, with small amounts of SlipSkin ${ }^{\mathrm{TM}}$ (SS), a random copolymer of hydrophilic N-vinylpyrrolidone (NVP) and hydrophobic N-butylmethacrylate (BMA). Our results show that the membranes with SS of 2 wt\% (indicated as PES-SS2) are mechanically stable in the ultrafiltration range and therefore suitable for dialysis treatment. More importantly, compared to the pristine PES and commercial PES with molecular weight (MW) of $50 \mathrm{kDa}$ membranes (indicated as PES- 50), they have increased hydrophilicity and higher high fouling resistance for proteins and middle-size molecules, such as, bovine serum albumin (BSA) and $\alpha$-Lactalbumin (LALBA), respectively.
\end{abstract}

Key words: hemodialysis; membranes; fouling. 


\section{Introduction}

Hemodialysis is an important therapy for End Stage Renal Disease (ESRD) patients if a donor kidney is not available. During four hours of conventional dialysis, small water-soluble toxins and a limited number of middle molecules are effectively removed from the patients' blood ${ }^{1,2}$. However, more time is needed to improve the clearance of, for example, middle molecules, because these toxins are mainly present in the intracellular space ${ }^{3}$. Therefore, many developments in hemodialysis focus on longer treatment times such as in nocturnal dialysis or the development of a portable or wearable artificial kidney ${ }^{3-7}$. Clearly, when the dialysis time is prolonged, the contact time between ESRD patients' blood and the dialyzer is also longer. For this reason, long-term hemocompatibility, selectivity and fouling resistance are seen as prerequisites for membranes used in long-term dialysis ${ }^{2}$.

Current hemodialysis membranes are often based on blends of hydrophobic polymers such as polysulfone (PS) or polyethersulfone (PES), with hydrophilic additives, such as polyvinylpyrrolidone (PVP) or polyethylene glycol (PEG) ${ }^{8}$. The creation of hydrophilic and hydrophobic patches, especially on the surface of dialysis membranes, could decrease protein adsorption onto the membranes' surface and therefore could increase the membranes' hemocompatibility and fouling resistance ${ }^{9}$. However, the major disadvantage of using hydrophilic additives, such as PVP, is that they elute from the membrane matrix due to wall shear stress during dialysis sessions or as the result of some sterilization techniques ${ }^{10-}$ 
12. For example, sterilization via autoclaving results in less cross-linked PVP than the gamma-radiation technique. This means that the original molecular weight and water solubility of PVP in the former membranes are preserved, resulting in more elution of PVP during, especially longterm, dialysis ${ }^{13}$. As a consequence, this changes the membrane's structure and alters its characteristics and performance ${ }^{10,11,13,14}$. Moreover, the eluted PVP can be potentially harmful for patients because it can accumulate in internal organs and induce allergies and anaphylactic shock $^{14-16}$.

Alternative methods to improve membrane compatibility and fouling resistance include, for example, coating or grafting a membrane's surface. In fact, coating a PES membrane with graphene oxide and sulfonated polyanion hydrogel thin film can be a relatively easy way to enhance the hydrophilicity of the membrane ${ }^{15,17,18}$. However, this coating and the membrane are linked together via a physical bond which is less strong than a covalent one. During hemodialysis sessions, blood flows and associated shear stress can result in decoupling and possibly the loss of the hydrophilic coating ${ }^{10,15,17}$. Besides, the difficulty of fabricating homogenous and continuous coatings is another drawback of the coating technique ${ }^{15}$.

Another example of modifying the membrane to improve fouling resistance is via grafting of hydrophilic polymers onto membranes' surfaces, for example, heparin-mimicking polymer brushes grafted onto functionalized carbon nanotube/ PES composite membranes ${ }^{19}$. Grafting 
hydrophilic polymers is a more stable and permanent technique and it can significantly improve the anti-fouling performance of membranes. However, the grafting often requires elaborate chemistry, and it is difficult to be applied to the fabrication process of hollow fiber membranes ${ }^{19}$.

In this work, we aim to develop low fouling membranes by blending PES with SlipSkin ${ }^{\mathrm{TM}}$ (50:50) (blends indicated as PES-SS) by phase inversion via immersion precipitation. The $\operatorname{SlipSkin}^{\mathrm{TM}}(50: 50)$ (SS) is a random copolymer of 50:50 ratio of hydrophilic N-vinylpyrrolidone (NVP) and hydrophobic $\mathrm{N}$-butylmethacrylate (BMA) originally developed for coating of catheters and guide wires for intravascular interventions (Fig. $1)^{20-22}$. The advantage of using SS for membrane preparation is that both hydrophilic and hydrophobic blocks contribute to the membranes' blood compatibility and fouling resistance ${ }^{2,23}$. In earlier work, we developed pristine SS membranes based on various ratio of NVP and BMA. The membranes with 50:50 ratio showed excellent biocompatibility and potential to be used as cascade filters in plasma fractionation applications but they had high water permeance of $100-200 \mathrm{~L} \mathrm{~m}^{-2} \mathrm{~h}^{-1}$ bar-1 and very high sieving coefficient (SC) for BSA of $83 \%$ to be applied as dialysis membranes ${ }^{24}$. Besides, due to high amounts of NVP, these SS membranes swell significantly in water and require delicate handling for filtration with aqueous solutions, buffers etc. Therefore, in this work we investigate development of membranes based on PES-SS polymer blends with relatively low amount of SS (2-6 wt\%) to achieve homogeneous polymer 
solution and minimize membrane swelling. We hypothesize that the membranes developed using these blends, even having low amounts of additive SS, would have low fouling properties.

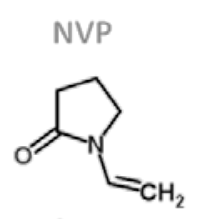

a

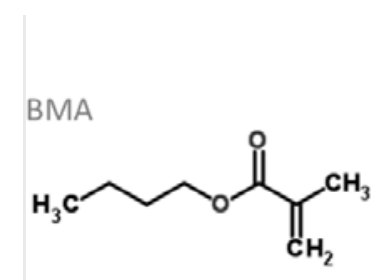

至

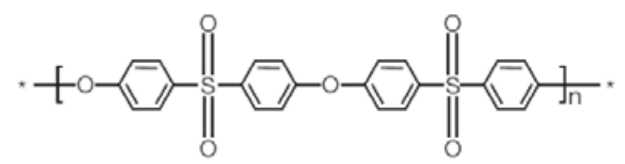

b

Fig. 1. Chemical structures of (a) SlipSkin ${ }^{\mathrm{TM}}$ copolymer with N-vinylpyrrolidone (NVP) and n-butylmethacrylate (BMA) and (b) PES.

The morphology of produced flat-sheet membranes is thoroughly characterized via Scanning Electron Microscopy (SEM), whereas the distribution of SS in the membrane is investigated via ATR-FTIR. Besides, the fouling resistance of the membranes is investigated using model solutions of $\mathrm{BSA}(\mathrm{MW}=66 \mathrm{kDa}$ ) that should be retained by the membranes and $\alpha$-Lactalbumin (LALBA, MW $=14 \mathrm{kDa}$ ) because it has similar size as the middle molecule $\beta_{2}$-microglobulin ( $M W=11 \mathrm{kDa}$ ) which needs to be removed during the dialysis treatment. The results are compared to custom-made PES membranes (indicated as PES) and commercially available PES membranes from Sartorius (molecular weight cut-off of $50 \mathrm{kDa}$, indicated as PES-50 kDa). 


\section{Materials and methods}

\section{Materials}

SlipSkin $^{\mathrm{TM}}$ (50:50) (SS), a copolymer of N-vinylpyrrolidone (NVP) and N-butylmethacrylate (BMA) (kindly provided by Interface BIOmaterials BV, Geleen, The Netherlands) and polyethersulfone (PES) (ULTRASON, E6020P, BASF, Arnhem, The Netherlands) were used to prepare the membranes. N-methyl-2pyrrolidone (NMP) (Acros Organics, Geel, Belgium) was used as solvent. PES membranes (MWCO of $50 \mathrm{kDa}$, purchased from Sartorius, Göttingen, Germany, indicated PES-50 kDa) were used as reference. A Milli-Q purification unit (Merck Millipore, Czech Republic) was used to prepare ultrapure water. Ultrapure water was used as a non-solvent in the coagulation bath and for transport experiments. Phosphate-buffered saline (PBS) (pH 7.45, GibCo, United Kingdom), bovine serum albumin (BSA) and $\alpha$-Lactalbumin (LALBA) from bovine milk both purchased from Sigma-Aldrich (Zwijndrecht, The Netherlands) were used to evaluate membranes' transport properties and fouling resistance. An Atto 647N Protein Labeling Kit was purchased from Sigma-Aldrich (France) for the microchip fouling experiments on the PES-50 kDa and custom-made PES-SS membranes.

\section{Membrane preparation}

Flat-sheet membranes were prepared by casting polymer solutions dissolved in NMP. To obtain homogeneous polymer solutions, we blended PES and small amounts of SS (2-6 wt\%). As references, 
custom-made flat-sheet membranes from 15 wt\% PES dissolved in NMP, as well as, PES-50 kDa membranes from Sartorius were used. Membranes based on SS alone were also prepared for ATR-FTIR studies. For this, 15 wt\% SS was dissolved in NMP. All membranes used are listed and coded in Table 1. The number in the codes of the PES-SS blend membranes refers to the weight percentage of SS used in the polymer solution. The polymer solutions were mixed on a roller bank at room temperature and degassed overnight before membrane preparation. All membranes were prepared by phase inversion. The polymer solutions were cast on a glass plate using a casting knife of $300 \mu \mathrm{m}$ thickness, and afterwards immediately immersed in a non-solvent ultrapure water coagulation bath. The membranes were rinsed thoroughly and stored in ultrapure water for subsequent characterization. 
Table 1. Codes and details of membranes used in this study.

\begin{tabular}{|c|c|c|c|c|}
\hline Code & $\begin{array}{l}\text { Polymer } \\
\text { (ratio in polymer } \\
\text { solution) }\end{array}$ & $\begin{array}{l}\text { Additive } \\
\text { (ratio in polymer } \\
\text { solution) }\end{array}$ & Solvent & Manufacturer \\
\hline PES & PES 15 wt $\%$ & - & NMP & this work \\
\hline SS & SlipSkin $^{\mathrm{TM}} 15$ wt\% & - & NMP & this work \\
\hline PES-SS2 & PES 15 wt\% & SlipSkin ${ }^{\mathrm{TM}} 2$ wt\% & NMP & this work \\
\hline PES-SS4 & PES 15 wt\% & SlipSkin $^{\mathrm{TM}} 4$ wt\% & NMP & this work \\
\hline PES-SS6 & PES 15 wt\% & SlipSkin ${ }^{\mathrm{TM}} 6$ wt\% & NMP & this work \\
\hline PES-50 & PES & - & - & Sartorius \\
\hline kDa & & & & \\
\hline
\end{tabular}

Membrane characterization

Scanning electron microscopy (SEM)

Flat-sheet membranes were dried overnight in air and broken cryogenically in liquid nitrogen to obtain cross-sections. The samples were placed in SEM holders and gold coated using a Cressington 108 autosputter coater. Then, the flat-sheet membranes were characterized using a Philips XL30 ESEM-FEG scanning electron microscope. 


\section{Attenuated Total Reflectance-Fourier Transform Infrared spectroscopy (ATR-FTIR)}

Analysis of the membrane surface was performed by ATR-FTIR spectroscopy (Spectrum Two, PerkinElmer) and Spectrum Quant software. All scans were performed in triplicate on various parts of the membrane surface, at a resolution of $4 \mathrm{~cm}^{-1}$ and at room temperature.

\section{Membrane transport properties}

To determine the fouling resistance of the membranes, an airpressurized dead-end Amicon ultrafiltration cell ( $3 \mathrm{~mL}$, Amicon ${ }^{\circledR}$ - Merck Millipore) with a $0.9 \mathrm{~cm}^{2}$ effective membrane area was used. The selective layer of the membrane was exposed to the protein solutions. First, the membranes were wetted and pre-compacted using ultrapure water at $\Delta \mathrm{P}$ $=1$ bar for 30 minutes. After this, ultrapure water was pressurized through the membranes at 1 bar for 1 hour and the flux, $\mathrm{J}\left(\mathrm{L} \mathrm{m}^{-2} \mathrm{~h}^{-1}\right)$, of the water through the membranes was determined by taking the permeated water volume, membrane surface area and time at each pressure into account. Then, the ultrapure water was replaced rapidly by a protein solution either a BSA solution of $1 \mathrm{mg} / \mathrm{mL}$ or a LALBA solution of $1 \mathrm{mg} / \mathrm{mL}-$ and it was stirred at a 300-rpm stirring rate. A pressure of 1 bar was applied for 1 hour and permeate was collected in order to calculate the protein solutions' flux. After the experiment with proteins, the Amicon cell was filled with ultrapure water again and the membranes were washed for 30 minutes. Finally, the clean water flux of the membranes after protein solution transport was investigated using ultrapure water and a pressure 
of 1 bar for 1 hour. The fouling resistance of the membranes was assessed via the flux recovery ratio:

flux recovery ratio $(\mathrm{FRR})=\frac{\mathrm{J}_{\mathrm{w}, 2}}{\mathrm{~J}_{\mathrm{w}, 1}} \cdot 100 \%$

where $J_{w, 1}$ is the first clean water flux measurement $\left(\mathrm{L} \mathrm{m}^{-2} \mathrm{~h}^{-1}\right)$ and $J_{w, 2}$ is the clean water flux measurement $\left(\mathrm{L} \mathrm{m}^{-2} \mathrm{~h}^{-1}\right)$ after the protein filtration experiment. The higher the FRR the higher membrane fouling resistance.

To determine the protein sieving coefficient $(\mathrm{SC})$ by the membranes, $2 \mathrm{~mL}$ samples of the feed solution and permeate were taken as soon as the protein solution transport measurements were completed. The BSA and LALBA concentrations were determined using a UVspectrophotometer (Varian, Cary 300 Scan UV-visible spectrophotometer) at $280 \mathrm{~nm}$. The SC was calculated as follows:

$\mathrm{SC}=\frac{\mathrm{C}_{\text {permeate }}}{\mathrm{C}_{\text {feed }}}$

where $C_{\text {permeate }}$ is the concentration of BSA or LALBA $(\mathrm{mg} / \mathrm{mL})$ in the permeate solution and $\mathrm{C}_{\text {feed }}$ is the BSA concentration or LALBA concentration $(\mathrm{mg} / \mathrm{mL})$ in the feed solution. A SC of 1 means that the proteins pass freely through the membrane, while a SC of 0 means that all proteins are fully retained by the membrane. 


\section{Microfluidic chip fouling experiments}

To monitor the LALBA distribution and adhesion over time at zero TMP, we used a microchip. LALBA was first labelled following the protocol proposed by Greene et $a{ }^{25}$. The final conjugate solution was diluted with PBS to achieve a concentration of $50 \mathrm{mg} / \mathrm{L}$, corresponding to clinically relevant median concentrations of $\beta$-2-microglobulin in human blood ${ }^{26}$. Then, the microfluidic chips were connected to a pressure-flow controller (Fluigent MFCS-Flex, FLOWELL) and placed on a microscope stage (Zeiss Axio Observer.zlm inverted microscope). Before the fouling resistance experiment was started, the membranes were wetted for 1 hour. For this, pure PBS was flowed through the microchip at $130 \mu \mathrm{L} / \mathrm{min}$ and zero pressure was applied from the permeate side. Next, the labelled LALBA was flowed through the microchip at three different flow rates $(35,75$ and $130 \mu \mathrm{L} / \mathrm{min})$, all in a single pass, which means that the feed solution after reaching the retentate reservoir was not resupplied to the system. Finally, the fluorescence on the membrane surface at the retentate compartment of the microchip was estimated: images of the whole channel were acquired every 5 minutes. The gray value as a unit of fluorescence intensity was measured using ImageJ software. A high gray value corresponds to high fluorescence (more white pixels). To evaluate the spatial distribution of fouling along the membrane, the analysis of gray values was performed at several positions in the channel of the chip: at the inlet, in the middle, and at the outlet. More information about the microfluidic chip experiments can be found in Appendix 1. 


\section{Results and discussion}

\section{Membrane characterization}

SEM. Figure 2 presents SEM images of the cross-sections and Table 2 presents the thickness of the membranes investigated. All membranes were mechanically stable during handling. The PES and PES-SS membranes have uniform thicknesses that are lower than the original casting thickness of $300 \mu \mathrm{m}$ (Table 2).

Table 2. Membrane thickness (polymer solutions have been cast with $300 \mu \mathrm{m}$ knife).

\begin{tabular}{lc}
\hline Code & $\begin{array}{c}\text { Dry thickness (SEM) } \\
(\mu \mathrm{m})\end{array}$ \\
\hline PES & $132 \pm 2$ \\
PES-SS2 & $191 \pm 2$ \\
PES-SS4 & $220 \pm 1$ \\
PES-SS6 & $219 \pm 1$ \\
PES-50 kDa & $127 \pm 2$ \\
\hline
\end{tabular}

PES membranes (Fig. 2A) have an asymmetric pore morphology: a dense selective layer and finger-like pores on the air-side and a layer with macrovoids on the glass-side, as a result of the slower exchange between NMP and water, the solvent in the polymer solution and the non-solvent in the coagulation bath, respectively. The addition of $2 \mathrm{wt} \%$ SS to PES also results in membranes (PES-SS2 in Fig. 2D) with a dense selective layer and finger-like pores on the air-side, but with larger macrovoids on the glassside. By increasing the amount of SS from 2 wt\% to 4 and $6 \mathrm{wt} \%$, the 
membranes' glass-sides present smaller and more finger-like macrovoids (Fig. 2D, G, J), similar to the pristine PES membrane of Fig 2A. This is possibly due to the higher amount of polymer present in the PES-SS4 and PES-SS6 membranes. Fig. 2E presents the PES-50 kDa membrane with a selective layer and small finger-like pores on top of a support layer. 

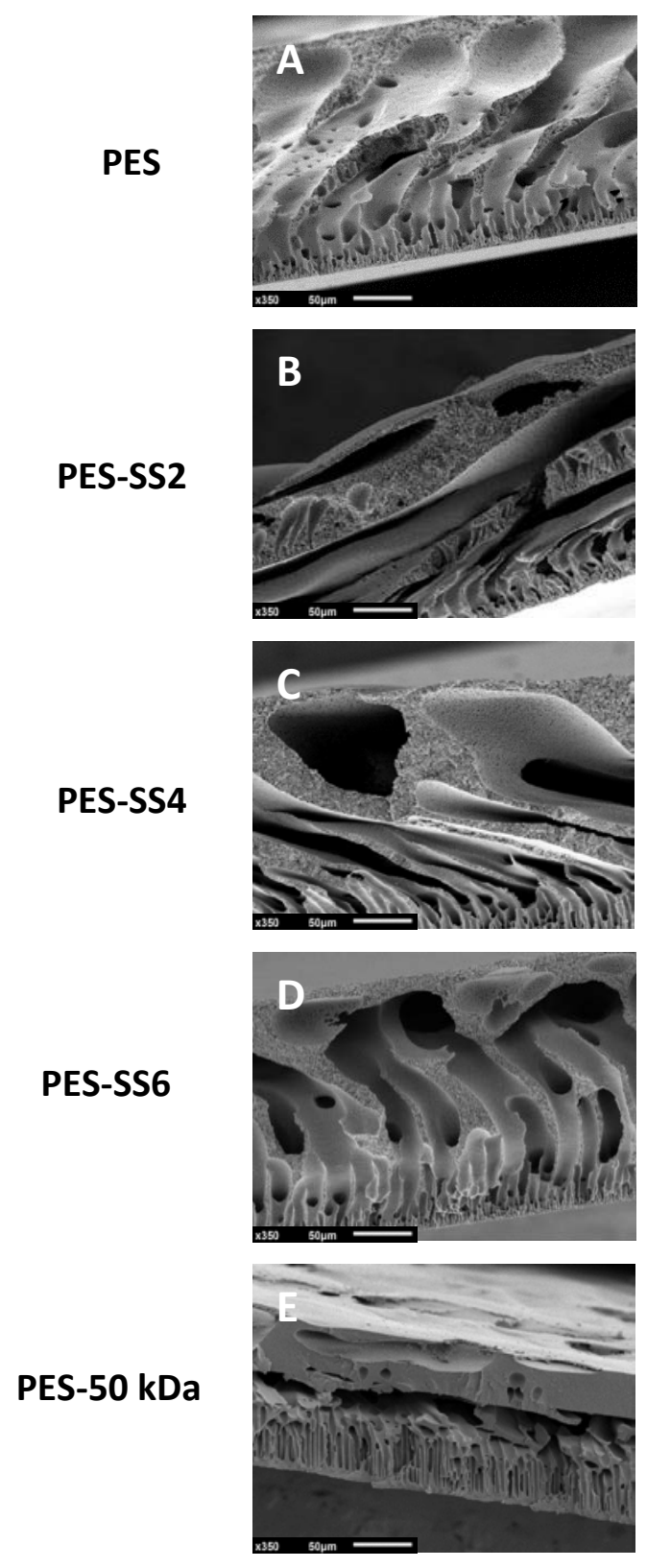

Fig. 2. Scanning electron microscopy images of the flat-sheet membranes: PES (A), PESSS2 (B), PES-SS4 (C), PES-SS6 (D) and PES-50 kDa (E). Images show cross-sections with magnifications of 350x. 
ATR-FTIR. Fig. 3 shows the ATR-FTIR spectra of the prepared flatsheet membranes which were used to investigate the distribution of SS in the PES-SS blend membranes. The SS membranes show characteristic peaks at $1680 \mathrm{~cm}^{-1}$ and $1740 \mathrm{~cm}^{-1}$ corresponding to the carbonyl groups of NVP (the hydrophilic block of SS) and the ester group of BMA (the hydrophobic block of SS), respectively ${ }^{27}$. As expected, the spectrum of the pure PES membranes shows no peaks at these wavelengths, because PES has no carbonyl or ester groups (Fig. 3A). The characteristic SS peaks at $1680 \mathrm{~cm}^{-1}$ and $1740 \mathrm{~cm}^{-1}$ are observed in the spectra of the PES-SS blend membranes, as well. The intensity of the peaks increases with an increase in SS concentration inside the membrane: highest intensity is found in PES-SS6 membranes and lowest in PES-SS2 membranes (Fig. 3B). Importantly, the PES-SS2 spectra (Fig. 3A) show that there is a higher amount of carbonyl and ester groups on the air-side than on the glass-side of the membrane. This indicates that during membrane formation, SS polymer migrates towards the water non-solvent phase and, thus, resulting in membranes with higher SS concentration in the selective layer $^{28}$. Similar phenomenon is also observed for PES-SS4 and PES-SS6 membranes where higher concentrations of SS are found at the selective layer of the membrane. 

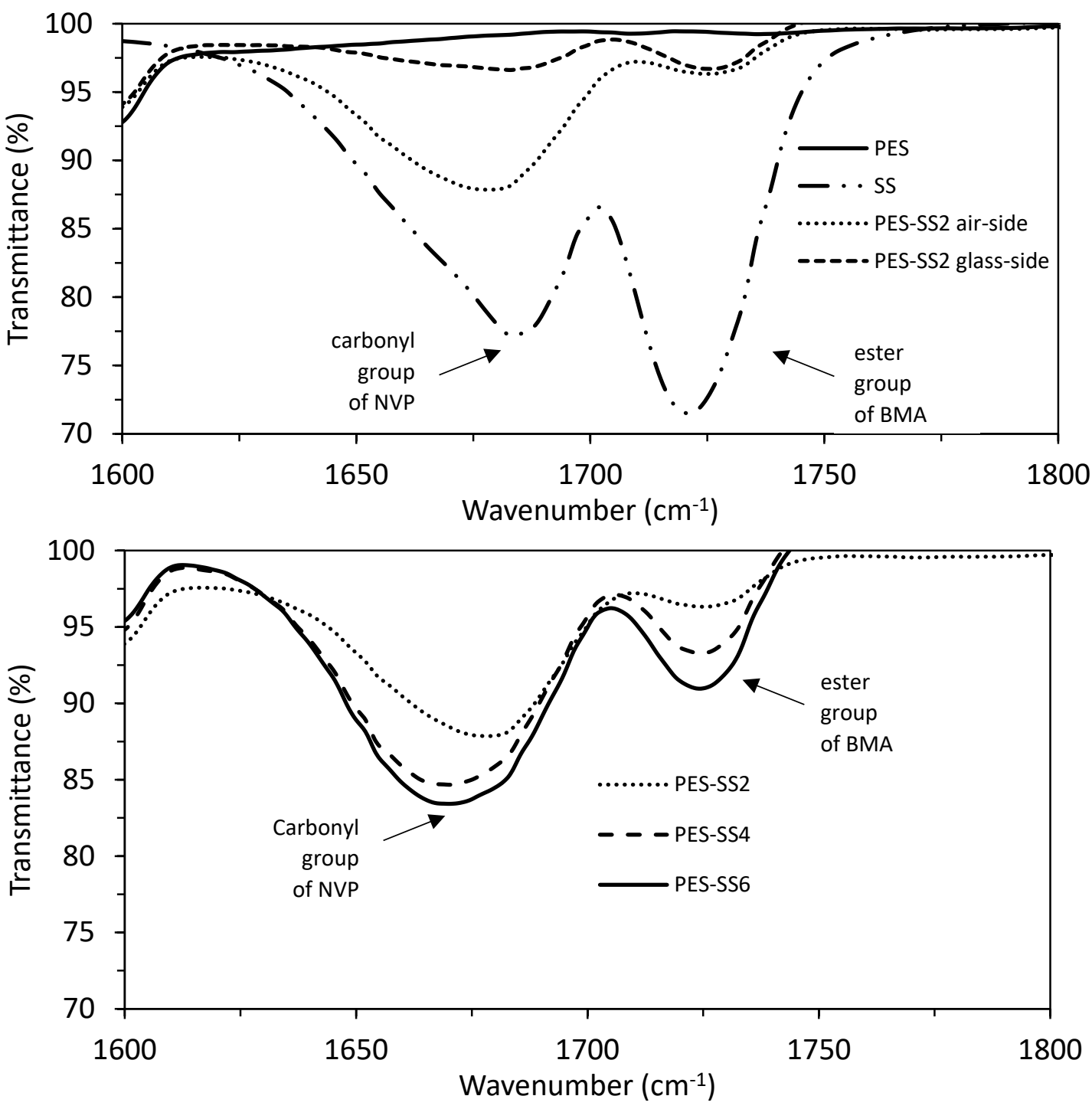

Fig. 3. A) ATR-FTIR spectra of PES membrane (air-side), SS membrane (air-side) and PESSS2 membrane (air-side and glass-side). B) ATR-FTIR spectra of air-sides of PES-SS2, PES-SS4 and PES-SS6 membranes. 


\section{Membrane transport properties}

During membrane preparation we noticed that the polymer solutions of PES-SS4 and PES-SS6 were not clear and they were somewhat turbid indicating phase separation in solution, similar to the observations of Song et al. for blends with copolymer amounts higher than 5 wt\% ${ }^{28}$. Based on these immiscibility issues of the PES-SS4 and PES-SS6 membranes, the PES-SS2 membranes were selected for further studies concerning membrane fouling and were compared to the controls, PES and PES-50 kDa membranes.

Protein transport studies - membrane fouling studies. Membrane fouling due to, for example, protein adsorption on the surface or pore blocking - remains as one of the key factors that hampers membrane performance over time. Self-evidently, hemodialysis membranes work in direct contact with blood, so high membrane resistance to protein fouling can only benefit this application. In this section, we measured the transport of water, BSA and LALBA through our membranes and we evaluated the fouling resistance by measuring the FRR of PES-SS2, PES and PES-50 kDa membranes after permeation of BSA and LALBA. Fig. 4 and Table 3 present the change of membrane flux due to protein transport as well as the change of water flux before and after the protein transport. 


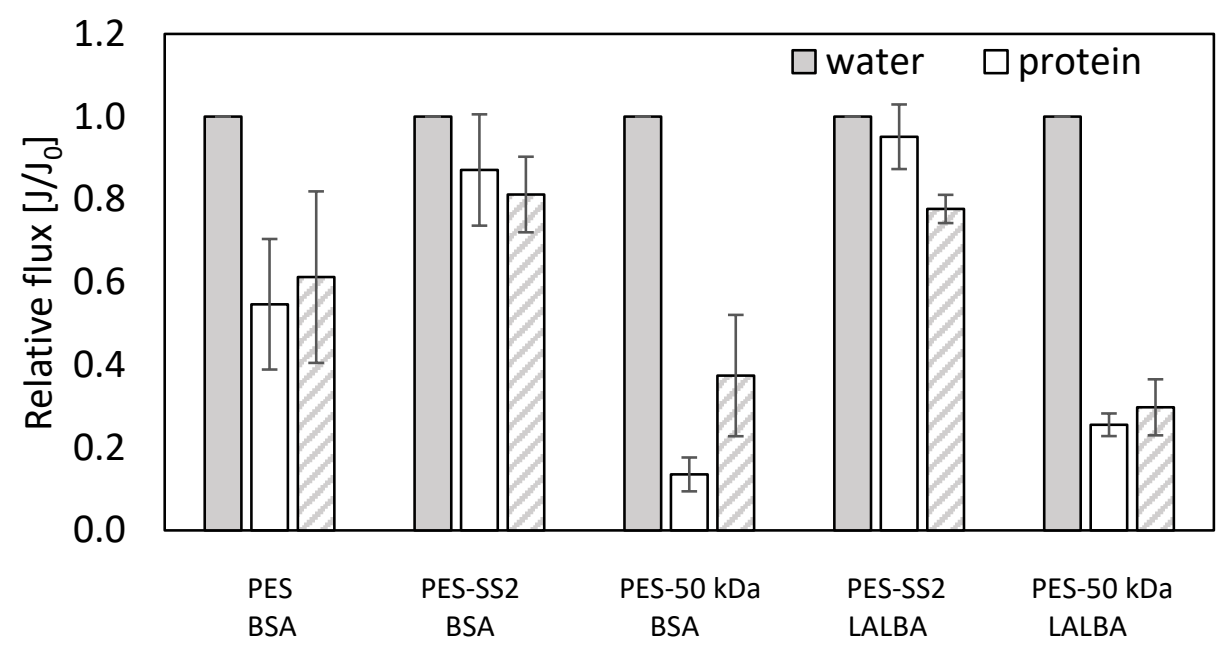

Fig. 4. Protein fouling experiments with flat-sheet membranes at 1 bar: PES, PES-SS2 and PES-50 kDa. The relative flux was determined first using water, then with BSA or LALBA in PBS solution, and finally using water again at transmembrane pressure of 1 bar. The error bars show standard deviation $(n \geq 2)$.

For the PES-SS2 membranes, the flux of BSA and LALBA is very close to the clean water flux indicating very low interaction of the protein with the membrane material. This happens even though both BSA and LALBA can still penetrate into the membrane pores (SC of BSA is 0.30 and of LALBA is 0.49 , respectively). In contrast, the BSA flux of the PES and PES-50 kDa membranes is much lower than the clean water flux although BSA is fully retained by the membranes. When the smaller LALBA is used and this penetrates into the pores of the PES-50 kDa membranes (SC $0.90)$ the interaction with the membrane is also evident.

Due to the above, it is obvious that the addition of SS results in a significant improvement of the membrane's fouling resistance. Our PESSS2 membranes have the highest recovery (FRR 80\%) in comparison to 
the PES and PES-50 kDa membranes (FRR 60\% and FRR 30\%, respectively). The significant difference in fouling behaviour could be attributed to the presence of SS, especially its NVP block, on the selective layer and inside the pores of PES-SS2 membranes improving hydrophilicity and preventing protein adsorption onto the surface and pore blockage, thus improving fouling resistance. For comparison, the study of Susanto et al. has shown that PES-PVP and PES-PEG blend membranes have similar BSA SC ( $S C=0.29$ and $S C=0.28$ respectively), but lower BSA FRR than PESSS2 membranes, approximately $28 \%$ and 15\%, respectively ${ }^{8}$. Furthermore, the PES-copolymer 3 wt\% blend membranes reported by Song et al. present a BSA SC of 0.05 and are therefore able to retain more BSA than our PES-SS2 membranes, but still the BSA FRR are in the same range $(81.97 \% \text { for PES-copolymer } 3 \text { wt\% blend membranes) })^{28}$. 
Table 3. Transport data of PES, PES-SS2 and PES-50 kDa membranes, measured at 1 bar.

\begin{tabular}{|c|c|c|c|c|c|c|c|c|c|c|}
\hline Membrane & $\begin{array}{c}\mathbf{J}_{\text {water }} \\
\left(\mathbf{L ~ m}^{-2} \mathbf{h}^{-1}\right)\end{array}$ & $\begin{array}{c}\mathrm{J}_{\mathrm{BSA}} \\
\left(\mathrm{L} \mathrm{m}^{-2} \mathrm{~h}^{-1}\right)\end{array}$ & $\begin{array}{c}J_{\text {water }} \\
\left(\mathbf{L ~ m}^{-2} \mathbf{h}^{-1}\right)\end{array}$ & $\begin{array}{l}\text { FRR } \\
\text { after } \\
\text { BSA } \\
(\%)\end{array}$ & $\mathrm{SC}_{\mathrm{BSA}}$ & $\begin{array}{c}J_{\text {water }} \\
\left(\mathbf{L ~ m}^{-2} \mathbf{h}^{-1}\right)\end{array}$ & $\begin{array}{c}J_{\text {LALBA }} \\
\left(\mathbf{L ~ m}^{-2} h^{-1}\right)\end{array}$ & $\begin{array}{c}\mathrm{J}_{\text {water }} \\
\left(\mathbf{L ~ m}^{-2} \mathbf{h}^{-1}\right)\end{array}$ & $\begin{array}{c}\text { FRR } \\
\text { after LALBA } \\
(\%)\end{array}$ & $S_{C_{\text {LALBA }}}$ \\
\hline PES & $221 \pm 35$ & $117 \pm 17$ & $131 \pm 32$ & 59 & $0.01 \pm 0.02$ & - & - & - & - & - \\
\hline PES-SS2 & $56 \pm 17$ & $49 \pm 16$ & $46 \pm 16$ & 82 & $0.30 \pm 0.11$ & $38 \pm 3$ & $36 \pm 5$ & $29 \pm 1$ & 76 & $0.49 \pm 0.27$ \\
\hline PES-50 kDa & $736 \pm 273$ & $93 \pm 7$ & $249 \pm 42$ & 34 & $0.02 \pm 0.01$ & $634 \pm 198$ & $159 \pm 33$ & $182 \pm 16$ & 29 & $0.87 \pm 0.21$ \\
\hline
\end{tabular}


All the above results showed clearly that the newly developed PES-SS2 membranes have higher fouling resistance in comparison to the control membranes. However, all these experiments were done using dead-end filtration at a 1 bar transmembrane pressure and for a certain time period. During dialysis, the proteins flow across the surface of the membrane. It is therefore important that one also evaluates the protein adhesion during flow of the solutions above the membrane surface. To achieve this, we used a microchip device and fluorescent-labelled LALBA under cross-flow conditions at $\mathrm{TMP}=0$. This test is obviously a screening test, not mimicking exactly the process conditions during dialysis. However, the low protein solution laminar flows $(35-130 \mu \mathrm{L} / \mathrm{min})$ can be considered the "worst" case scenario, since high flow rates can achieve less fouling.

Fig. 5 compares the results for the PES-50 kDa and PES-SS2 membranes. In Fig. 5A, the adhesion of the protein onto the membrane channel is presented as grey scale values. High numbers in grey scale indicate higher concentration of the LALBA on the membrane surface. In Fig. 5B fouling is presented in form of dye staining: intense color at the membrane surface indicates a higher concentration of LALBA there. The results clearly show that for the PES-SS2 membrane the interaction with the LABLA is much lower consistent to the lower membrane fouling measured earlier than the commercial PES-50 kDa membrane. Similar observations were made for various flow rates and are valid for the whole length of the membrane in the microchannel (Fig. 5C, D). It should be 
noted that though hydrodynamic conditions play crucial role in protein fouling of the membranes, for example unfolding of the protein molecules and sheer stress on the membrane surface, PES-SS2 membranes showed better fouling resistance in comparison to PES-50 kDa membranes at all studied conditions (Fig. 5). These results also indicate that the PES-SS2 membrane could be a low fouling membrane. 

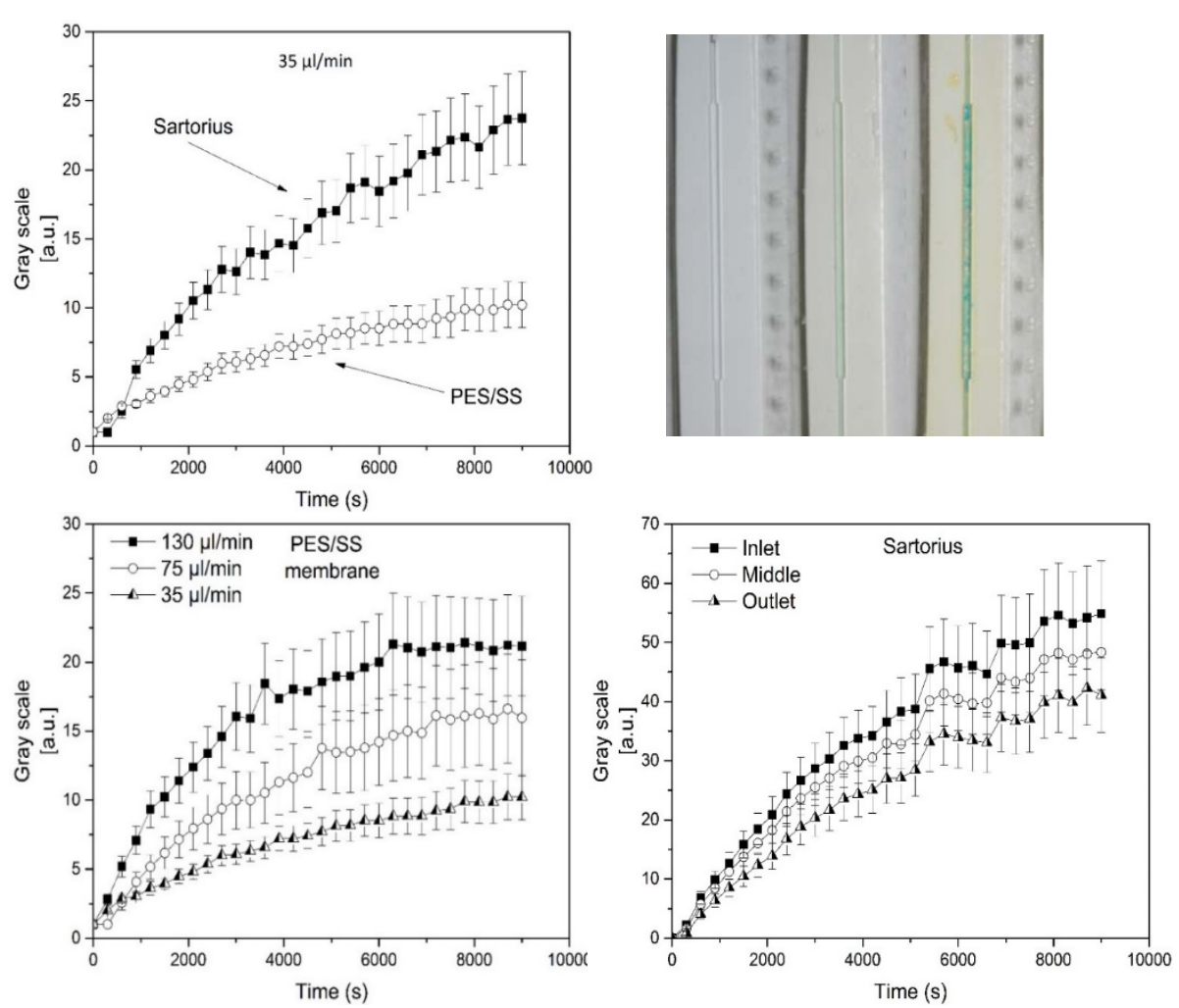

Fig. 5. Microchip LALBA fouling results of PES-50 kDa membranes from Sartorius and PESSS2 membranes. Top-left: LALBA fouling behaviour of membranes at $35 \mu \mathrm{L} / \mathrm{min}$. Topright: The corresponding macroscopic view of studied membranes in microchip: virgin PES-50 kDa membrane (left), fouled PES-SS2 membrane (centre) and fouled PES-50 kDa membrane (right). Bottom-left: LALBA fouling behaviour of PES-SS2 membranes under different flow conditions, at the centre of the channel. Bottom-right: LALBA fouling behaviour of PES-50 kDa membranes at different parts of the microchannel.

\section{Conclusions and Outlook}

This study presents the development and characterization of new flat-sheet membranes from a blend of PES and SS biomaterial with excellent hemocompatibility. A blend of PES and small amount of SS (2 wt\%) resulted to mechanically stable flat-sheet PES-SS2 membranes in the 
low ultrafiltration range. Compared to pristine PES and PES-50 kDa commercial membranes, the increased hydrophilicity of PES-SS2 membranes ensures high fouling resistance for both large and middle-size proteins such as BSA and LALBA, respectively. In the future, we plan to develop hollow fiber membranes based on PES-SS2 blend and investigate their application for prolonged hemodialysis including blood compatibility studies. 


\section{Appendix}

\section{Microfluidic chip fouling experiments}

In order to monitor the LALBA distribution and adhesion over time at zero TMP with the microchip, the proteins need to be labelled first following the protocol of Greene et $a{ }^{25}$. In short, LALBA was dissolved in sodium bicarbonate buffer to obtain a concentration of $10 \mathrm{mg} / \mathrm{mL}$. Subsequently, reactive dye was dissolved in $20 \mu \mathrm{L}$ of DMSO of the labelling kit. After dissolution of both protein and corresponding dye, two mixtures were transferred into the same vial and stirred gently for 2 hours. As the finishing step in the procedure, protein-dye conjugates were separated from free excess dye by gel filtration columns (size exclusion limit 5 kDa). To start the elution $5 \mathrm{~mL}$ of PBS was added. Solvent flow in the column was achieved by gravity only, without addition of extra pressure. The final protein concentration $(\mathrm{mg} / \mathrm{mL})$ was calculated as follows:

$$
c_{\text {protein }}=\frac{A_{280}-0.05 \cdot A_{647}}{\varepsilon_{\text {protein }}} \cdot M W_{\text {protein }} \cdot \text { dilution factor }
$$

where $A_{647}$ is absorbance of the conjugate at $647 \mathrm{~nm}, A_{280}$ is the absorbance of the conjugate at $280 \mathrm{~nm}, \varepsilon_{\text {protein }}$ is the molar extinction coefficient of protein $\left(27400 \mathrm{~cm}^{-1} \mathrm{M}^{-1}\right)$ at $280 \mathrm{~nm}, \mathrm{MW}_{\text {protein }}$ is the molecular weight of the protein $(\mathrm{g} / \mathrm{mol})$ and the dilution factor is the dilution of the labelled conjugate prior to the absorbance measurement. A dilution factor of 10 was used in order to obtain a maximum absorbance in the range from 0.5 to 1 . The absorbance of the conjugates was measured with a Libra S12 UV-spectrophotometer (Biochrom, UK). The 
final conjugate solution was diluted with PBS in order to achieve a concentration of $50 \mathrm{mg} / \mathrm{L}$ as it corresponds to clinically relevant median concentrations of $\beta$-2-microglobulin in human blood ${ }^{26}$.

The filtration experiments were performed with two systems: 1) a Zeiss Axio Observer.zlm inverted microscope equipped with a HXP $120 \mathrm{C}$ power supply (Zeiss Axio Vision Software), a filter set 38 (to detect the fluorescence of $\alpha$-lactalbumin-Atto-647N), and an automated stage and 2) a Fluigent MFCS-Flex pressure controller, combined with a FLOWELL flow-controller (MAESFLO software). A total of 3 pressure and 3 flow controllers were used. Two pressure controllers can supply a pressure of up to $1000 \mathrm{mbar}$, while the other one goes up to $350 \mathrm{mbar}$. As for the flow controllers, the first one can operate at a maximum flow of $7715 \mu \mathrm{L} / \mathrm{min}$, the second one at maximum flow of $55 \mu \mathrm{L} / \mathrm{min}$, and the last one at a maximum flow of $1100 \mu \mathrm{L} / \mathrm{min}$. The microfluidic chips were connected to the tubes of the pressure-flow controller and placed on the microscope stage to start the experimental protocol (Appendix Fig. 1). 


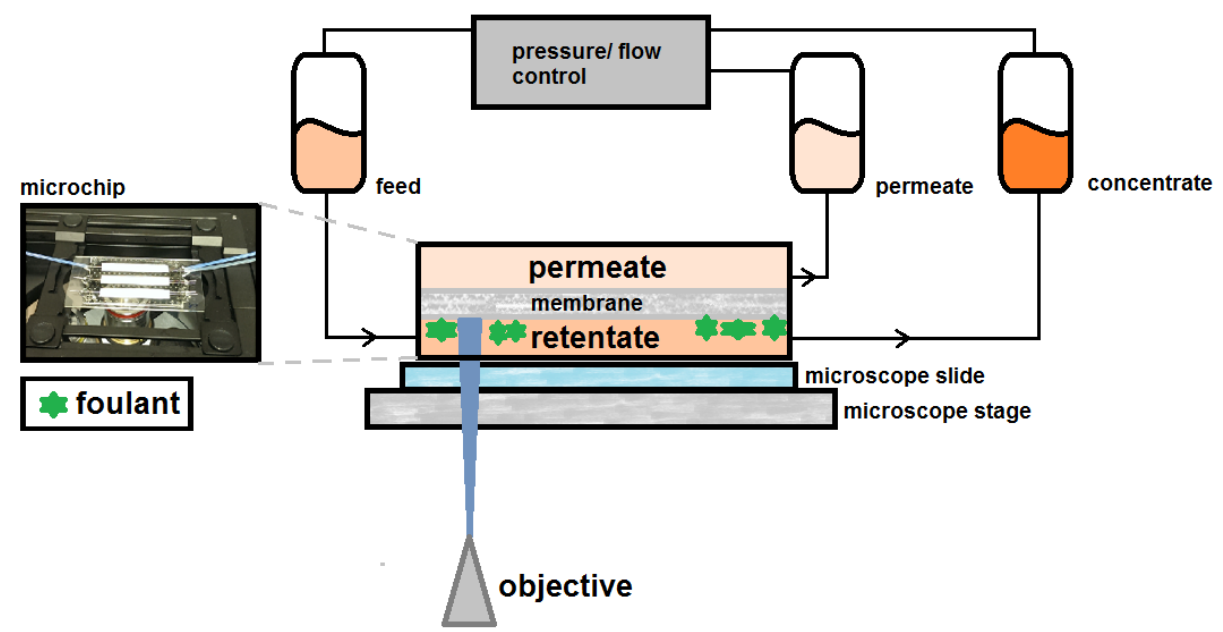

Appendix Fig. 1. Schematic representation of the experimental set-up used combining the fluorescent microscope and the microchip.

Before the filtration was started, the membrane was wet for 1 hour. For this, pure PBS was flown through the microchip at $130 \mu \mathrm{L} / \mathrm{min}$ and no pressure was applied from the permeate side. Then, the filtration process inside the microchip was performed at a single pass mode, meaning that the feed solution after reaching the retentate reservoir was not resupplied to the system. The control over the cross-flow velocity and transmembrane pressure was done by adjustments of the pressures at the inlet, the retentate, and the permeate reservoirs. Finally, the fluorescence on the membrane surface at the retentate compartment of the microchip was estimated: images of the whole channel were acquired every 5 minutes with a Cy5 filter. The gray value as a unit of a fluorescence intensity was measured with ImageJ software. A higher fluorescence is reflected by a bigger number of white pixels, which in turn results in the higher gray value. In order to evaluate the effect of flow rate on 
membrane fouling, three feed flow rates of 35,75 , and $130 \mu \mathrm{L} / \mathrm{min}$ were applied. Moreover, the spatial distribution of fouling along the membrane was evaluated using gray value analysis at three different positions in the channel: at the inlet, in the middle, and at the outlet. With the use of the software, the gray value of each pixel along the line of the channel was measured, yielding an average gray value with its respective standard deviation. 


\section{Bibliography}

1 Tijink, M. S. L. et al. Mixed matrix hollow fiber membranes for removal of protein-bound toxins from human plasma. Biomaterials 34, 78197828, doi:10.1016/j.biomaterials.2013.07.008 (2013).

2 Tijink, M. et al. Development of novel membranes for blood purification therapies based on copolymers of $\mathrm{N}$-vinylpyrrolidone and $\mathrm{n}$ butylmethacrylate. J Mater Chem B 1, 6066-6077, doi:10.1039/c3tb20964d (2013).

3 Davenport, A. Portable and wearable dialysis devices for the treatment of patients with end-stage kidney failure: Wishful thinking or just over the horizon? Pediatric nephrology 30, 2053-2060, doi:10.1007/s00467014-2968-3 (2014).

4 Davenport, A. et al. A wearable haemodialysis device for patients with end-stage renal failure: a pilot study. Lancet 370, 2005-2010, doi:Doi 10.1016/S0140-6736(07)61864-9 (2007).

5 Fissell, W. H., Roy, S. \& Davenport, A. Achieving more frequent and longer dialysis for the majority: wearable dialysis and implantable artificial kidney devices. Kidney Int 84, 256-264, doi:10.1038/ki.2012.466 (2013).

6 Eloot, S., Ledebo, I. \& Ward, R. A. Extracorporeal Removal of Uremic Toxins: Can We Still Do Better? Semin Nephrol 34, 209-227, doi:10.1016/j.semnephrol.2014.02.011 (2014).

7 Gura, V., Beizai, M., Ezon, C. \& Polaschegg, H. D. Continuous renal replacement therapy for end-stage renal disease - The wearable artificial kidney (WAK). Cardiovascular Disorders in Hemodialysis 149, 325-333 (2005).

8 Susanto, H. \& Ulbricht, M. Characteristics, performance and stability of polyethersulfone ultrafiltration membranes prepared by phase separation method using different macromolecular additives. I Membrane Sci 327, 125-135, doi:10.1016/j.memsci.2008.11.025 (2009).

9 Teodorescu, M. \& Bercea, M. Poly(vinylpyrrolidone) - A Versatile Polymer for Biomedical and Beyond Medical Applications. Polym-Plast Technol 54, 923-943, doi:10.1080/03602559.2014.979506 (2015). 
10 Matsuda, M. et al. Effects of fluid flow on elution of hydrophilic modifier from dialysis membrane surfaces. J Artif Organs 11, 148-155, doi:10.1007/s10047-008-0417-4 (2008).

11 Namekawa, K., Matsuda, M., Fukuda, M., Kaneko, A. \& Sakai, K. Poly(Nvinyl-2-pyrrolidone) elution from polysulfone dialysis membranes by varying solvent and wall shear stress. J Artif Organs 15, 185-192, doi:10.1007/s10047-012-0629-5 (2012).

12 Madsen, B., Britt, D. W., Griffiths, F., McKenna, E. \& Ho, C. H. Effect of Sterilization Techniques on the Physicochemical Properties of Polysulfone Hollow Fibers. J Appl Polym Sci 119, 3429-3436, doi:10.1002/app.32994 (2011).

13 Miyata, M., Konishi, S., Shimamoto, Y., Kamada, A. \& Umimoto, K. Influence of Sterilization and Storage Period on Elution of Polyvinylpyrrolidone from Wet-Type Polysulfone Membrane Dialyzers. ASAIO journal 61, 468-473, doi:10.1097/Mat.0000000000000224 (2015).

14 Namekawa, K., Kaneko, A., Sakai, K., Kunikata, S. \& Matsuda, M. Longer storage of dialyzers increases elution of poly( $\mathrm{N}$-vinyl-2-pyrrolidone) from polysulfone-group dialysis membranes. J Artif Organs 14, 52-57, doi:10.1007/s10047-011-0552-1 (2011).

15 Liu, X. L., Xu, Y. J., Wu, Z. Q. \& Chen, H. Poly(N-vinylpyrrolidone)-Modified Surfaces for Biomedical Applications. Macromol Biosci 13, 147-154, doi:10.1002/mabi.201200269 (2013).

16 Konishi, S., Fukunaga, A., Yamashita, H., Miyata, M. \& Usami, M. Eluted substances from hemodialysis membranes elicit positive skin prick tests in bioincompatible patients. Artif Organs 39, 343-351, doi:10.1111/aor.12392 (2015).

17 Nady, N. et al. Modification methods for poly(arylsulfone) membranes: A mini-review focusing on surface modification. Desalination 275, 1-9, doi:10.1016/j.desal.2011.03.010 (2011).

$18 \mathrm{He}, \mathrm{C}$. et al. Graphene oxide and sulfonated polyanion co-doped hydrogel films for dual-layered membranes with superior hemocompatibility and antibacterial activity. Biomater Sci-Uk 4, 14311440, doi:10.1039/c6bm00494f (2016). 
19 Nie, C. X. et al. Novel heparin-mimicking polymer brush grafted carbon nanotube/PES composite membranes for safe and efficient blood purification. J Membrane Sci 475, 455-468, doi:10.1016/j.memsci.2014.11.005 (2015).

20 Hanssen, H. H. L. et al. Metallic wires with an adherent lubricious and blood-compatible polymeric coating and their use in the manufacture of novel slippery-when-wet guidewires: Possible applications related to controlled local drug delivery. J Biomed Mater Res 48, 820-828, doi:Doi 10.1002/(Sici)1097-4636(1999)48:6<820::Aid-Jbm9>3.0.Co;2-K (1999).

21 Peerlings, C. C. L. et al. Heparin release from slippery-when-wet guide wires for intravascular use. J Biomed Mater Res 63, 692-698, doi:10.1002/jbm.10381 (2002).

22 Pijls, R. T., Hanssen, H. H. L., Nuijts, R. M. M. A. \& Koole, L. H. Flexible coils with a drug-releasing hydrophilic coating: A new platform for controlled delivery of drugs to the eye? Bio-Med Mater Eng 14, 383-393 (2004).

23 Liu, Y. A. et al. Improved antifouling properties of polyethersulfone membrane by blending the amphiphilic surface modifier with crosslinked hydrophobic segments. J Membrane Sci 486, 195-206, doi:10.1016/j.memsci.2015.03.045 (2015).

24 Pavlenko, D. et al. New low-flux mixed matrix membranes that offer superior removal of protein-bound toxins from human plasma. Scientific reports 6, 34429, doi:10.1038/srep34429 (2016).

25 Greene, L. H. et al. Stability, activity and flexibility in alpha-lactalbumin. Protein Eng 12, 581-587, doi:DOI 10.1093/protein/12.7.581 (1999).

26 Meireles, M., Aimar, P. \& Sanchez, V. Albumin Denaturation during Ultrafiltration - Effects of Operating-Conditions and Consequences on Membrane Fouling. Biotechnol Bioeng 38, 528-534, doi:DOI 10.1002/bit.260380511 (1991).

27 Kumar, S. V., Musturappa, T. E., Prasannakumar, S., Mahadevan, K. M. \& Sherigara, B. S. N-vinylpyrrolidone and ethoxyethyl methacrylate copolymer: Synthesis, characterization and reactivity ratios. J Macromol Sci A 44, 1161-1169, doi:10.1080/10601320701561072 (2007). 
28 Song, H. M. et al. Hemocompatibility and ultrafiltration performance of surface-functionalized polyethersulfone membrane by blending comblike amphiphilic block copolymer. J Membrane Sci 471, 319-327, doi:10.1016/j.memsci.2014.08.013 (2014). 



\section{Chapter 6}

Conclusions and outlook 


\section{General conclusions}

Hemodialysis is well-established clinical solution to sustain the life of kidney patients while they wait for transplantation. Despite impressive development in the field of hemodialysis, mortality rate remains high mostly due to inadequate removal of uremic toxins. Therefore, this thesis is focused on the developments in uremic toxin removal which will provide kidney patients with more efficient and complete treatment.

Chapter 1 provides the general overview of the state-of-art of blood purification techniques as well as highlights bottlenecks of current technologies. This chapter also discusses the use of mixed matrix membranes (MMM), that combine benefits of two widely used techniques: hemodialysis and hemoperfusion. Development and performance of a new MMM is discussed in Chapter 2. In fact, essential steps are done to bring $\mathrm{MMM}$ from a concept to a tool that provides better removal of protein-bound toxins from human plasma in direct comparison to industrial membranes. Comparison of the obtained results of the MMM to literature studies indicates that new MMM have high potential for clinical implementation.

An important aspect of all new medical membranes and medical devices in general is the absence of negative response from the patient blood. Chapter 3 provides insights compatibility of newly developed MMM and compares them to benchmark hemodialysis membranes. The results clearly show that MMM have very good hemocompatibility 
comparable to Fresenius F60 dialysis membranes and, therefore, may be used in in vivo studies.

In the search for sorbents which could achieve removal of a broad range of uremic toxins, Chapter 4 presents the application of a new sorbent, CMK-3, which has dual porosity (contains micro- and mesopores) and therefore has high selectivity and adsorption capacity to small, as well as, middle molecules and cytokines. In fact, CMK-3 sorbent could be used as stand-along material in hemosorption column as well as be used for preparation of MMM.

In the last experimental chapter, Chapter 5, new fouling resistant membranes are developed by combining polyethersulfone with unique polymeric material SlipSkin which is a copolymenr of $\mathrm{N}$-vinylpyrrolidone and $n$-butylmethacrylate. The developed membranes have low fouling for proteins for both dead-end and cross-flow modes of operation, which makes them of high interest in prolonged hemodialysis therapies. 


\section{Outlook}

Improvements in MMM performance.

Chapter 2 describes development and optimization of MMM. After a sequence of spinning parameter optimizations, we were able to successfully produce double layer mixed matrix membranes that outperforms industrial membranes. Even though membranes showed remarkable improvements in comparison to single layer fibers they can be significantly improved in several directions which are described below.

a. Further decrease of fiber diameter. Mixed matrix membranes from Chapter 2 had internal diameter of $376 \mu \mathrm{m}$, which is larger than clinically used membranes (with $200 \mu \mathrm{m}$ of internal diameter). Even though last laboratory spinning sessions resulted in fibers of around $300 \mu \mathrm{m}$ with similar permeance values, further reduction of the fiber diameter down to $200 \mu \mathrm{m}$ is needed to achieve improved surface area to volume ratios of membrane modules (an important step in case MMM would be considered for wearable device). A possible way to accomplish smaller fiber dimensions is via the design of new spinneret type and adjusting spinning parameters, like polymer dope flow rate, collecting wheel speed and bore liquid flow rate.

b. Increase in membranes flux and MWCO. The permeance of the mixed matrix membranes described from Chapters 2 and 3 puts 
them into the category of low-flux dialysis membranes ( 3 $\mathrm{L} / \mathrm{h} / \mathrm{bar} / \mathrm{m}^{2}$ ). Additionally, MWCO values of around $12 \mathrm{kDa}$ does make them suitable for efficient removal of protein-bound toxins but limits their application for removal of middle molecule, for example $\beta$-2microglobulin (MW $13 \mathrm{kDa}$ ). Therefore, one can consider increasing both permeance and MWCO values of the produced membranes. It can be accomplished by delaying the phase inversion of the fibers using different bore liquid compositions: for example, stepwise addition of NMP to bore solution will result in membranes with larger surface porosity.

c. Use another membrane material. In all tested membranes from Chapters 2 and 3 a blend of PES and PVP was used. Even though this blend dominates the hemodialysis market it is of a high scientific and industrial interest to find formulation that works better than PES/PVP: i.e. that has long-term hemocompatibility and improved fouling and sterilization resistance. We, therefore, believe that future improvement of the MMM performance can be done by the change of the polymer formulation with better performing polymer (for example, SlipSkin or other PES/PVP mixture) for inner membrane layer.

d. Change of adsorptive particles. Chapter 4 of the thesis describes the performance of new CMK-3 particles that can be used for efficient removal of wide spectrum of uremic toxins: middle molecules, small water soluble and protein-bound solutes. We 
showed that this type of adsorbent has evident benefits in comparison to Norit Supra activated carbon used in MMM. Logically, next step in MMM development should be the substitution of the Norit Supra by CMK-3 in the next generation of MMM to evaluate the influence of new particles on MMM performance. Firstly, one should determine optimum loading capacity of the polymer matrix of the choice (for example, 15\% PES/ 7\% PVP) with CMK-3 particles: higher loading results in higher adsorption capacity of the final fiber, but decreases the mechanical strength of the membrane material. Secondly, spinning parameters should be adapted for the change of the material used as outer membrane layer based on first spinning trials.

e. Mode of filtration. All described membranes in this thesis as well as currently used hemodialyzers use inside-out filtration: feed solution (blood) is pumped inside the fiber lumen, while permeate is removed together with dialysate flow on other side of the fiber. Some studies, for example Dukhin et $\mathrm{al}^{1}$, draw attention to benefits of reversed mode of operation, namely, outside-in filtration. In their study, they showed that change of the filtration mode provides hydrodynamic advantages in comparison to inside-out filtration: no pressure drops due to thrombi deposition in outside-in hemodialysis results in prolonged life of hemodialysis modules (important for prolonged dialysis and wearable devices) Additionally, reduced sheer

${ }^{1}$ Dukhin, S. S. et al. Outside-in hemofiltration for prolonged operation without clogging. J. Memb. Sci. 464, 173-178 (2014). 
rates in the inter-fiber space may reduce the clog formation and, thus, the device can be operated at increased blood flow rates. Therefore, it is of interest to develop and evaluate performance of MMM with outside-in geometry, which can be accomplished by, for example, tuning spinning parameters and via development of adapted spinneret. This step will require adaptation of a number of spinning parameters as selective layer should be on the outer side of the fiber: a) air gap should be decreased in height or avoided (immersed spinneret) during spinning session while bore composition should be tuned the way demixing of the inner side of the fiber is delayed (addition of NMP to the bore solution).

\section{Module design and upscaling}

In this thesis, we used relatively small membrane module of $\sim 4$ $\mathrm{cm}^{2}$ (Chapter 2 and 3) and $65 \mathrm{~cm}^{2}$ (Chapter 3) which are smaller than industrial dialyzer with 1-2 $\mathrm{m}^{2}$ of fiber in them. As concept of the double layer mixed matrix membranes proved to improve hemodialytic removal of protein-bound toxins one should focus on experiments with MMM in animal model which require membrane upscaling and module design. Here, a couple of points deserve attention.

a. Upscaling: spinning. MMM fabrication was performed on the lab-scale spinning line with extrusion speed of around 3-5 $\mathrm{m} / \mathrm{min}$ and total capacity to extrude 300-500 $\mathrm{m}$ of the MMM per spinning session. Additionally, polymer formulations were extruded from 
syringes with relatively small volumes (around $70 \mathrm{~mL}$ ). As one of the first and unavoidable steps of MMM upscaling, switch to larger spinning line should be considered. As dispersion of adsorptive particles in the PES/PVP solution is a non-Newtonian fluid, increase in extrusion speed will not result in MMM fibers with similar properties and, thus, slight process adaptation would be required. Additionally, big volumes of dope solutions with adsorptive particles will also raise the issue of the solution stability and uniformity in time, which should be addressed before and during spinning.

b. Upscaling: module design. Our first attempts to scale-up membrane module (with the help of Dr. Lemke from eXcorLab GmbH) resulted in membrane modules with 0.25-0.4 $\mathrm{m}^{2} \mathrm{MMM}$ inside which we planned to use in animal model. Among the available options preferences were given to membrane modules with $0.25 \mathrm{~m}^{2}$ (Figure 1a) to avoid too dense packing of the membranes inside the module, which could result in suboptimal dialysate distribution inside the module. First animal experiments with upscaled modules highlighted several imperfections in our initial module design. Here, the critical point was the use of inlet tubed for the dialysis flow: narrow inlet channels for dialysate flow are connected perpendicular to the direction of the MMM fibers and result in high dialysate flow impact on the MMM. Consequently, after 2-15 minutes of experiment the dialysis machine detected leakage of blood through the MMM and experiments were aborted. 
Taking into account, the findings of the first round of experiments, the next membrane modules were made using housings from Gambro (now Baxter, see Figures 1b). Here, the inlet diameter of the dialysate flow is increased and, to ensure safety of the fibers and disperse dialysate flow, special protective net is installed. 

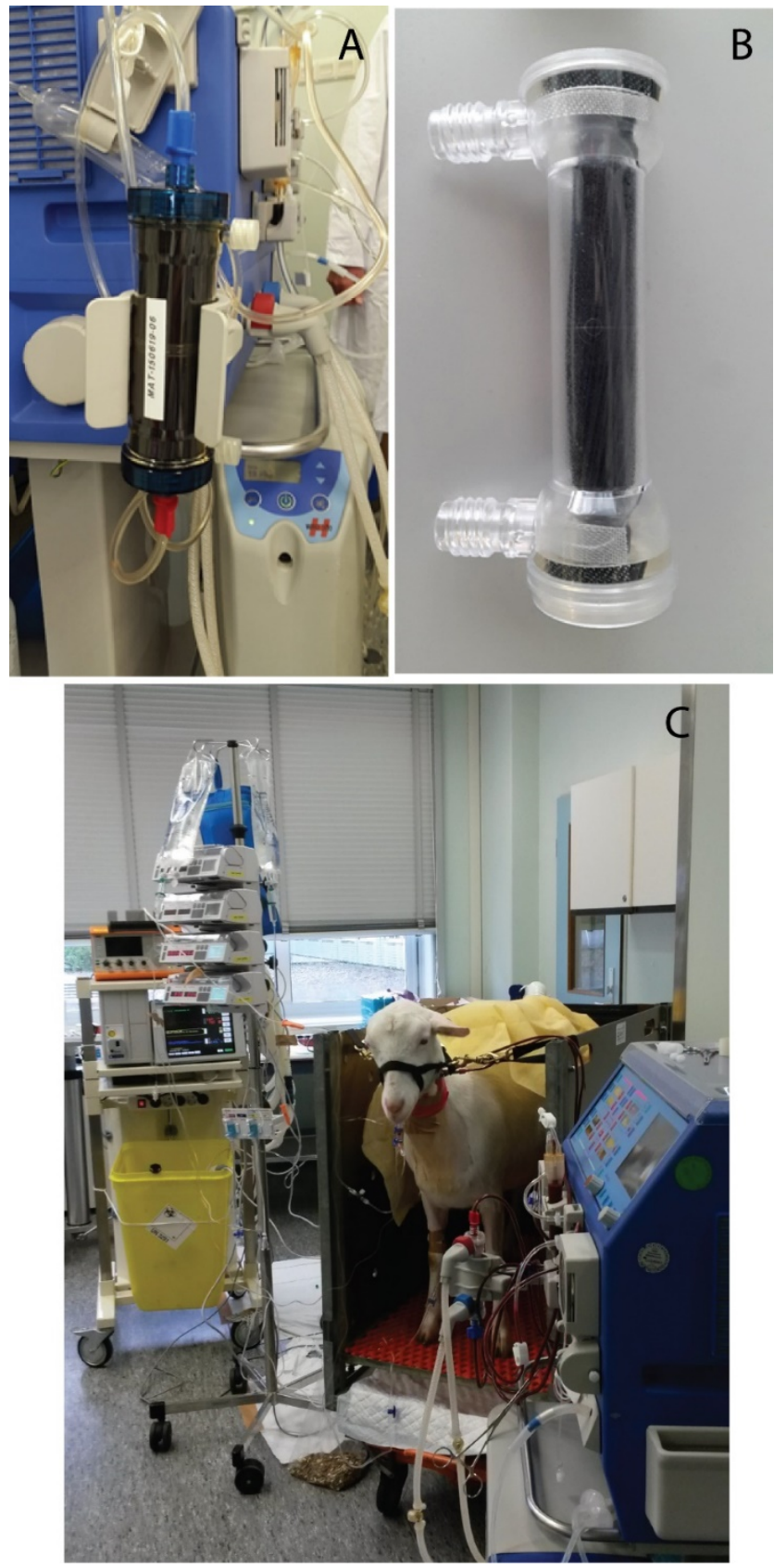

Fig. 1. First (a) and second (b) generations of the dialysis modules produced during upscaling. Figure $1 \mathrm{c}$ depicts animal model set-up used in our MMM experiments. 
c. Module design: gluing and cutting. One important aspect of membrane module design is the development of the proper gluing and cutting procedure. Ideally gluing should result in homogenous distribution of fibers inside the module to avoid "dead" interfiber volumes. Additionally, one should consider developing cutting protocol after fibers are glued inside the module with the aim to create smooth cut while keeping all the fibers open. This step is important to avoid blood compatibility issues when cut results in rough surfaces of the inlet and outlet of the module

d. Upscaling: sterilization. Sterilization is a crucial step in medical device development. It is vital to understand the influence of the sterilization method on the fiber properties (flux, MWCO and hemocompatibility) to select proper sterilization technique and/or adapt existing ones. One should consider testing the performance of the produced fibers before and after the sterilization step (e.g. gamma sterilization) to ensure that membrane properties were not changed.

e. Upscaling: membrane packing and undulation. All membranes discussed in this thesis were tested in small modules of 3 to 60 fibers inside with large space for dialysate fluid. For larger modules, proper membrane packing should come into consideration: denser membrane packing results in higher surface areas per module, but limit space for proper dialysate fluid distribution. We believe that time should be invested to find an optimum in membrane packing in order to fully benefit from advantages that MMMs provide. Here 
modeling can be employed as the initial step in packing evaluation followed by laboratory tests of the selected packing range.

Undulation is one more important aspect in module fabrication: straight fibers do not support distribution of the dialysate liquid. Therefore, in most industrial modules membranes are undulated. Undulation here can be easily achieved by changing of the membrane drying process: MMM tend to keep the shape in which they were dried. Computer modeling should give an estimate of the optimal membrane undulation.

\section{Design of Experiments (DoE).}

Fabrication of the membranes with optimum performance requires large number of experiments due to the fact that a lot of parameters have influence on final membrane properties. For example, during spinning of single layer membranes from defined polymer dope parameters like bore solution (composition, temperature, speed), air gap, temperature, humidity, pulling speed, coagulation bath (composition, temperature, time in the bath) will play major role in defining final properties of the fiber. Depending on the range of each parameter and size of the step with which these parameters are changed, number of experiments can easily raise up to $1000+$. Taking into account that max 2-3 spinning sessions per week (with couple of parameters varied during each session) is possible to perform, one factor at a time (OFAT) membrane optimization can last 
longer than a duration of the PhD. Introduction of the second layer and mixed matrix membranes here will only increase the number of parameters that should be taken into account (Figure 2, Ishikawa diagram illustrates most of the parameters that contribute to final membrane performance). In order to create "peak"-performing MMM in future one should consider development of relevant DoE. Here, DoE should minimize number of hours and resources spend on the MMM development on the later scale-up stages of product development. 


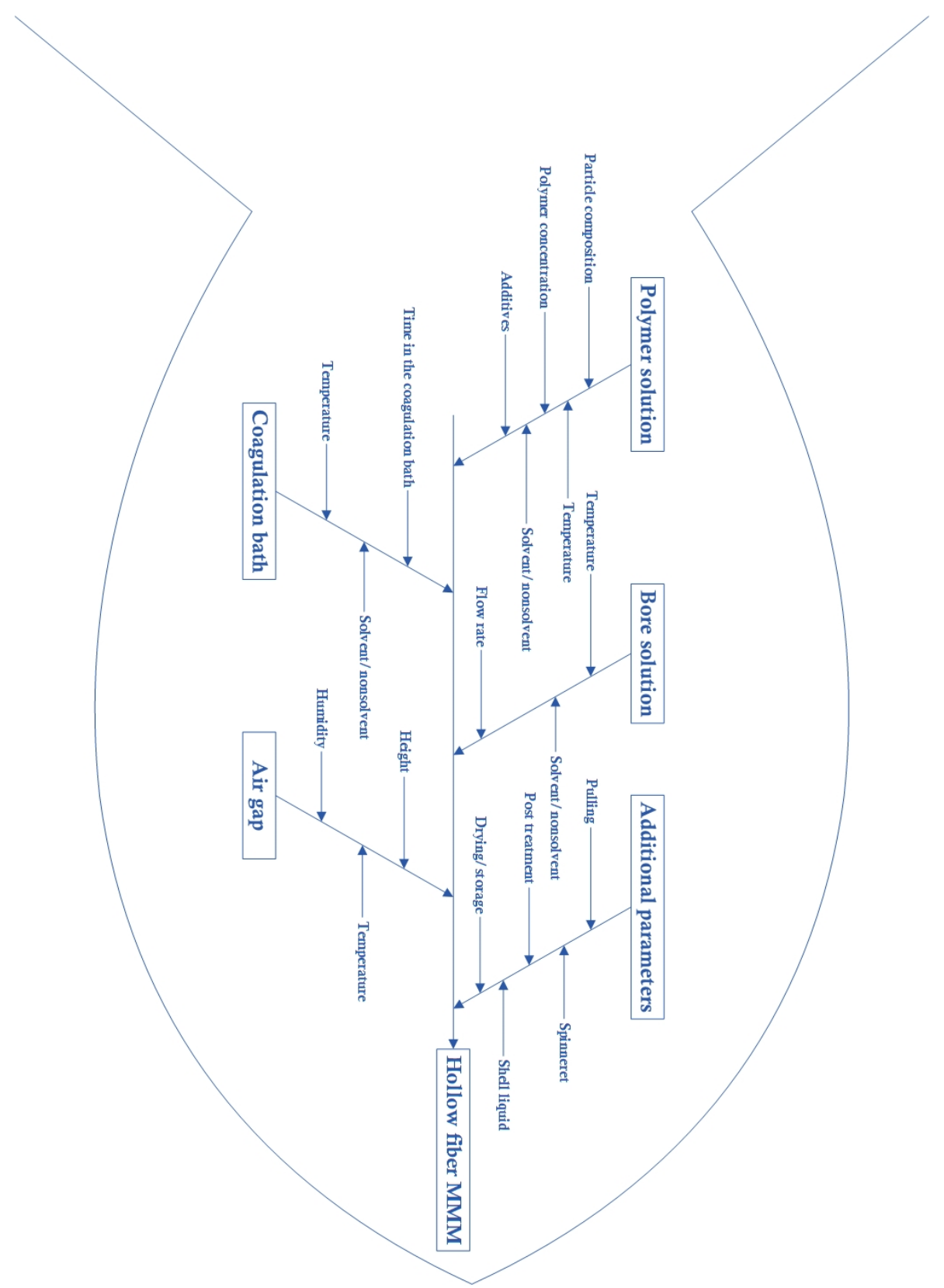

Fig. 2. Ishikawa diagram with critical spinning parameters. 
Summary 
Hemodialysis is well-established clinical solution to sustain the life of kidney patients while they wait for transplantation. Despite impressive development in the field of hemodialysis, mortality rate remains high mostly due to inadequate removal of uremic toxins. Therefore, this thesis is focused on the developments in uremic toxin removal which will provide kidney patients with more efficient and complete treatment.

Chapter 1 provides overview of the state-of-art of blood purification techniques as well as highlights bottlenecks of current technologies. It also discusses the use of mixed matrix membranes (MMM), that combine benefits of two widely used techniques: hemodialysis and hemoperfusion. This chapter finally formulates aim and presents the general structure of the thesis.

Chapter 2 discusses development and performance of a new MMM. Firstly, essential steps to bring the MMM from a concept to a tool that provides better removal of protein-bound toxins from human plasma are reported. Secondly, the MMM performance in uremic toxin removal from human plasma is studied and compared to industrial membranes. The optimized MMM offer superior ability in removing the PBUT indoxyl sulfate (IS) and p-cresyl sulfate (pCS) in comparison to first generation MMMs (30\% and $125 \%$ respectively), as well as, a commercial dialysis membrane (more than $100 \%$ better removal). The obtained results of the optimized MMM, as well as their comparison to literature studies, indicate the high potential of MMM for clinical implementation. 
Chapter 3 provides insights into the blood compatibility of newly developed MMM and compares them to benchmark hemodialysis membranes. The absence of any negative response of the patient blood is an important aspect of all new medical membranes and medical devices. In this chapter, we performed extensive blood compatibility testing of the MMM following the ISO protocol 10993-4. Our tests show that MMM has low drop in white blood cell and platelet count combined with low TAT and C5a generation. Additionally, absence of hemolysis and no significant drop in red blood cell count makes them promising candidates for application in the clinic.

In search for better sorbents which could achieve removal of a broad range of uremic toxins, Chapter 4 presents a new sorbent, CMK-3. This sorbent is developed by nanocasting methods, has dual porosity of micro- and mesopores, and therefore shows high adsorption capacity towards small water soluble toxins (creatinine (113 Da)), protein-bound molecules (indoxyl sulfate (213 Da) and hippuric acid(179 Da)), middle molecules ( $\beta 2$-microglobulin(11.6 kDa)) and cytokines of different sizes (IL-6 (24 kDa) and IL-8 (8 kDa)). Moreover, the performance of CMK-3 is compared with two commercially available carbon-based sorbents with predominant mesoporosity (Norit A Supra) and microporosity (Takeda $5 A)$. Our results show that even small amounts of CMK-3 could provide effective removal of uremic toxins of various sizes and types.

In the last experimental chapter, Chapter 5, new fouling resistant membranes are developed by combining polyethersulfone (PES) and 
SlipSkin (SS) which is a copolymer of N-vinylpyrrolidone and $\mathrm{n}$ butylmethacrylate. Our results show that a blend of PES and a small amount of SS (2 wt\%) is enough to produce mechanically stable flat-sheet membranes in the low ultrafiltration range. Compared to the pristine PES and commercial Sartorius (MWCO $50 \mathrm{kDa}$ ) membranes, the PES/SS membranes have increased hydrophilicity ensuring high fouling resistance for both large and middle-size proteins such as bovine serum albumin (BSA) and $\alpha$-Lactalbumin (LALBA), respectively.

Chapter 6 presents general conclusions and outlook of future directions in the development of better and more complete uremic toxin removal therapies. 
Samenvatting 
Hemodialyse is een gevestigde klinische oplossing voor het in leven houden van nierpatiënten die op een niertransplantatie wachten. Ondanks grootse ontwikkelingen op het gebied van hemodialyse blijft het sterftecijfer onder nierpatiënten hoog. Dit komt doordat huidige hemodialyse technieken onvoldoende in staat zijn om uremische toxines te verwijderen. Voor een efficiëntere en meer complete behandeling van nierpatiënten zijn nieuwe technieken en/ of therapieën nodig. Daarom zal deze thesis gaan over de ontwikkelingen op het gebied van het verwijderen van uremische toxines.

Hoofdstuk 1 geeft een overzicht van "state-of-the-art" technieken voor bloedzuivering en benadrukt daarnaast de knelpunten van huidige technieken. Verder wordt het gebruik van "mixed matrix membranen" (MMM) behandeld, die de voordelen van twee veelvuldig gebruikte technieken - hemodialyse en hemoperfusie - combineren. Dit hoofdstuk wordt afgesloten met zowel de formulering van het doel, als de presentatie van de algemene structuur van deze thesis.

In Hoofdstuk 2 worden de ontwikkeling en werking van nieuwe MMM behandeld. Ten eerste, worden de stappen beschreven die essentieel zijn om van het concept MMM, een tool te maken dat zorgt voor een betere verwijdering van eiwitgebonden toxines uit humaan bloedplasma. Ten tweede, wordt de werking van MMM, het verwijderen van uremische toxines uit humaan plasma, onderzocht en de resultaten vergeleken met industriële membranen. De geoptimaliseerde MMM bieden superieure verwijdering van de eiwitgebonden toxines indoxyl 
sulfate (IS) en p-cresylsulfate (pCS) in vergelijking met zowel eerste generatie $\mathrm{MMM}$ (respectievelijk $30 \%$ en 125\%), als commerciële dialysemembranen (meer dan 100\% betere verwijdering). De verkregen resultaten van de geoptimaliseerde $\mathrm{MMM}$ en de vergelijking van deze resultaten met andere studies uit de literatuur, duiden op de grote potentie van MMM voor klinische implementatie.

Hoofdstuk 3 biedt inzicht in de bloedcompatibiliteit van de nieuwe ontwikkelde $\mathrm{MMM}$ en vergelijkt deze met standaard hemodialyse membranen. Het is belangrijk dat negatieve reacties van het bloed van een patiënt uitblijven bij alle nieuwe medische membranen en medische apparaten. Daarom hebben we in dit hoofdstuk uitvoerige bloedcompatibiliteit testen met de MMM uitgevoerd volgens ISO protocol 10993-4. Uit onze testen blijkt dat MMM een lage TAT en C5a generatie hebben en dat ze zorgen voor een kleine daling in witte bloedcellen en bloedplaatjes. Daarnaast zorgen het uitblijven van zowel hemolyse als het uitblijven van een significante daling in rode bloedcellen ervoor dat MMM veelbelovende kandidaten zijn voor klinische toepassing.

In de zoektocht naar betere sorptiemiddelen voor het verwijderen van een breed scala aan uremische toxines, presenteert Hoofdstuk 4 een nieuw sorptiemiddel, CMK-3. Dit sorptiemiddel is ontwikkeld door "nanocasting" methodes en heeft een duale porositeit, namelijk microen mesoporiën. Hierdoor heeft CMK-3 een grote adsorptiecapaciteit voor kleine, wateroplosbare toxines (creatinine: $113 \mathrm{Da}$ ), eiwitgebonden 
moleculen (IS: 213 Da en hippuric acid: $179 \mathrm{Da}$ ), middelgrote moleculen ( $\beta 2$-microglobulin: 11,6 kDa) en cytokines van verschillende groottes (IL6: $24 \mathrm{kDa}$ en IL-8: $8 \mathrm{kDa}$ ). In dit hoofdstuk wordt de werking van CMK-3 vergeleken met de werking van twee commerciële sorptiemiddelen die gebaseerd zijn op koolstof: Norit A Supra met voornamelijk een mesoporositeit en Takeda 5A met voornamelijk een microporositeit. Onze resultaten laten zien dat zelfs kleine hoeveelheden CMK-3 zorgen voor een effectieve verwijdering van verschillende typen en groottes uremische toxines.

In het laatste experimentele hoofdstuk, Hoofdstuk 5, worden nieuwe vervuiling-bestendige ("fouling resistant"), membranen ontwikkeld door middel van het combineren van polyethersulfone (PES) met SlipSkin (SS), een copolymeer van N-vinylpyrrolidone en $\mathrm{n}$ butylmethacrylate. Onze resultaten laten zien dat een "blend" van PES met een kleine hoeveelheid SS (2 wt\%) genoeg is om mechanisch stabiele, platte membranen te produceren in de lage ultrafiltratie range. In vergelijking met pure PES membranen en commerciële Sartorius membranen (MWCO 50 kDa) zijn PES/SS membranen meer hydrofiel, waardoor PES/SS membranen een betere fouling resistance hebben voor grote en middelgrote eiwitten zoals respectievelijk bovine serum albumin (BSA) en $\alpha$-Lactalbumin (LALBA).

Hoofdstuk 6 bevat de algemene conclusies en geeft aanbevelingen voor toekomstige ontwikkelingen op het gebied van betere en meer complete, uremische toxine-verwijderende therapieën. 


\section{Acknowledgements}

I feel a bit stressed (really) to write possibly the most popular chapter of my thesis. Honestly, a bit more than three years passed by too quickly and I do believe it was one of the most amazing times of my life. I liked everything about my PhD: environment, challenges, science and most of all I liked people around me.

First of all I would like to thank my supervisor Prof. Dr. Dimitrios Stamatialis for the opportunity to work on this amazing project. I really appreciate your encouragements when I was down and your enthusiasm when everything was going "according to the plan". I do believe that my research would not be successful without "the helicopter view" during our meetings as sometimes I was getting lost in small details. Thank you, Dimitrios.

Importantly, I am also really grateful to my graduation committee for their time and effort spent on reading my thesis and coming to my defense. Prof. Dr. D. W. Grijpma, Prof. Dr. N. E. Benes, Prof. Dr. R. Masereeuw, Prof. Dr. Ing. J. Vienken and Dr. K.G.F. Gerritsen - thank you all.

I would also like to thank Karin Hendriks, our BST magician, for all the work and help you have done. Thank you for making my arrival, life and even "life after PhD" less stressful regarding administrative issues. 
Unforgettably, I would also like to express my gratitude to Zlata, Anita, Marc and Hetty. Thank you for the help when I was in need for it and for short talks near coffee machine. Thank you Lydia for your priceless contribution, for our HPLC struggles and for our short trips to Utrecht, I really appreciate the work you've done.

Big thanks go to my beloved office mates: Aga (Dr. Evil), Aysun, Bade, Jia and Vincent. Thank you for unbelievable environment, talks and fun we had. Aga, thank you for being so concentrated and energetic in everything you do, it always inspired me when I feel lazy. I wish you and Mateo (master cook) all the best in Denmark. Aysun, I know everything will be fine, stay strong as you are. Bade, Vincent and Jia, thank you for being essential part of our nice office environment.

Natalia, I already told you that I am really happy that you joined BST: without you my PhD life would not be so bright and enjoyable. Thank you for being the most reliable person in BST for eating early lunch (or two) and for always being brutally honest (I do miss it now). I wish you and Felix all the best and hope to see you both at my defense.

Kasia, my muffin buddy, thank you for great time. There is a lot to say "thank you" for: warm welcome upon my arrival, funny complaints when I try to leave party at 10 (or earlier) and for your amazing ability to understand my frustrations. It was also really fun to travel with you and Emi to Rome and Japan. I hope we will continue to discover the world. Also thank you for agreeing to be my paranymph. 
Odyl, my second paranymph, thank you for being always positive and patient. I always considered myself as a calm and optimistic person, but you are setting just a new level. Thank you for all your help, talks and agreeing to be my paranymph.

Next I would like to thank my gym buddies, Renaud and Bas (and now also Dooli), for sharing my enthusiasm about early morning workout. I do hope you enjoyed them as much as I did.

I think I do not need to introduce llaria here, it feels like everyone knows you already. Thank you for introducing so much laugh and fun to my already dynamic life.

My brave students Esmee, Meina and Tiago, I really appreciate you joining me on my way to this thesis.

Additionally I want to acknowledge all the rest of the BST group for creating unbelievable environment in the group: Thijs, Mike, Nick, Frits, Erwin, Tony, Gijs, Hui, Iris, Jonas, Deby, Djadhank, Praneeth (extra thanks for your unbelievable Indian food(:)), Tushar, Dwi, Jai, Suvi, Duco, Pia, Gert-Jan, Dalila, Jos and Sebastien. It was a pleasure to meet you all.

I would also like to extend my acknowledgments to Tymen, who "adopted" me after my PhD time was over. I really appreciate your trust in me and all words of advice you give me on a daily basis. 
My BioArt fiends, I am really happy to meet you all and for all the fun we had all around Europe. You are all incredibly bright and fun people and I hope we will stay in touch wherever life will send us.

Lia (aka Linda), I was really fortunate to meet you here. For already 4 years you are making this place sunnier and wormer. I really appreciate your patience and enthusiasm with which you treat my strange ideas and for sharing my passion for Asian food and Placebo. My PhD life would not be that great without your support. Beijinhos. 


\section{List of publications}

D. Pavlenko, E. van Geffen, M. J. van Steenbergen, G. Glorieux, R. Vanholder, K. G. F. Gerritsen, D. Stamatialis. New low-flux mixed matrix membranes that offer superior removal of protein-bound toxins from human plasma. Scientific Reports. 2016. 34429

D. Snisarenko, D. Pavlenko, D. Stamatialis, P. Aimar, C. Causserand, P. Bacchin. Insight into the transport mechanism of solute removal in dialysis by a membrane with double functionality. Chemical Engineering Research and Design. Volume 126, 97-108.

D. Pavlenko, D. Giasafaki, G. Charalambopoulou, E. van Geffen, K.G.F. Gerritsen, T. Steriotis, D. Stamatialis. Carbon adsorbents with dual porosity for efficient removal of uremic toxins and cytokines from human plasma. Scientific Reports. 2017. 14914.

O. ter Beek, I. Geremia, D. Pavlenko, and D. Stamatialis. Advanced Blood Purification Therapies. Chapter 3 in the book: Biomedical Membranes and (Bio) Artificial Organs. 2018. pp. 59-82.

D. Pavlenko, K. Maksymow, H.-D. Lemke, D. Stamatialis. Insights into blood compatibility of mixed matrix membranes. In preparation.

O. ter Beek, D. Pavlenko, D. Snisarenko, M. H. Suck, S Helfrich, C. Causserand, D. Stamatialis. Low fouling membranes for hemodialysis based on polyethersulfone/Slipskin ${ }^{\mathrm{TM}}$ polymer blend. In preparation. 